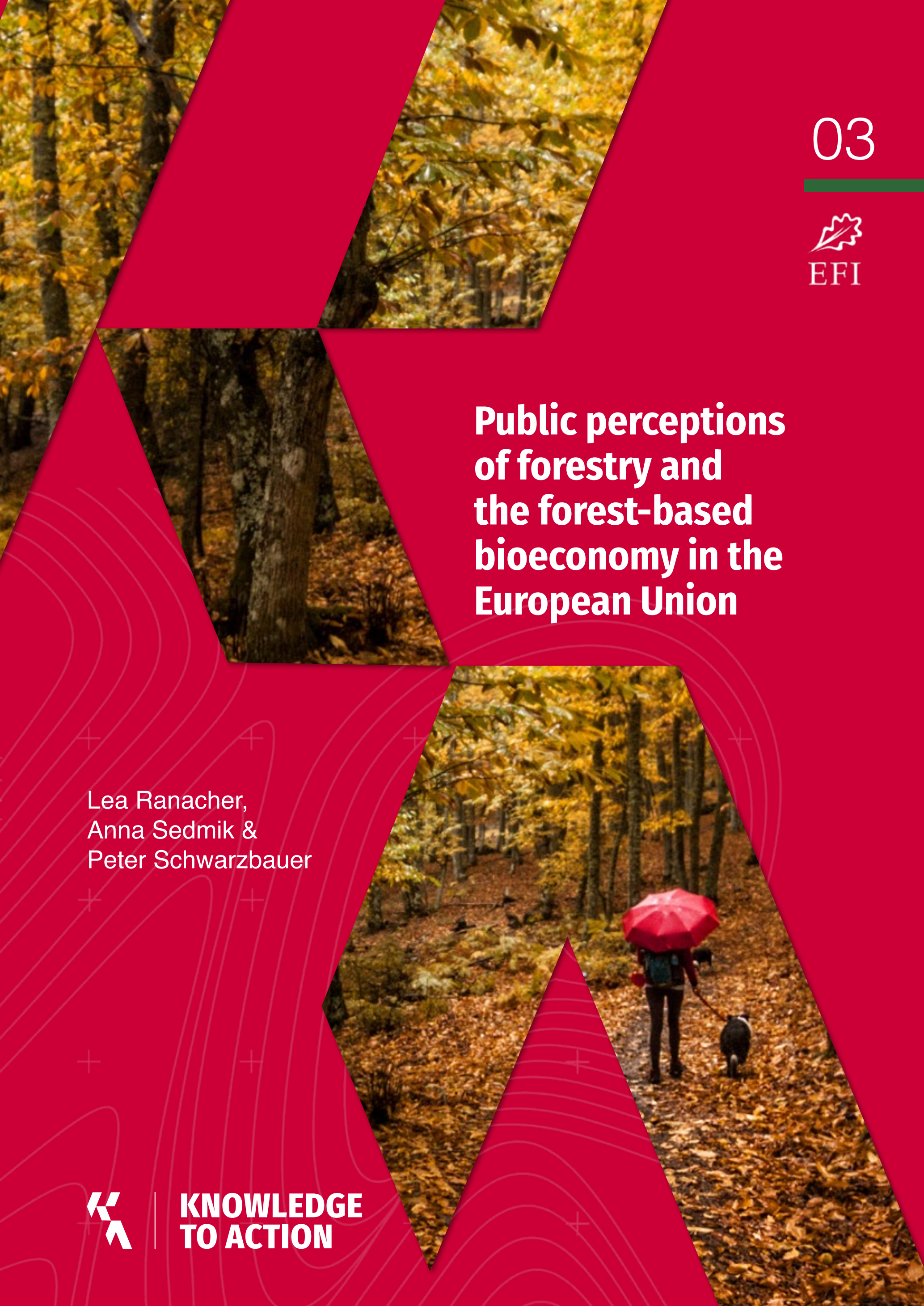




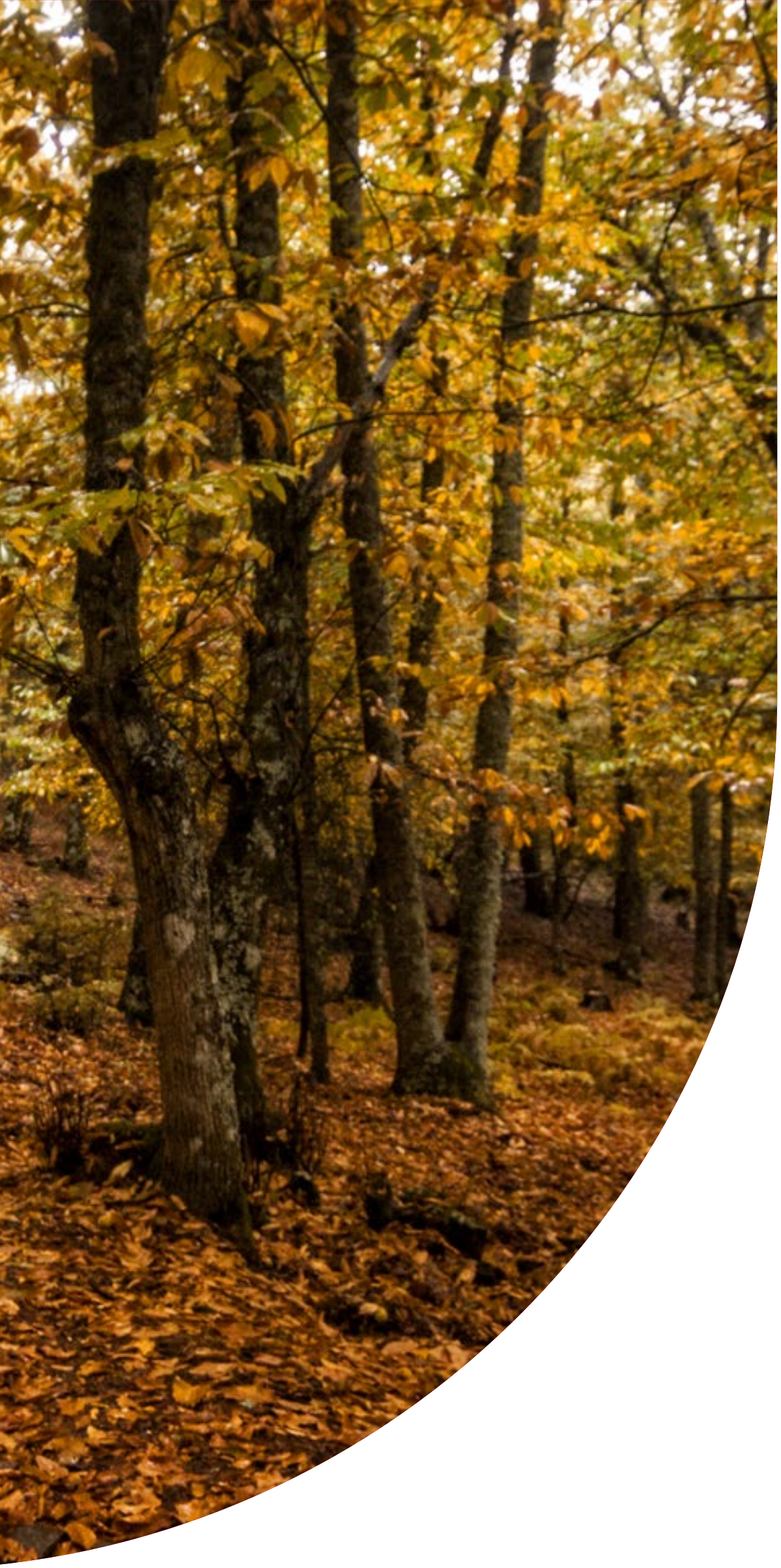

\section{Lukas Giessen \\ Editor-In-Chief}

\section{Sarah Adams \\ Managing editor \\ Inazio Martinez de Arano \\ Associate Editor}

The editorial office can be contacted at k2a@efi.int

This work and publication has been financed by EFI's Multi-Donor Trust Fund for policy support, which is supported by the governments of Austria, Czech Republic, Finland, Germany, Ireland, Italy, Lithuania, Norway, Spain and Sweden.

\section{Acknowledgements:}

The report benefited from helpful comments by external reviewers, Lukas Giessen from European Forest Institute, Maria Nijnik from the James Hutton Institute, and Georg Winkel from the European Forest Institute. We wish to express our thanks for their insights and comments that helped to improve the report, and acknowledge that they are in no way responsible for any remaining errors.

\section{Layout: Lina Salamanca}

Disclaimer: The views expressed in this publication are those of the authors and do not necessarily represent those of the European Forest Institute or of the funders..

Recommended citation: Ranacher, L., Sedmik, A. and Schwarzbauer, P. 2020. Public perceptions of forestry and the forest-based bioeconomy in the European Union. Knowledge to Action 03, European Forest Institute.

https://doi.org/10.36333/k2a03

Lea Ranacher (1), Anna Sedmik (1),

Peter Schwarzbauer (2)

${ }^{1}$ Wood K plus - Competence Center for Wood Composites and Wood Chemistry, Kompetenzzentrum Holz GmbH, Altenberger Straße 69, 4040 Linz, Austria,

2 University of Natural Resources and Life Sciences, Department of Economics and Social Sciences, Feistmantelstraße 4, 1180 Vienna, Austria

ISBN 978-952-5980-26-4 (pdf) 


\title{
Public perceptions of forestry and the forest- based bioeconomy in the European Union
}

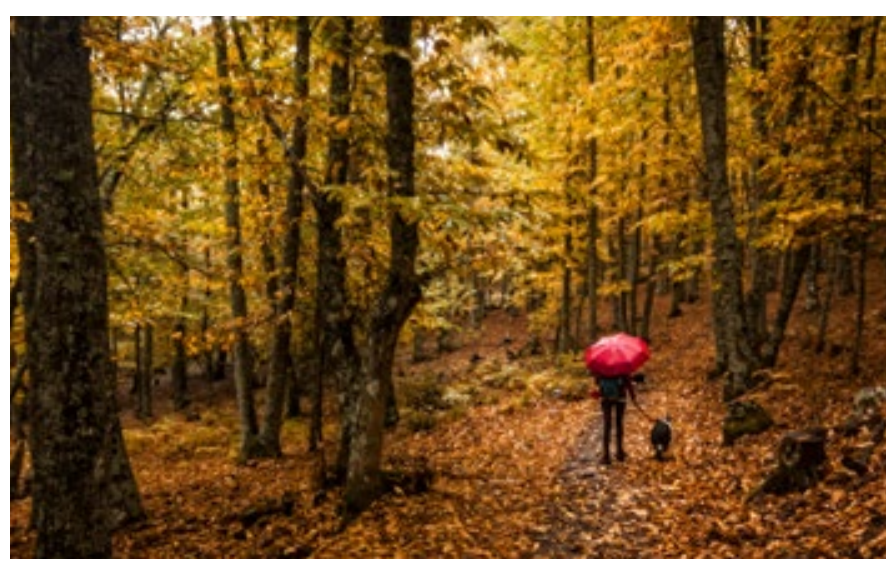

\author{
3 Introduction and study aim \\ 4 1. Conceptual background \\ 6 2. Methods \\ 7 2.1 Research concept \\ 92.2 Identification of studies \\ $13 \quad 2.3$ Analysis of studies
}

\section{Results}

3.1 Descriptive analysis of reviewed studies

3.1.1 Place of study

3.1.2 The respondents of the reviewed studies

3.1.3 Survey and sampling methods used in the reviewed studies

3.1.4 Frequency and focus of reviewed studies over time

3.2 Perceptions of forest ecosystem services

3.3 Perceptions of forestry and forest management

3.4 Perceptions of the forest-based industry

3.5 Perceptions of wood and wood-based products

\section{Synthesis and discussion}

4.1 Forest ecosystem services are highly valued

4.2 Preference for forest protection and diversity

$85 \quad$ List of reviewed studies

89 Annex 



\section{Introduction}

\section{The terms \\ "bioeconomy" \\ and "bio-based \\ economy" refer \\ to one of the \\ most prominent \\ political-economic \\ concepts in \\ Europe, which also \\ includes ecological \\ aspects.}

In 2012 the EU launched the

strategy A bioeconomy for

Europe which aims at a transition

from a fossil-based economy to

a bio-based economy (European

Commission, 2012). As the

European Commission (2012)

explains: "The bioeconomy's

cross-cutting nature offers

a unique opportunity to

comprehensively address inter-

connected societal challenges

such as food, security, natural

resource scarcity, fossil resource

dependence and climate change,

while achieving sustainable

economic growth." This urge to

re-orient societies towards "bio-

based", "sustainable" or "green"

economies revives the forest-

based sector as a key player

for delivering raw material for

bio-based products and energy

(UNECE/FAO, 2016).
The forest-based sector's contribution to a bioeconomy depends on stakeholders, such as policymakers, citizens and consumers, and how they perceive, accept and promote the forest-based value chain and its products and services. In the past, several surveys indicated scepticism among the general public regarding the forest-based sector's impact on the environment, and forest conservation was a key topic for European citizens when asked about forests in their country (Rametsteiner et al., 2009). Furthermore, they were found to have a limited knowledge about the forest-based sector and its activities (European Commission, 2002). Recent studies (e.g. Ranacher et al., 2017a; Edwards et al., 2016) point in the same direction and raise questions regarding the forest-based sector's legitimacy among the public.

Acknowledging the public concern regarding forests and forest-based sector sustainability, an increased understanding of the public perception of these issues is needed. In the past decade, several surveys looking at perceptions and attitudes towards forests, forestry and the forest-based sector have been carried out in different European countries. However, what is lacking is a meta-study reviewing and summarising the current knowledge in public perception research. The last comprehensive studies at the European level were done in the 2000s (Rametsteiner and Kraxner, 2003; Rametsteiner et al., 2007; Rametsteiner et al., 2009). Since then, new economic, social and environmental issues, as well as challenges, have surfaced, especially in context of the political vision of a bioeconomy and forest-based bioeconomy (i.e. products, services and technologies that stem from forests and the forestbased sector) (Giurca et al., 2020; Winkel, 2017).

Therefore, the aim of this study is to address this gap by conducting a meta-study of the public perception of forestry and the forest-based bioeconomy. This study reviews the recent (2010-2019) public perception studies on four topics: forest ecosystem services, forestry and forest management, forestbased industry, and wood and wood-based products. The study will formulate conclusions on which topics public awareness is positive and where there is room for improvement. It will inform practitioners and the scientific community alike about methodological and thematic research gaps, as well as identify opportunities to improve interaction with the general public. It will also make policy recommendations. 


\title{
1. Conceptual background
}

\author{
Forests and other wooded land cover $40 \%$ of the European \\ Union's (EU) land area, with great diversity across regions. Forest \\ area in the $E U$ is increasing by around $0.4 \%$ with $60-70 \%$ of the \\ annual increment cut every year. However, globally, forest area is \\ decreasing ${ }^{1}$. In order to realise the bioeconomy, it is crucial to replace \\ fossil-based, non-renewable materials, or non-sustainable products, \\ through innovation ${ }^{2}$.
}

For example, forest-based biorefineries aim to use the large potential of the availability of wood as a raw material to substitute fossil-based products and, to some extent, to reduce greenhouse gas (GHG) emissions (Stern et al., 2015; Leskinen et al., 2018). Harvested wood products can positively contribute to reducing GHG emissions by substituting for fossil-based materials and fuels or by forming a storage pool of sequestered carbon in long-lived products (Braun et al., 2016). The main markets for this are textiles, construction, fuels, chemicals, packaging and wood-plastic composites (Hurmekoski et al., 2018).

For the forest-based sector, the transition towards a bioeconomy represents a chance to be competitive in the future by renewing its products and service portfolio (Hetemäki et al., 2014). While forests are an important biomass supplier for material and energy purposes, they also support a rich portfolio of other ecosystem services that range from protective functions (e.g. preventing soil erosion) to cultural services (e.g. recreation and health related) and the provision of goods such as game and mushrooms (Winkel, 2017). The increasing demand for raw material that comes with the vision of a forest-based bioeconomy needs to balance different forest demands, which requires adequate policy measures (Roos and Stendahl, 2016; Kleinschmit et al., 2014). Forest owners increasingly become suppliers of raw materials and services, responding to a multitude of needs, and policymakers have to manage these societal and economic demands (Rametsteiner et al., 2009).

Environmental awareness is increasing, as seen in recent Eurobarometer studies. According to the most recent Eurobarometer 501 study (European Commission, 2020), environmental protection is important to $94 \%$ of all EU citizens, and $76 \%$ see climate change as a very serious problem for the EU. When asked about the most important environmental issues, climate change 


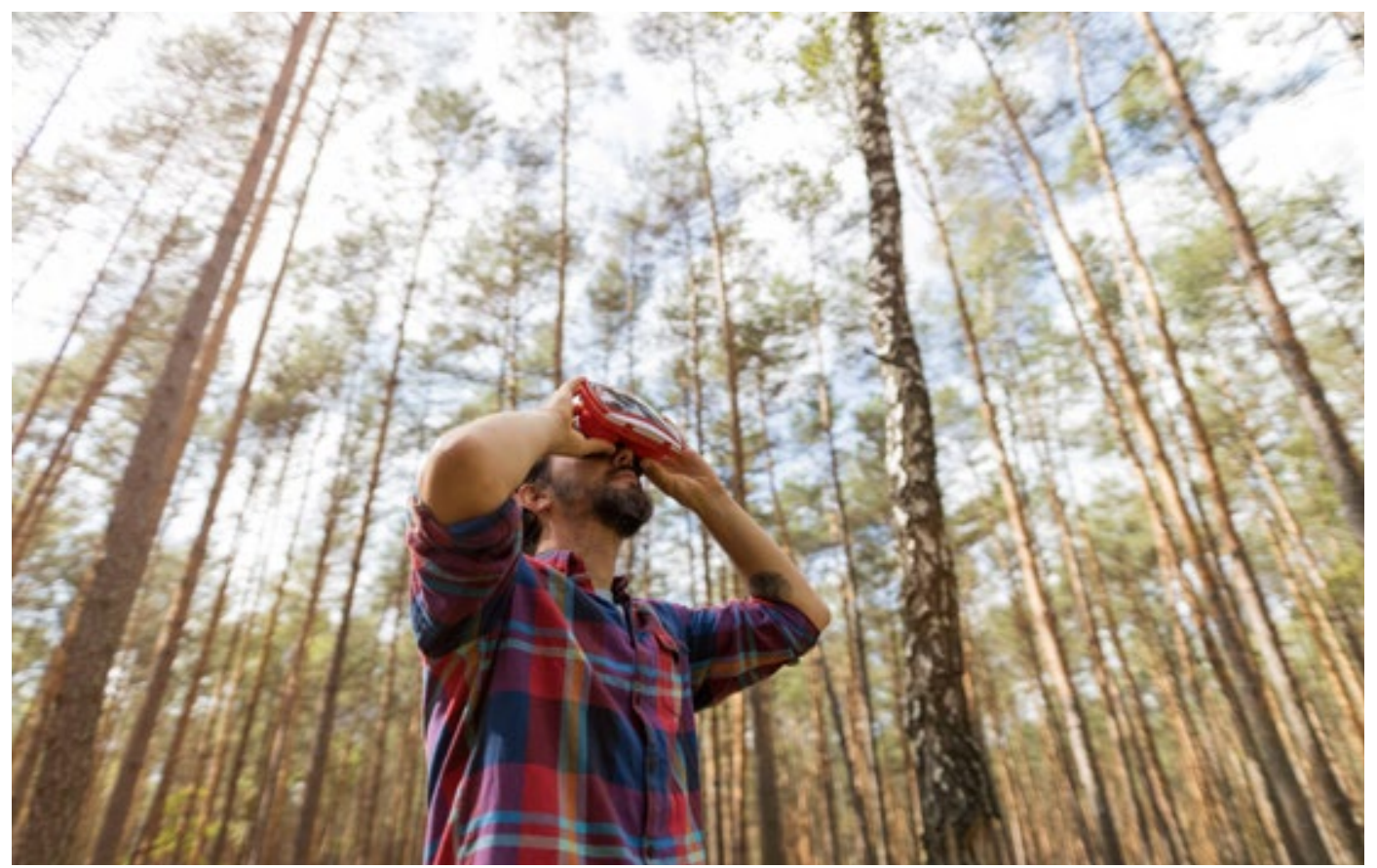

Photo by: @ pikselstock / Adobe Stock

ranked highest (51\%), followed by air pollution, growth in waste (both $45 \%$ ) and the decline or extinction of species and habitats and loss of natural ecosystems (36\%). According to the Eurobarometer 379 (European Commission, 2013b), 86\% consider the decline and possible extinction of animal and plant species as a serious or very serious problem and $97 \%$ consider the decline and disappearance of forests a serious or very serious problem for the loss of biodiversity.

Modern understanding of sustainable forest management goes beyond the principle of sustainable yield management and is shaped by a range of different social demands. Therefore, an advanced understanding of stakeholder perceptions is needed to ensure the development of socially acceptable policy and market instruments in the forest-based sector (Šimunović et al., 2017; Šimunović et al., 2019). Alongside this, consumer expectations and attitudes towards the forest-based sector and its products and services are drivers for innovation in material research and development (Näyhä et al., 2014). Considering these expectations, attitudes and demands can increase the support for forest management practices and acceptance of products and services.

As the meaning of the bioeconomy is in constant flux (Pülzl et al., 2014) and the bioeconomy has many policy agendas, it presents a variety of demands, expectations and challenges for forestry and the forest-based sector. Several of these imply a need for social-science contributions (Kleinschmit et al., 2014), and major research gaps regarding the societal dimension of a forestbased bioeconomy and a need for societal inclusion have been identified (Mustalahti, 2018). Recent studies have investigated forest stakeholders' (e.g. Hodge et al., 2017; Korhonen et al., 2018; Stein et al., 2018; Giurca, 2020) or citizens' perceptions of the bioeconomy (Stern et al., 2018). However, a review of the public perception on forestry and the forest bioeconomy is missing. 


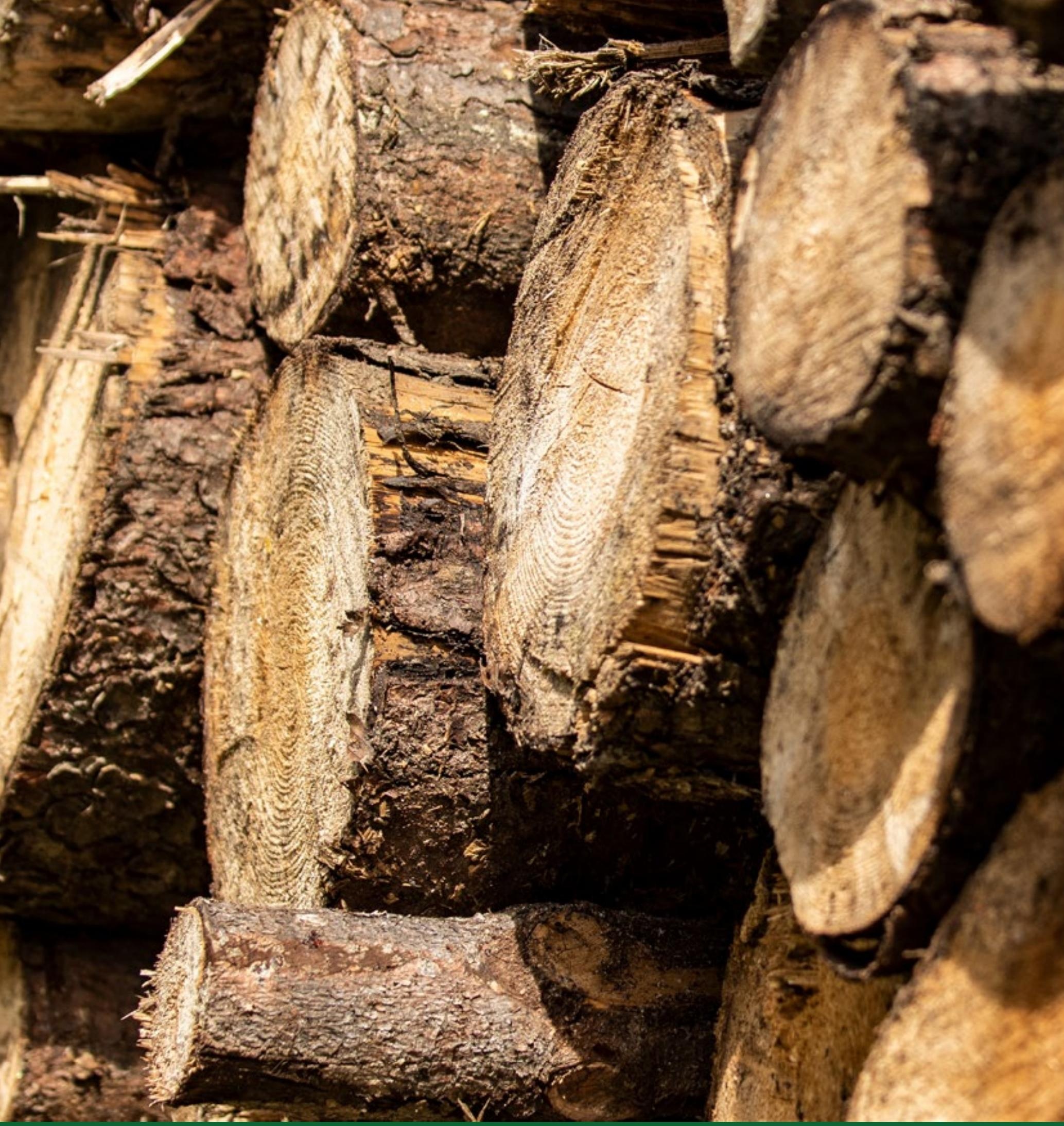

Photo by: (c) andreaobzerova / Adobe Stock

\section{CHAPTER 2}

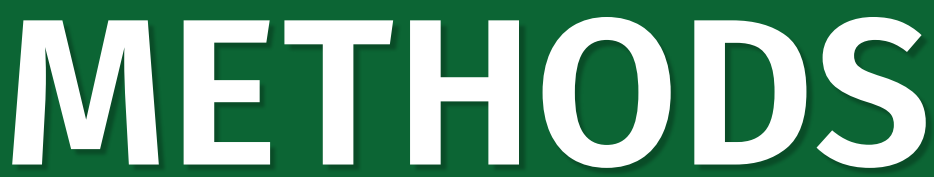




\subsection{Research concept}

The forest-based sector plays a crucial role in the bioeconomy, by providing forest ecosystem services, raw materials and products. The forest-based sector plays a crucial role in the bioeconomy, by providing forest ecosystem services, raw materials and products. The forest-based sector is defined as forestry, the wood products industry (including the pulp and paper industry) and companies from industry sectors that are increasingly developing new products and services based on forest biomass, such as bioenergy (e.g. biofuels for transportation), raw material for textile industries, nano-pulp and micro-fibrillated cellulose, which can be used in a variety of sectors ${ }^{3}$.

The forest-based bioeconomy uses wood to produce a wide array of products such as construction materials, chemicals, biofuel, heat, power, bioplastics, packaging materials, food, livestock feed, ingredients, textiles, health and pharmaceuticals. However, it also includes the services directly related to forests and those connected to forest management, wood processing and forest products (Hetemäki et al., 2017). This study refers only to forest-related services that are directly related to forests (such as nature tourism and recreation, hunting, mushroom and berry picking, or other forest ecosystem services such as soil and water services and carbon sequestration in forests) as the other forest-based sector services are so business/sector specific that the general public is unlikely to be aware of them. Thus, the reviewed studies have to address the following aspects either in the study aim or in their survey questions:

- Perceptions of forest-based sector activities: this relates to forestry and forest management activities and the forest-based industry itself.

- Perceptions of forest-based sector services and products: this relates to products and services generated from the forest-based sector, such as wood and wood-based products and forest ecosystem services.

This resulted in four main topics (Figure 1). Surveys that cover the public perception of forests without relevance to the forest-based sector are, therefore, not covered. 
To investigate public perception, we refer to a broad concept of perception, often used in policy research (Assefa and Frostell, 2007; Wüstenhagen et al., 2007). This broad concept of perception includes attitudes, preferences, values and beliefs. In this way we can identify and compare a wide array of studies with very specific research aims and questions. Further, the review focuses on public perception studies that collect and analyse primary data from quantitative and qualitative surveys.

\section{Public perception of forestry and the forest-based bioeconomy}
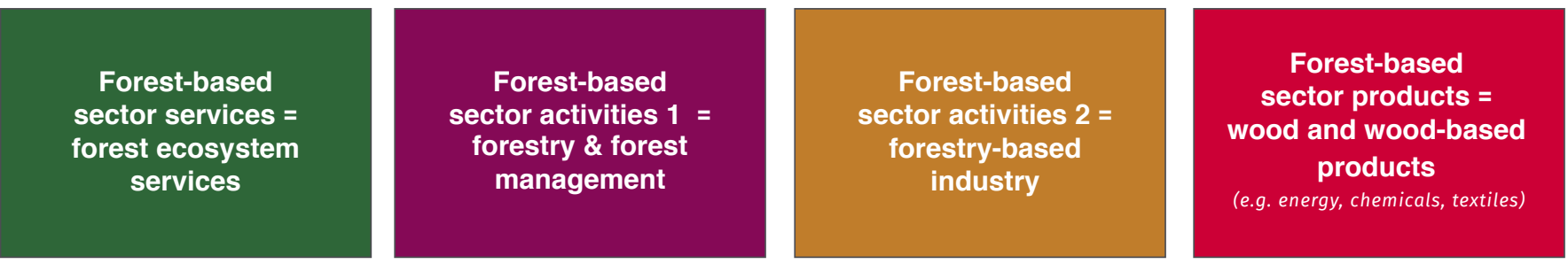

Figure 1. Conceptualisation of the study (own illustration)

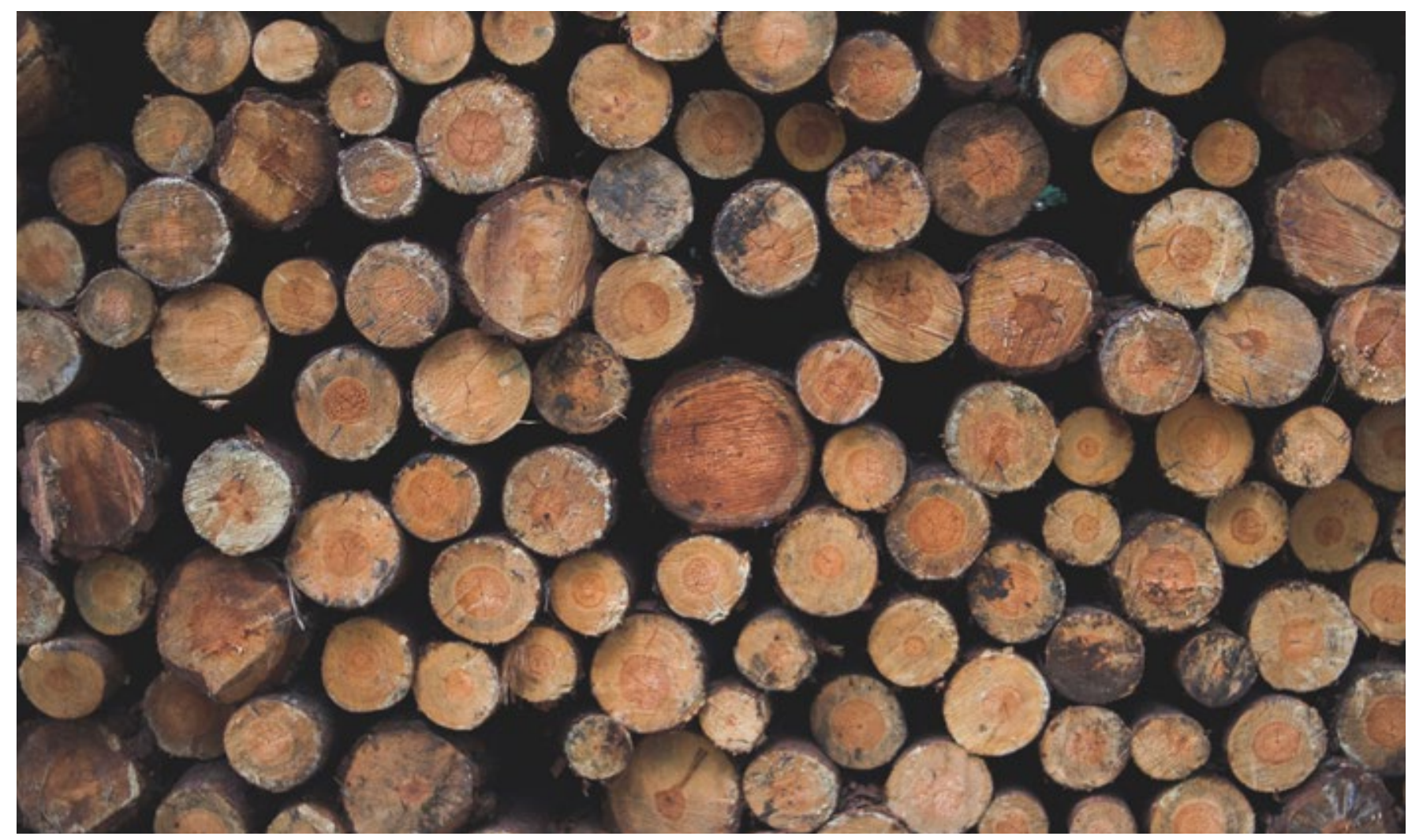

Photo by: (C) Pexels 


\title{
2.2 Identification of studies
}

\author{
The review investigates the public perception of forestry and the \\ forest bioeconomy using a systematic literature review that aims to \\ "comprehensively identify all relevant studies to answer a particular \\ question, and assesses the validity (or 'soundness') of each study \\ taking this into account when reaching conclusions" 4.
}

We chose to focus on peer-reviewed studies based on primary data despite being aware that there is a substantial body of grey literature. Firstly, because peer-reviewed literature ensures a certain standard of quality as a result of the peer review process. Secondly, because it is generally accessible and can be searched for systematically to ensure that all relevant studies have been identified. Thirdly, to be able to carry out the study in the given resource frame (i.e.to limit the amount of studies). We also considered using the snowball system and other literature databases, but this would have significantly increased the time spent searching and analysing the identified literature. Being aware that there are a few studies from European and national authorities that (partly) surveyed forestry related issues, we added their findings to the synthesis chapter when suitable. A study was defined as suitable when its survey questions addressed one of the four topics presented in chapter 2.1.

The data collection, i.e. identification of relevant articles, was performed with a query on Scopus, the largest database for peer-reviewed literature. We selected this database as it is multidisciplinary and the largest database of scientific literature abstracts (Aghaei Chadegani et al., 2013). The used search terms (Table 1) were chosen based on the conceptualisation in Figure 1. Those search terms that contain a hyphen (i.e. forest-based, bio-textile, bio-chemical, bio-fuel, wood-based and bio-energy) were also searched without hyphen to consider different spellings (e.g. bio-fuel, biofuel and bio fuel). Some of the search terms were combined with a boolean operator (“*”), to include relevant search results of search terms with different endings (e.g. "perception*" to cover "perceptions" and "perception").

As we did not investigate the public perception of forests, the search term "forest* is not included. Despite acknowledging that the general public might not be aware of specific terms such as "forest ecosystem services" or "forest management", relevant studies are filed under these terms (e.g.by using them as keywords). 
The settings used in the SCOPUS search mask are given in Table 2 . The studies identified in the SCOPUS database had to fulfil the following criteria:

- Studies are based on primary social science data from quantitative or qualitative surveys. More precisely, the survey data - or at least a share of it - ought to originate from the general public, local or regional population, consumers, forest visitors, or students. Studies targeting exclusively experts or representatives of professional groups were excluded.

- Respondents of the studies are from at least one EU 27 country plus UK. Note that in the respective time span the UK was part of the EU. As there are several multi- country studies, the survey data had to come from at least one of these countries.

- The study was published between 2010 and 2019 as the last meta study with a similar study scope was conducted before then (Rametsteiner et al., 2009).

The identified hits generated through the SCOPUS inquiry were then manually evaluated to see whether they matched the scope of the study based on the criteria above. Note, due to the large number of search terms, the same studies were often identified with different search terms, which required an additional check to avoid doublets. In total 129 abstracts were identified in this first step. As the abstract only provides limited information, for each study the full-text articles were downloaded and checked

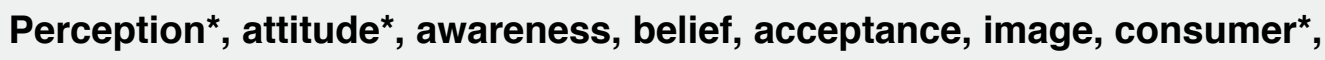
opinion*, preference ${ }^{\star}$, demand ${ }^{\star}$, view ${ }^{\star}$

\begin{tabular}{|c|c|c|}
\hline \multicolumn{3}{|c|}{ AND } \\
\hline $\begin{array}{c}\text { Forest- } \\
\text { ecosystem } \\
\text { service }^{\star} \\
\text { Forest function* }^{\star}\end{array}$ & $\begin{array}{c}\text { Forest management } \\
\text { Forestry } \\
\text { Forest sector } \\
\text { Forestry sector } \\
\text { Forest-based sector } \\
\text { Forest industry } \\
\text { Forest bioeconom } \\
\text { Forest-based bioeconom* } \\
\text { Wood-based bioeconom* }\end{array}$ & $\begin{array}{c}\text { Wood } \\
\text { Timber } \\
\text { Wood-based } \\
\text { Pulp and paper } \\
\text { Pulp product } \\
\text { Paper board } \\
\text { Viscose } \\
\text { Cellulose fibre } \\
\text { Bio-textile* } \\
\text { Bio-chemical* }^{*} \\
\text { Bio-fuel* } \\
\text { Bio-energy }\end{array}$ \\
\hline
\end{tabular}

Table 1. Search terms used for the systematic literature review in SCOPUS. 
again for relevance. In total, 52 studies were excluded in this second step for the following reasons:

- No full-text article: the full-text articles were not available (13 studies).

- No English language: the full-text article was not available in English (three studies).

- Data not from EU27 and UK: author is from an EU 27 country and UK and was therefore identified as relevant in step 1 but the primary data does not refer to an EU 27 country or UK (two studies).

- No primary survey data: study based on secondary data, review or no survey data (seven studies).

- Wrong target group: those studies that only surveyed forestbased sector related experts and stakeholders (e.g. forest owners, forestry professionals), other professional groups (e.g. architects, tourism officers, policymakers) (12 studies).
- Insufficient scope: Studies that did not cover the public perception, but focused narrowly on quality criteria or market analyses, which was mainly the case for studies in the category "product", or development of valuation methods without providing information about the public perception of the subject matter were excluded (15 studies).

Concluding, the material used for this review consists of 77 studies conducted in $19 \mathrm{EU}$ countries and the UK. Based on their study aim, the studies were categorised into the four topics "forest ecosystem services", "forestry and forest management", "forest-based industry", and "wood and wood-based products". The whole process is illustrated in Figure 2.

\title{
Total hits on title, abstract, keywords
}

\author{
$>17000$ studies
}

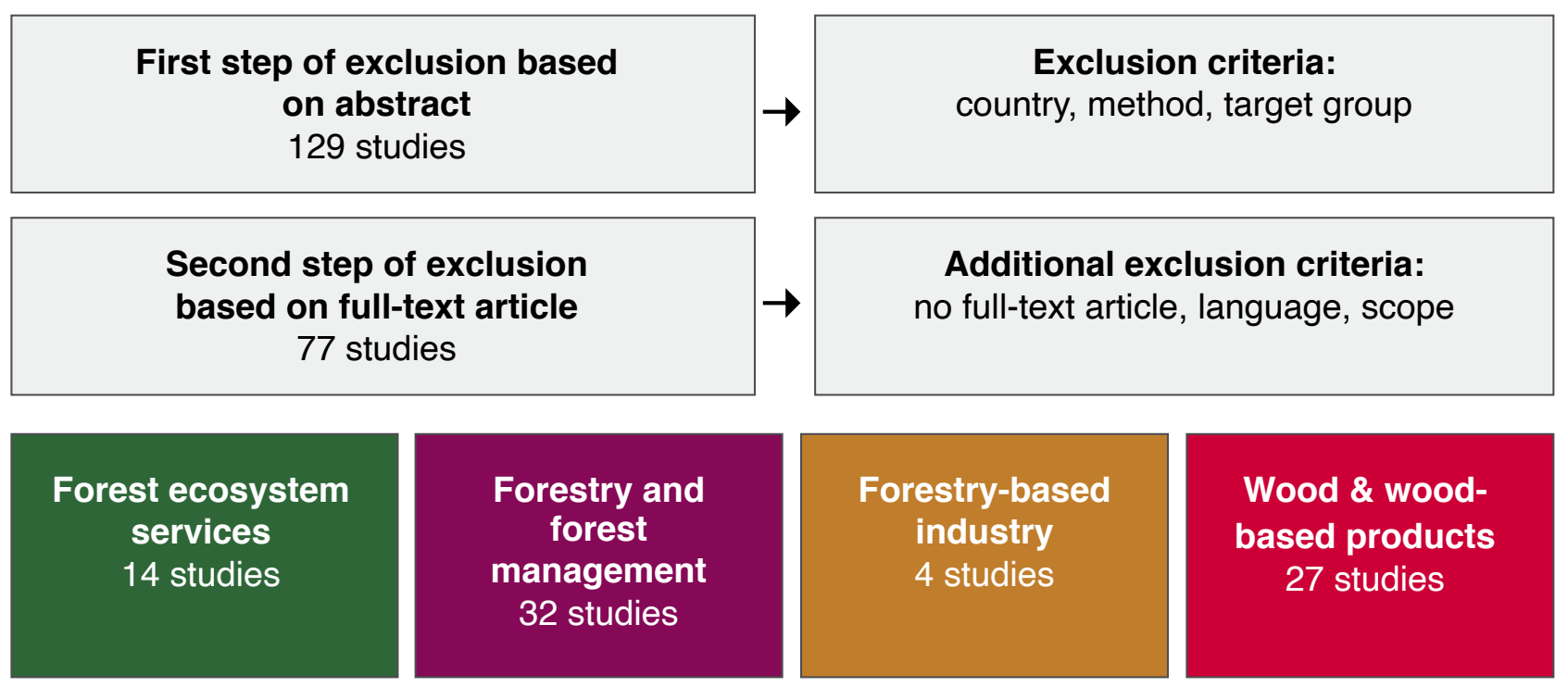

Figure 2. Steps of systematic literature review. 

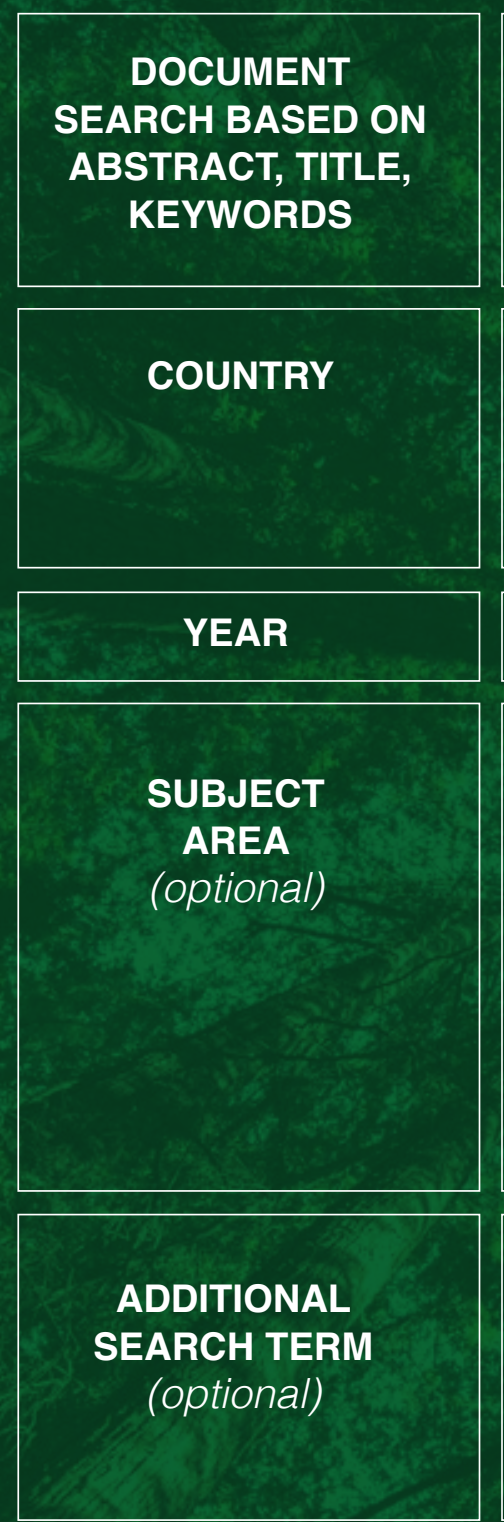

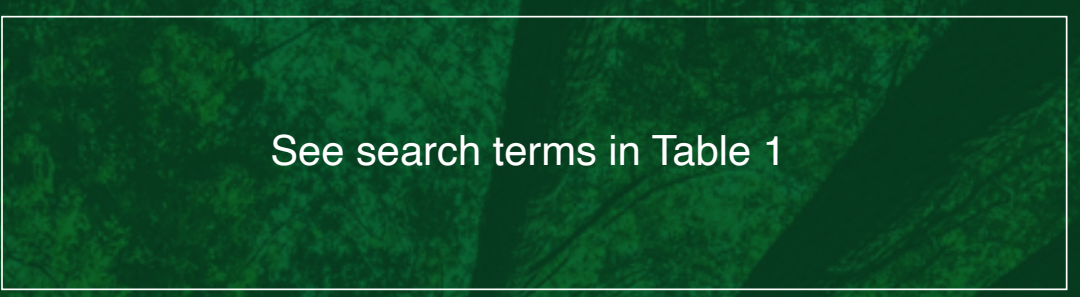

EU 27 and UK were chosen in the "country/territory" filter option. This setting means that only studies with their authors having an affiliation from these countries are included.
Some of the search terms overlapped with subject areas not relevant to the study. For example, the search terms "image", which can be used in context of "public image", resulted in a high number of studies about GIS data and material images. In these cases, we excluded studies that were filed under subject areas such as computer science, physics and astronomy, and chemical engineering.

The search terms bio-energy and bio-fuels resulted in large number of studies not related to the scope of the study. To reduce the number of studies we used the additional search term "wood" and "forest". 


\subsection{Analysis of studies}

The first part of the analysis is a descriptive analysis of the identified studies, with the variables used (Table 3). The full-text article served as the unit of analysis with the aim of describing the available literature based on surveyed target groups, survey methods and sampling procedures used. We reviewed the full-text article and coded the respective sections. By doing this, more detailed information was collected about the sampling procedure (e.g. random or convenience sampling), how data was collected (e.g. online survey or face to face) and the sample size. Based on this information and the method used in the study, the studies were categorised into quantitative, qualitative and mixed method studies (i.e. both qualitative and quantitative data collection). This was done to better evaluate how the results of the studies were generated and judge their comparability. Methods such as such as random sampling or quota sampling make it possible to generate a representative sample and a generalisation of results to a wider population (Bryman, 2012). However, studies without these sampling methods can also generate valuable results, especially when aiming to identify differences between different groups.

\begin{tabular}{|c|c|}
\hline Variable & Description / categories \\
\hline Year & Year of publication \\
\hline Journal & Name of published journal \\
\hline Country & Country the data was collected in \\
\hline Method & Categories: quantitative, qualitative or mixed method \\
\hline Target group & $\begin{array}{l}\text { Categories: general public, local or regional population, } \\
\text { consumers, forest visitors, education or other }\end{array}$ \\
\hline $\begin{array}{l}\text { Sampling } \\
\text { procedure }\end{array}$ & $\begin{array}{l}\text { Categories: random and stratified random sampling, } \\
\text { quota sampling, on-site convenience sampling, } \\
\text { convenience sampling by mail or postal-survey or not } \\
\text { specified }\end{array}$ \\
\hline Forest level & $\begin{array}{l}\text { Categories: regional or local, national, global, not } \\
\text { specified or not relevant }\end{array}$ \\
\hline Topic & Categories: forest ecosystem services, forestry, sector, products \\
\hline
\end{tabular}

Table 3. Overview of variables to describe the identified studies. 
In addition to the descriptive variables in Table 3, the results sections of the articles were coded using the qualitative data analysis software MaxQDA. For this, the code system in Table 4 was developed and used. This was done to get a more detailed view of what exactly respondents have been surveyed about (e.g. identify all results on perception of forest ecosystem services). This data driven, inductive coding manual further allowed us to see the distribution of topics and on what topics the current public perception research is focusing. We also searched for variables that indicate a significant relationship (mostly correlations) with another variable measuring perceptions, such as socio-demographic and psychographic factors. It should be noted that only some papers provided the exact survey questions or items used, which also influences the level of detail in presenting the results. A summary of all studies is provided in the chapters 3.2-3.5 and a summarising table on target group, sampling procedure and study aim is given in Table 7 in the Annex.
During coding we observed that several studies covered a wide array of different, often overlapping, topics. For example, some studies surveyed the perception of both forest ecosystem services and forestry e.g. a study is categorised as and summarised in "forest ecosystem services", while also providing other relevant results on perceived forest condition. In these cases, the respective sections were also coded and reported in the chapter 4 synthesis.

We aimed to compare the coded sections by country and over time. As we found that the studies vary greatly regarding the target groups, sampling procedures, study aims and operationalisation, these comparisons are only indicative. Any differences regarding country and time can only serve as a first indication of differences and should not be overinterpreted.

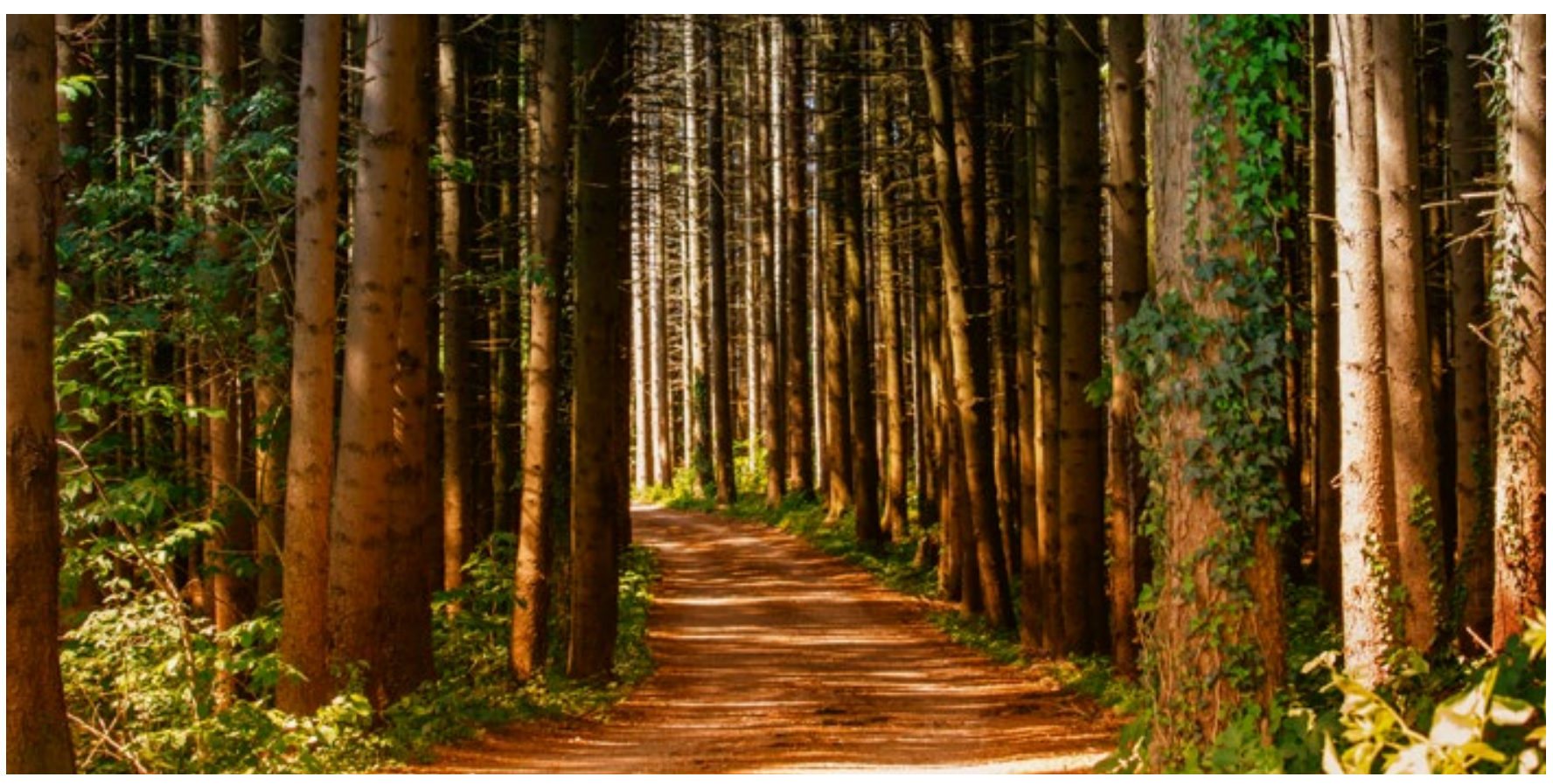

Photo by: (C) Pexels 


\begin{tabular}{|c|c|c|}
\hline Topic & Sub-topic & Description \\
\hline \multirow{3}{*}{$\begin{array}{c}\text { Forest } \\
\text { ecosystem } \\
\text { services }\end{array}$} & $\begin{array}{l}\text { Enviromental } \\
\text { benefits }\end{array}$ & $\begin{array}{l}\text { Climate change mitigation, biodiversity, water \& soil } \\
\text { protection }\end{array}$ \\
\hline & Social benefits & Recreation and social cohesion, spiritual values \\
\hline & Economic Benefits & $\begin{array}{l}\text { Timber, tourism, non-timber forest products for } \\
\text { economic purposes }\end{array}$ \\
\hline \multirow{3}{*}{$\begin{array}{c}\text { Forestry } \\
\text { and forest } \\
\text { management }\end{array}$} & Forest condition & Forest health, forest threats \\
\hline & $\begin{array}{l}\text { Management } \\
\text { activities }\end{array}$ & $\begin{array}{l}\text { Forest conservation, afforestation, pest management, } \\
\text { intensification }\end{array}$ \\
\hline & Forest attributes & $\begin{array}{l}\text { Tree species, structural attributes management clear } \\
\text { cuts }\end{array}$ \\
\hline \multirow{2}{*}{$\begin{array}{l}\text { Forest-based } \\
\text { industry }\end{array}$} & Impact forest & Sustainability performance regarding wood supply \\
\hline & Impact value chain & Sustainability performance of production \\
\hline \multirow{7}{*}{$\begin{array}{l}\text { Wood and } \\
\text { wood-based } \\
\text { products }\end{array}$} & $\begin{array}{l}\text { Technical } \\
\text { performance }\end{array}$ & Strength, maintenance, fire resistance \\
\hline & Appearance & Visual and emotional aspects \\
\hline & Health & Mental, physical, additives \\
\hline & $\begin{array}{l}\text { Environmental } \\
\text { impact }\end{array}$ & Perceived environmental sustainability of product \\
\hline & $\begin{array}{l}\text { Purchasing } \\
\text { behavior }\end{array}$ & $\begin{array}{l}\text { Willingness to buy product, attributes influencing } \\
\text { purchasing behaviour }\end{array}$ \\
\hline & Wood origin & Legal, country, management system \\
\hline & Social aspects & Labour conditions, socio-economic impact \\
\hline
\end{tabular}

Table 4. Code system used for qualitative analysis of studies. 


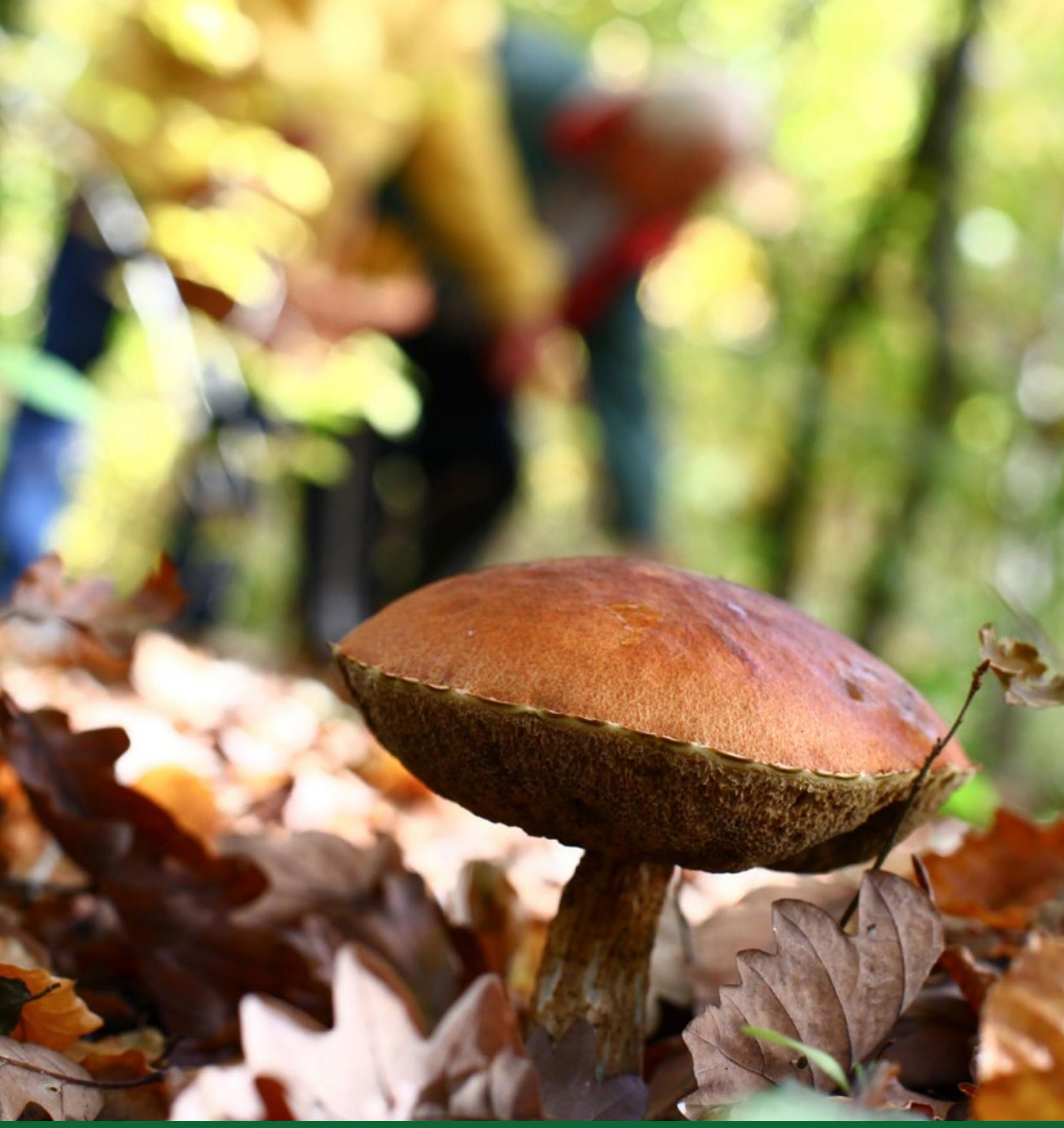

Photo by: ( ๑ Patrice Lucenet / Pexels

CHAPTER 3

RESULTS 


\subsection{Descriptive analysis of reviewed studies}

\subsubsection{Place of study}

Figure 3 shows the distribution of the studies by countries in which the primary data was collected. In 12 studies the data was collected in more than country, followed by Finland, the country with the largest forest area as a proportion of a country's total land area in the European Union (Cook and Eurostat 2020) with 10 studies, Germany (nine studies), Sweden (seven studies), Czech Republic and Italy (five studies each).

Structuring the countries by region (Table 5 and Figure 13 in Annex) shows that the majority of the studies were conducted in Eastern and Northern Europe. However, note that Eastern Europe also has the highest number of countries. After reviewing the descriptions of the journals, they were categorised into nine groups: forestry, environment, agriculture/food, geography, ecology, landscape, engineering, production, mountain and energy (Table 6 in Annex). The majority of the studies were published in forestry journals (49\%), followed by environment journals $(26 \%)$.

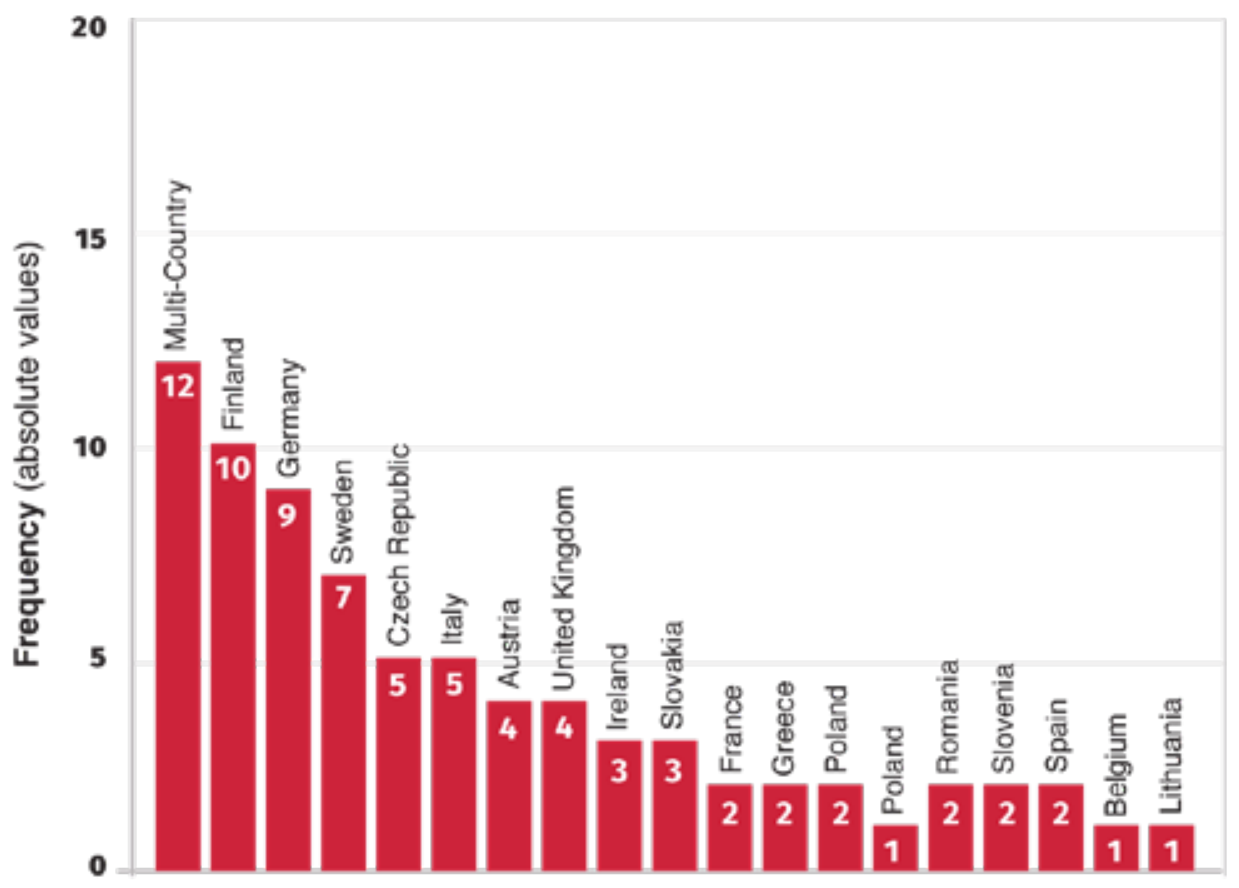

Figure 3. Distribution of countries in the survey in absolute numbers. 


\subsubsection{The respondents of the reviewed studies}

In order to better describe and compare the studies, we differentiated the respondents by target groups. Their distribution is given in Figure 4. Note that the categorisation in the target groups listed here is based on the descriptions found in the reviewed studies:

- General public: one quarter (26\%) of studies surveyed the general public of a country, often referring to the "citizens of a country". However, who was considered as general public or citizen was found to be interpreted very broadly in the reviewed studies. For example, in one study (Jepson et al., 2017a) visitors to a trade fair on trees, plants, nature and landscape were defined as general public by the authors. Furthermore, several studies do not go into detail about how the sample of the general public was defined and selected.

- Local or regional population: $12 \%$ of the studies refer to a specific region or city. This group was differentiated from "general public" since these studies referred to the population of a specific area.

- Forest visitors: forest visitors constitute the third largest share, with $16 \%$. Visitors to a national park, forest visitors and people who frequently visit a forest were surveyed, regardless of their place of residence (e.g. forest visitors can be locals or tourists from the same or different country).

- Students: at 9\%, students comprise the smallest target group. The studies refer to data collected at universities, secondary and primary schools.

- Consumers: at $27 \%$, consumers are the majority surveyed, which can be explained by the large share of studies on wood and wood-based products. From the 21 studies only five of them refer to defined consumers of wood or wood products, such as owners of a wooden house or furniture shop visitors. In the majority of cases, the studies referred to the general public or potential consumers. In some cases, data collection was not fully explained and the definition of "consumers" is not transparent.

- Other: the "other" category makes up $10 \%$ and includes all studies whose respondents could not be categorised in any of the groups above (e.g. young adults), surveyed respondents from different target groups (e.g. students and local population), or surveyed one of the target groups and non-target groups (e.g. local population and forestry professionals). For example, in one study (Almeida et al., 2018) foresters, policymakers, researchers, NGOs, people associated with tourism and recreation clubs (such as hiking or cycling), students and teachers were surveyed.

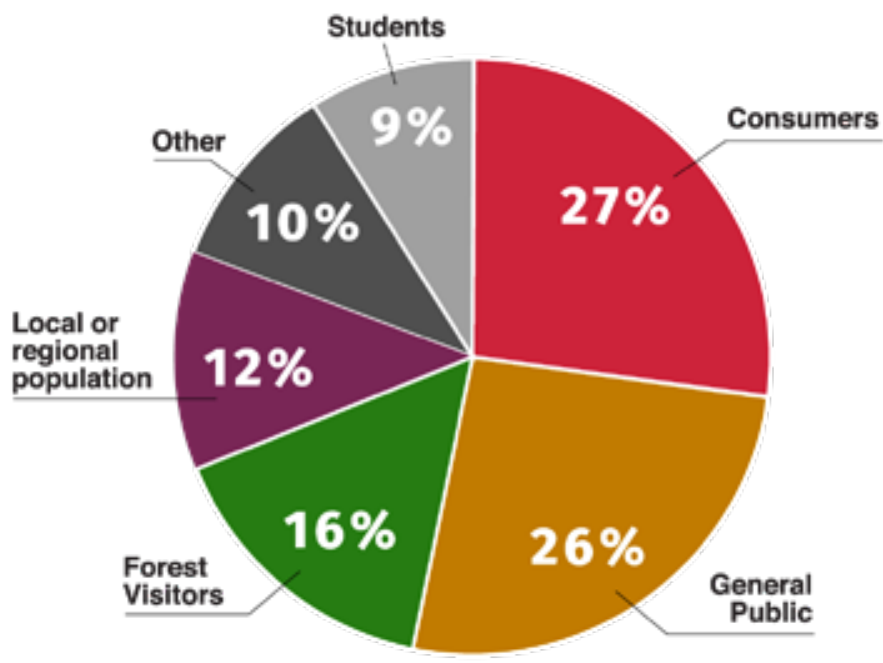




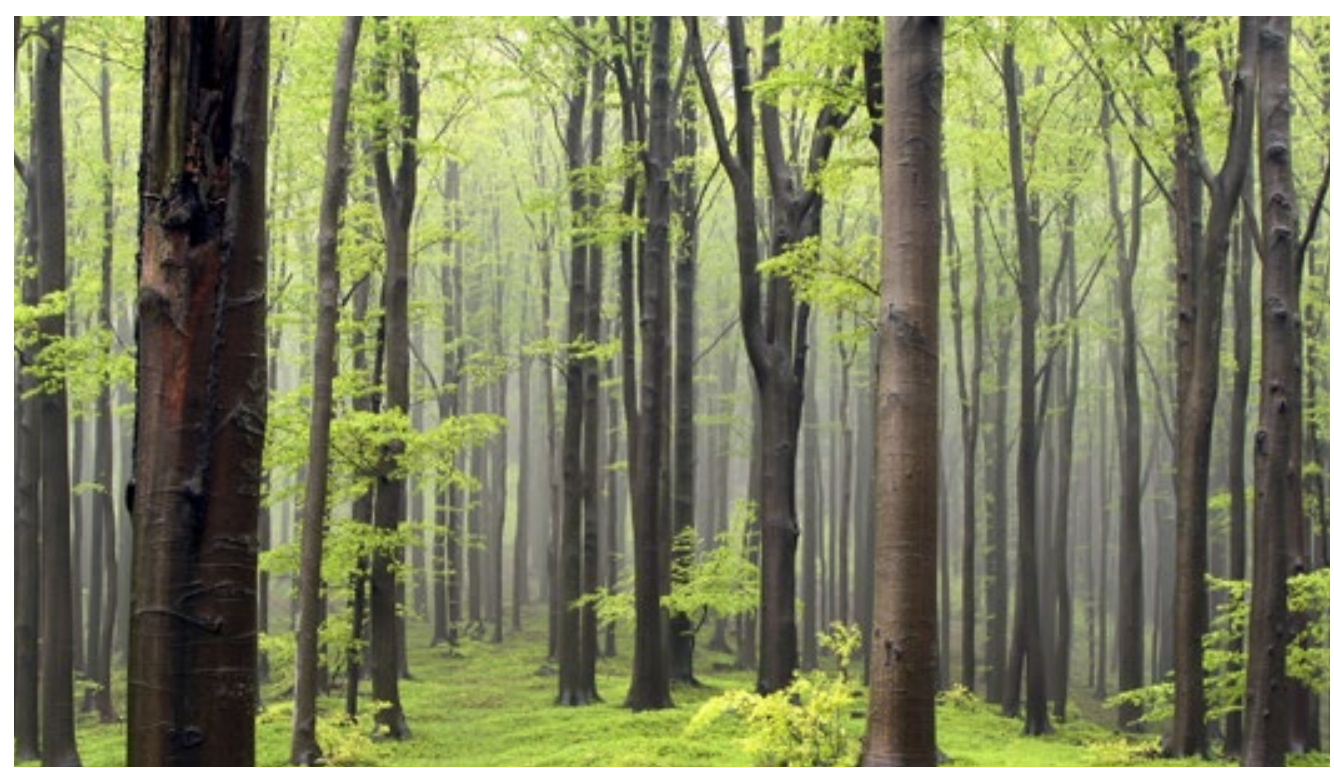

Photo by: (c) joda / Adobe Stock

\subsubsection{Survey \& sampling methods used in the reviewed studies.}

We categorised the survey methods into quantitative, qualitative and mixed methods. With 67 studies, quantitative surveys are the most frequently used method. The quantitative surveys often used choice experiments to measure utility values and/or willingness

to pay, to investigate preferences regarding forest ecosystem services, forest management practices or product attributes. Figure 5 shows that qualitative and mixed methods appear to be increasing but are still the exception. Only five studies were qualitative (using interviews or focus groups) and five used mixed methods, which were often employed to survey different target groups. For example, the local population was surveyed with a large-scale survey and forestry professionals with qualitative interviews.

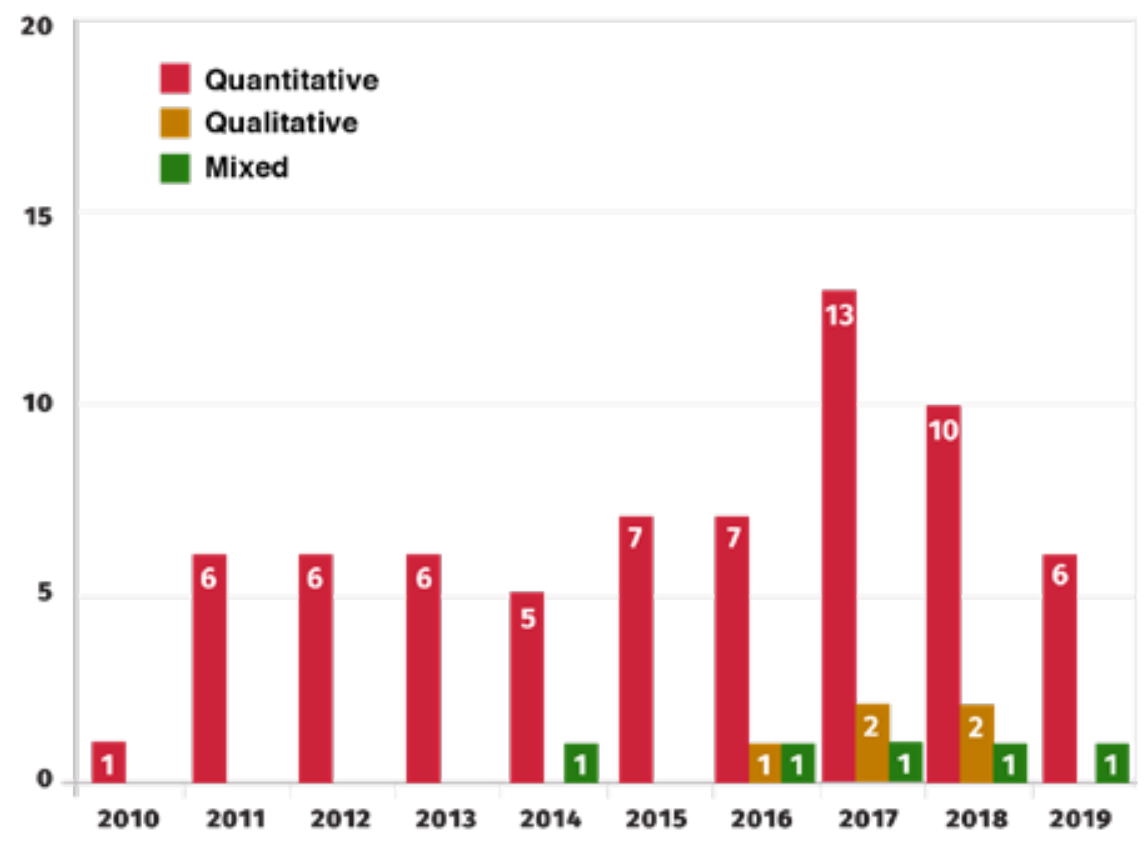

Figure 5. Distribution of methods of the reviewed studies between 2010 and 2019 . Distribution of methods of the reviewed studies between 2010 and 2019. 
Different sampling procedures were used (Figure 6) with convenience sampling being the most common sampling procedure, encompassing both face-to-face surveys (35\%), postal and online surveys (26\%). Also, $19 \%$ of the studies used random or stratified random sampling and $17 \%$ employed a quota, whereas $3 \%$ of studies did not provide information about the sampling. In total, $40 \%$ of the studies can be considered as representative based on the number of studies using random and quota sampling and three studies that used other methods but, according to the authors, generated a representative sample. Note that a lack of representativity limits the comparability of studies across country and time. However, here we point out that non-representative studies can also provide valuable results if the studies aim to identify differences between groups (e.g. respondents with forest-based sector and without forest-based sector involvement) or differences of agreement between different items. Owing to the variety of survey methods and sampling procedures, the results of the studies cannot be fully compared to investigate geographical differences and changes over time. Also, many studies report relative values or quantifications of relationships between two or more variables, instead of absolute values.

Figure 6. Distribution of different sampling procedures and methods used in reviewed studies $(\mathrm{N}=77)$

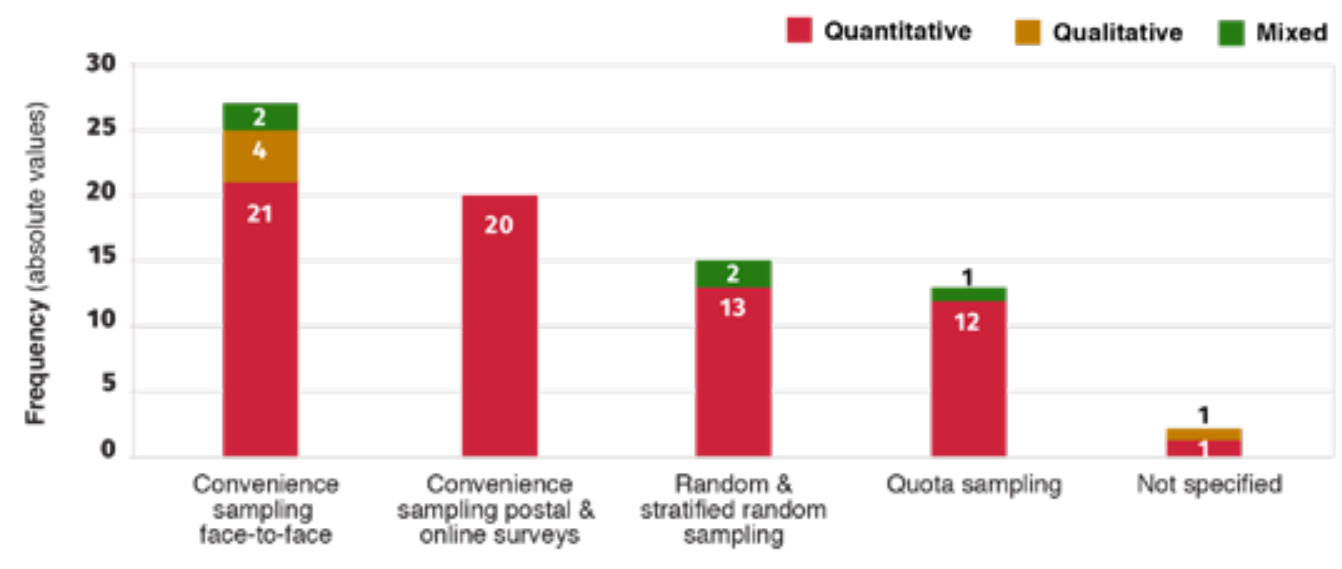




\subsubsection{Frequency \& focus of reviewed studies over time}

Figure 7 shows the distribution of studies across the time span of 10 years. While there was only one study published in 2010 , there was a peak of 16 studies in 2017. The majority of the studies from 2017 were from Northern and Western Europe. Looking at the distribution by topic, Figure 8 shows that all four topics developed equally with the peak in 2017 being the result of studies about "forestry and forest management" (nine studies).
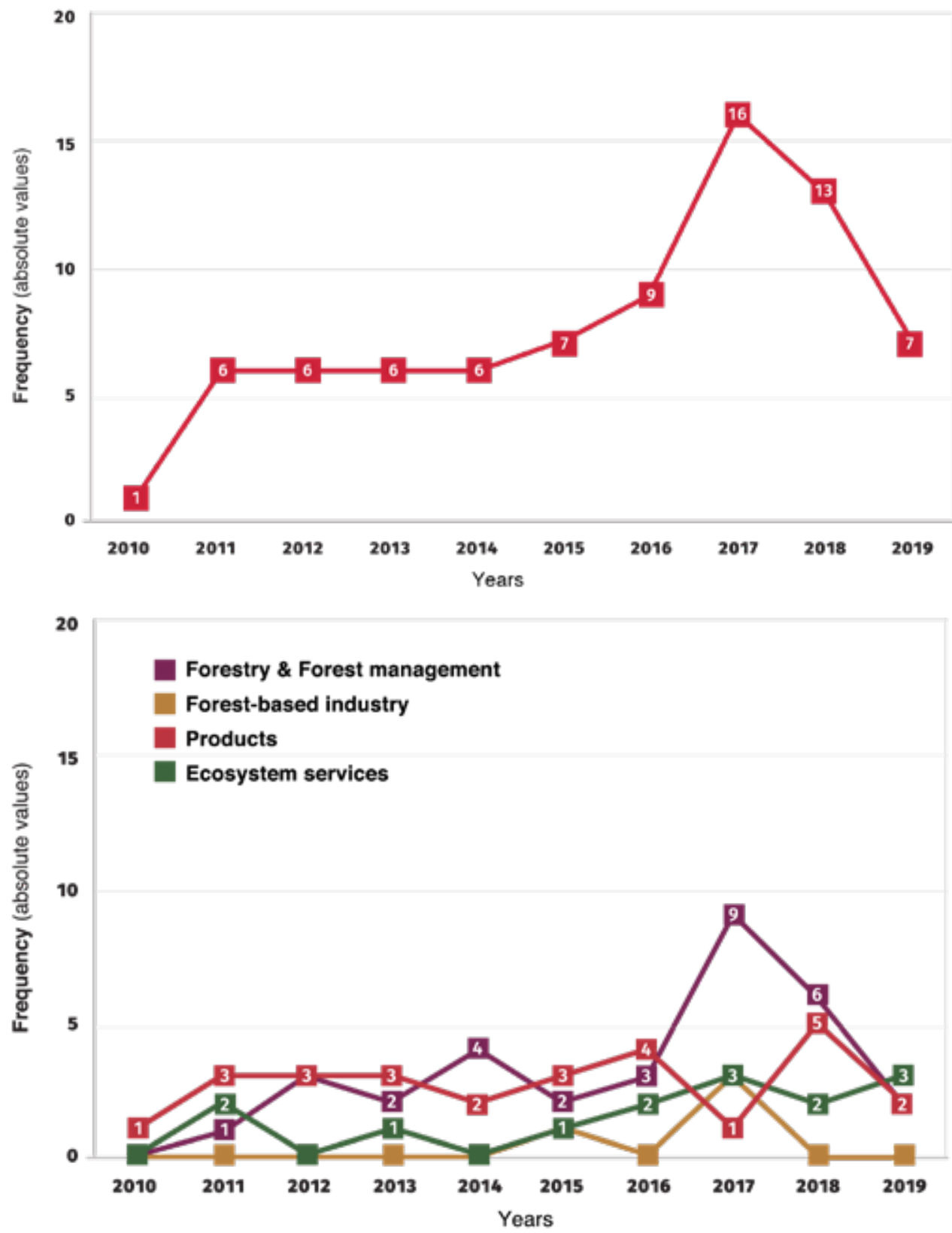


\subsection{Perceptions of forest ecosystem services}

This chapter summarises those studies that focused on the public perception, importance or preference regarding forest ecosystem services.

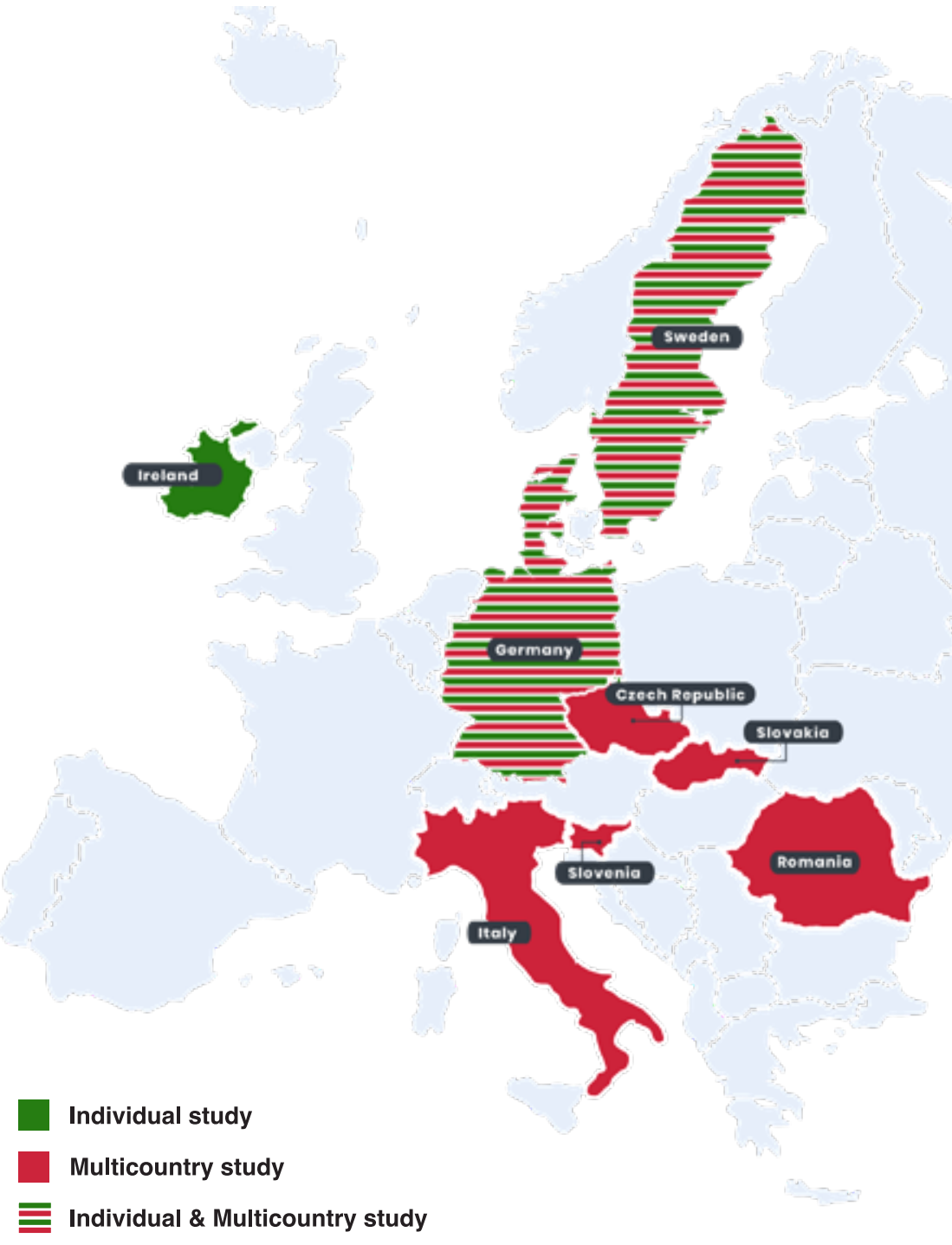

In total, there are 14 studies from the following countries: Czech Republic (1), Germany (3), Ireland (2), Italy (1), Romania (1), Slovakia (1), Slovenia (1), Sweden (3) and one multi-country study. 
The studies covered different target groups such as the general public, forest visitors, the local population and students (Figure 9a). The studies mostly used convenience samples and took place in the forest (Figure 9b). There are two qualitative studies and two mixed methods studies, which used qualitative methods in addition to their quantitative survey (e.g. interviews, observations, content analysis).

In the Czech Republic, Šišák et al. (2011) asked forest visitors $(\mathrm{N}=112)$ of publicly owned forests (i.e. Forests of the Czech Republic) which forest functions should be provided by the forest. The survey is based on a convenience sample and was conducted in three selected areas: a mountain area (Nová Louka in the Jizerské hory mountains in the north of the Czech Republic), a highland area (Pasecká skála in the Czech-Moravian Highlands in the central part of the Czech Republic) and a lowland forest (Knížecí les in the south-eastern part of the Czech Republic, by the Svratka River). The forest functions that should be provided, ranked by their importance are: nature protection, soil conservation, climate protection, hydrological function, health (i.e. recreational) function, timber production and production of non-timber products.

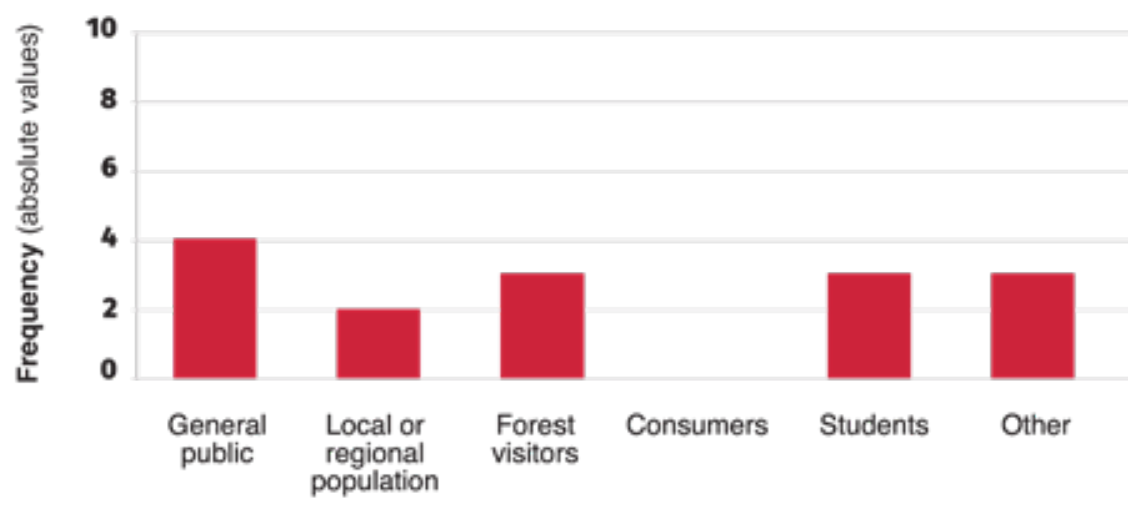

Figure 9a. Target groups of studies on forest ecosystem services

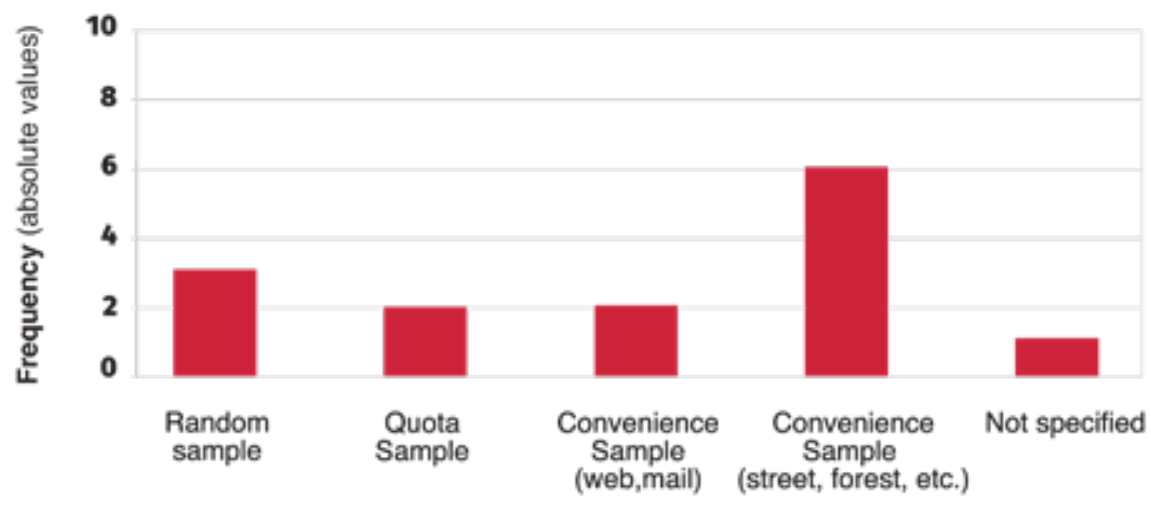


In addition, respondents were asked for their desired sources of finance to provide improved non-market services of the forest, and the majority said that payment should partly or completely come from timber sales or public money, such as state budget, and only a minority said it should come from forest users themselves. Regarding forest operations, respondents consider tree planting and tree protection to be the most important, followed by road and water stream protection and maintenance, whereas timber transport and timber harvesting are considered the least important.

In Germany, Almeida et al. (2018) investigated the perceived forest benefits $(\mathrm{N}=520)$ in mixed and monoculture forests in southwest Germany, surveying different stakeholders such as foresters and people working in forest industries, policymakers, researchers, people working in non-governmental organisations (NGOs), people associated with tourism and recreation clubs (hiking, cycling, horse riding, hunting etc.), students and others (e.g., teachers, engineers etc.) with a web-based survey using convenience sampling. The study shows that $80 \%$ of respondents found a mixed forest type (beech-fir) more pleasant and perceived forest ecosystem services to be higher in mixed-forest types compared to monoculture with beech or fir only. While $46 \%$ of the respondents believed that old and big trees are more likely to be found in mixed forests than in monospecific forests, there was no indication whether they preferred these kind of trees. $59 \%$ of respondents had a greater "feeling at home" in mixed forests, whereas up to $24 \%$ of the respondents felt more at home in monospecific forests. As the study specifically investigated the perception of forest ecosystem services and related forest attributes in mixed and monospecific forests, they found that respondents perceived biodiversity, climate change adaptation and disease resistance to be higher in mixed forests. Conversely, respondents believed that ecosystem services such as profitability, timber yield and hunting potential were higher in monospecific forests than in mixed forests. Note that there were several respondents who answered "I don't know" to all questions, while "I don't know" answers ranged between $18 \%$ and $30 \%$ for questions relating to timber yield, profitability and hunting potential. This indicates that respondents have a higher awareness of ecosystem services and related attributes of forests such as biodiversity, plant and wildlife observation, recreation and resilience, whereas they had a lower level of awareness about hunting, profitability and wood production. Regarding significant differences, respondents who did not own any private forest lands were more likely to believe environmental ecosystem services are higher in in mixed forests than private forest owners.

Another study (Lupp et al., 2016) found that forest visitors in the North of the Munich Metropolitan Region ( $\mathrm{N}=290)$, who were surveyed at the forest trail, ranked air purification, biodiversity and carbon sequestration among the most important ecosystem services, whereas provisioning services such as timber, fuel wood, berries and mushrooms were of less importance. When asked about the positive characteristics of the forest in an open-ended question, most respondents associated "Nature" and natural features of the forest. Regarding monetary values, recreational services were valued 
higher than timber production, which highlights the importance of sociocultural ecosystem services.

In Germany, Meyer et al. (2019), surveyed on-site forest visitors $(\mathrm{N}=478)$ to the urban forest of Augsburg and the rural "Brugger" forest in Bavaria about their spatial preferences in the context of pathway choice. Half of the stated reasons for pathway choice were not related to forest ecosystem services such as spontaneity or habit and around one fifth mentioned general forest characteristics, such as beauty, tranquillity and fresh air. Non-forest elements (i.e., elements in the forest but not part of the ecosystem such a good pathway, monuments) amounted to $16 \%$ while $14 \%$ named exercise and social cohesion. Only a minority (4\%) explained their pathway choice with specific ecosystem elements such as specific plants, deadwood or forest structure. Forest characteristics showed a weak influence on forest benefits ratings and were a less relevant reason for pathway choice. Regarding temporal aspects, most forest benefits were rated lower during winter than during summer. Only the aspects of peace and tranquillity and health did not significantly vary depending on the season. Ratings for forest benefits differentiated significantly between sport groups and families, who placed higher value on sport and health, or spending time with family and friends and fresh air, respectively. In addition, walkers, dog walkers, and mountain bikers had a higher preference for fresh air.

In Ireland, Howley et al. (2011) surveyed the Irish population $(\mathrm{N}=430)$ with quota sampling asking them about the benefits provided by forests relative to other landscape elements. While timber production was held as being either important or very important by a large proportion $(71 \%)$ of individuals, this was still less than the other reported benefits such as biodiversity (85\%) and mitigating climate change by taking carbon dioxide out of the atmosphere $(82 \%)$ and offering opportunities for recreational activities $(81 \%)$. As the country engages in afforestation measures on agricultural land, they asked a single question on respondents' views on the amount of land currently in forestry use. Note, the study does not differentiate between different types of forest (e.g. conifers, broadleaves, native, non-native species). $21 \%$ of respondents state that farmers have converted too much of their land to forest land, whereas $42 \%$ disagreed and $36 \%$ reported they do not know. Also, $78 \%$ rated forests either very highly or highly as a landscape element, whereas water bodies received highest agreement with $91 \%$. However, the study authors raise the question of whether the general public will maintain such a positive view if forest lands become more common. Regarding significant differences, respondents with forest-based sector involvement or farming households were more likely to rank timber higher and recreation and conservation outputs lower than other respondents.

Upton et al. (2015) surveyed Irish residents $(\mathrm{N}=996)$ with stratified quota sampling to rank the most important forest outputs in Ireland. The study uses the same survey data as Upton et al. (2012) but runs a different type of analysis. $92 \%$ of respondents agree that forests are an important part of traditional landscape of the Irish countryside and $79 \%$ agree that all types of forests are good for the environment. The conservation of plants and animals was ranked first by the largest proportion of the sample $(37 \%)$. In contrast, protecting water and climate received 


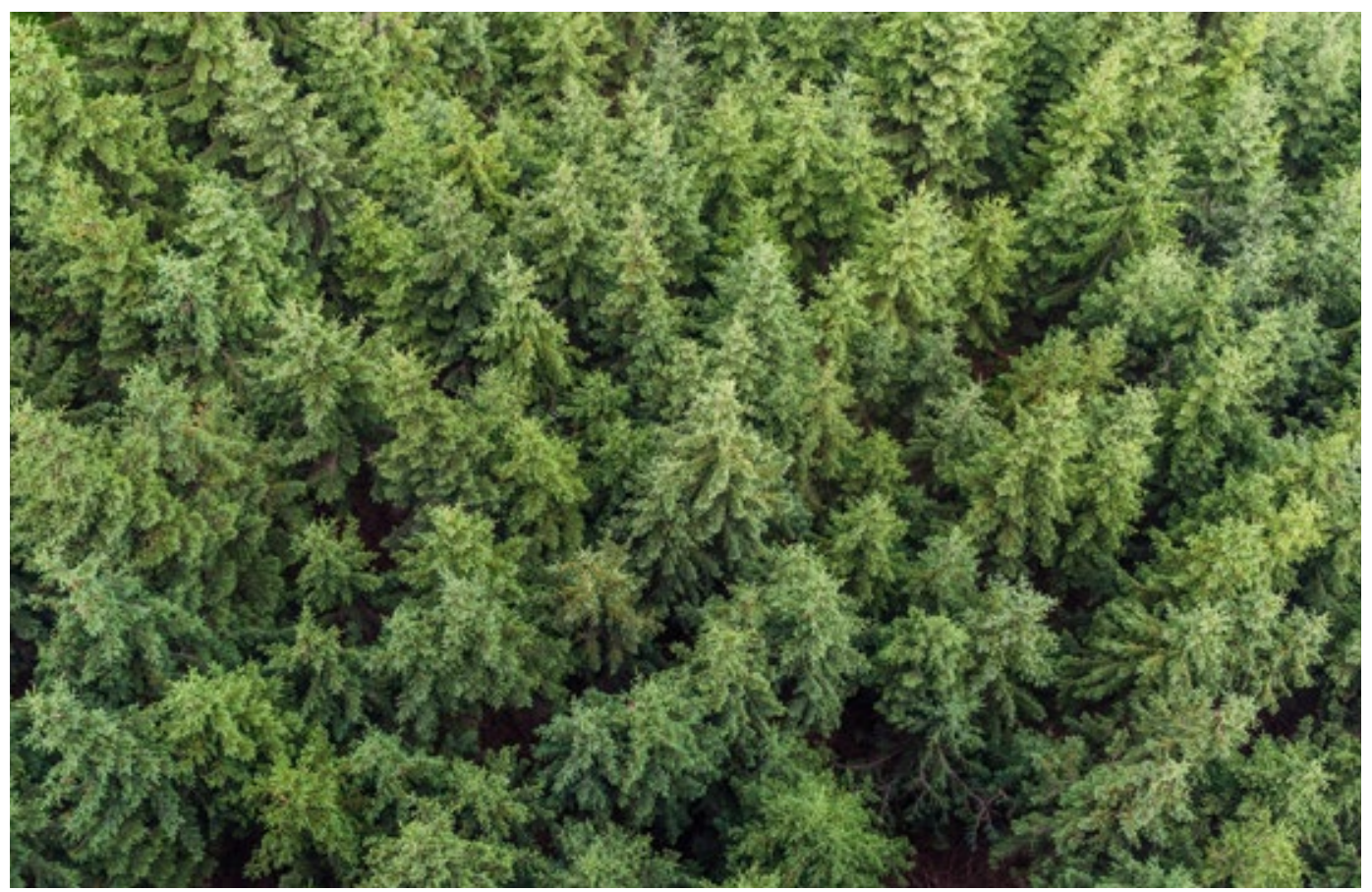

Photo by: @ Lukas / Pexels

$21 \%$, employment and jobs $18 \%$, and recreation and timber production were ranked first by a relatively small proportion of the sample (12\% for both). Respondents from a farming household were more likely to rank timber higher and recreation and conservation outputs lower than other respondents. Respondents with a third level education were more likely to rank employment lower and protection and conservation higher and those from urban areas were more likely to rank recreation higher and timber lower. Regarding forest policy, $48 \%$ agree that private forest owners should have the right to deny public access to their land and $60 \%$ said they would trust foresters to always make the right decisions. Furthermore, $38 \%$ agree that the general public should only be asked their opinions on forests in their local area whilst $77 \%$ agree that general public should have more opportunities to comment on how forests are managed in Ireland. Also, $63 \%$ said knowing how Irish forests are managed is important to them and only $24 \%$ agree that the public should not be asked their opinions on forests because they do not know enough about forestry.

In Italy, Paletto et al. (2013a), surveyed randomly selected households $(\mathrm{N}=242)$ belonging to the Trent municipality about the role of forests based on random and stratified random sampling. High values were put on environmental functions of forests: regulation of air quality and reduction of the greenhouse effect, habitat for biodiversity and a protection from avalanches, landslides and flooding. The lowest values were instead found for timber and fuel-wood production and tourist development. The environmental functions were mostly valued and referred to the importance of the forest to improve air quality, to provide protection against disasters and to provide shelter and habitats for a wide variety of species. Medium value was linked to the positive effects of forests on landscapes and recreational activities. The economic 
value of the forest, concerned with incomes and job opportunities derived from wood production and tourism, obtained the lowest score. Regarding significant differences, men were found to assign higher scores to forest functions and younger people showed a greater preference for broadleaves, while the elderly preferred conifers.

In Romania, Pacurar et al. (2018) interviewed the local community $(\mathrm{N}=40)$ qualitatively about Brasov's forests without further specifying how the individuals were selected. The majority (87\%) of the subjects stated that they are aware of the forest functions. When asked about the role of forests in their community life, the provision of oxygen, ecosystems protection, benefits for human health, pollution reduction and opportunities for relaxation in a beautiful scenery were mostly mentioned. Interestingly, while $54 \%$ said that production and protection functions have an equal importance, the remaining respondents regarded protection as more important. When asked to rank protective functions, the most important forest function was agreed to be "protection against climate and industrial threats", followed closely by "land and soil protection". In addition, about half of the respondents $(57 \%)$ said that forests are well managed. Factors negatively affecting the quality of Brasov's forests were pollution, lack of ecological education, intensive wood harvesting, too many buildings close to wooded areas, recreational activities and too many large carnivores. According to the study authors this indicates that the distinction between forest condition and management quality may not be very clear, as only two aspects (wood harvesting and large carnivore presence) are directly linked with forest management. Thus, the information flow between forest managers and their activities and the local community could be improved. Additionally, $85 \%$ said they have no information about different forest protection projects and $75 \%$ stated their willingness for volunteering in projects aimed to protect the forests from the Brasov area.

In Slovakia, Dobsinska et al. (2016) surveyed the general public $(\mathrm{N}=1503)$ using random sampling and private forest owners ( $N=151$ ) using convenience sampling, asking them about the main purpose of forests. For the general public "ecological values" (84\%), "social aspects" (10\%) and "economic purposes" $(7 \%)$ were the main purpose of the forest. On the contrary, for the forest owners "economic purposes" (41\%), "social aspects" (34\%) and "ecological values" (23\%) were perceived as the main purposes. The results of the public survey indicate that the general public has expectations with regards to forests and forestry, expecting greater protection and management for ecosystem services emphasising ecological values rather than economic purpose. However, forest owners stress the economic function and were more likely to rank timber higher and recreation and conservation outputs lower than other respondents, although no statistical tests were conducted. Furthermore, a majority in both groups rated the forest management of private forest owners as "good" and "satisfying".

In Slovenia, Torkar et al. (2019) surveyed sixth and ninth grades of nine-year compulsory school students from northern Slovenia, from the Upper Carniola region, $(\mathrm{N}=377)$ using convenience sampling regarding their attitudes towards provisioning, regulating, cultural, and supporting forest ecosystem service using 15 items. Students placed the highest personal importance on supporting forest services 
providing habitats for animals and plants and the production of clean air and clean water. They placed lower importance on provisioning services and cultural services. Overall, the lowest score was given to the aesthetic value. Regarding significant differences, they found that the level of education and gender affects the perceptions of forest ecosystem services positively. Ninthgrade students expressed more positive attitudes toward provisioning ecosystem services than sixth-grade students, which can be explained by the different knowledge levels. Regarding gender, female students expressed more positive attitudes and knowledge towards ecosystem services than male students. Female students also demonstrated better knowledge of ecosystems than male students.

In Sweden, Goodwin et al. (2019) surveyed primary school students ( $\mathrm{N}=397$ ) using convenience sampling at student workshops taking place at the Universeum science centre in the Gothenburg area of western Sweden. Students reported discovery $(47 \%)$, fun (36\%), tranquillity (37\%), physical and emotional wellbeing and health (32\%) as individually perceived forest benefits. In terms of activities, recreation and the collection of food, e.g. mushrooms or berries, were both present (each 25\%). By comparison, experiences of escapism (8\%) and belonging (4\%) scored relatively low. In follow up focus group sessions $(\mathrm{N}=42)$ with picture cards, respondents identified carbon absorption, the picking of berries and mushrooms, and homes for animals as the most important ecosystem services provided by forests, out of six choices.
Another study (Kronholm et al., 2017) used convenience sampling with Forest Story Cards in focus groups $(\mathrm{N}=49)$ to investigate young adults' relationships to forests in Northern Sweden. The respondents reported that, in their childhood, recreational activities were central, whereas as adults, their current thoughts and perceptions about forests were more often connected to money. Respondents explained this to be partly the result of a knowledge increase about the connections between the industry, forests, forest owners' finances and the national economy. Young adults expressed strong hopes of being able to foster their own children's relationship to forests in similar ways as they experienced themselves and "taking good care of the forest environment" was very important for them.

Nummelin et al. (2017) surveyed university students of different disciplines (forestry, social sciences, humanities and arts, and natural sciences) in Umeä ( $\mathrm{N}=1002)$ with convenience sampling at one campus using mind maps about students' visions of future forests. The mind maps reveal a complex network of students' visions, showing that recreational, cultural and ecological values related to forests were of great importance. Interestingly, students tended to remove variables connected to business-related aspects of the forest and production and the business categories have the weakest connection to other categories, which may indicate that students view the production aspects of forests as separate from other uses.

In a multi-country study in Germany and Sweden, Nordlund et al. (2017), surveyed rural and urban general public $(\mathrm{N}=2446)$ with a 
randomised postal survey about forest requirements and qualities. Regarding forest qualities, respondents mostly agreed that "forests are important to mitigate global warming" and considered forests to be important for "physical and mental wellbeing" and "the opportunity to experience quiet and peacefulness". Regarding forest conditions, only limited agreement was found for "forests are sufficiently robust to cope with the current environmental problems" and "I am not concerned that the current environmental problems will harm forests". Public access to forests was rated higher than the opportunity to experience quiet and peacefulness, and the importance of forests for physical and mental wellbeing. Regarding forest requirements, "experiencing quietness", "no visible influence of other people on the environment", and "no visible trace of active forestry e.g. clear cuts or forestry machinery" were most important. The greatest differences between the German and Swedish sample was in the area of forest requirements. German respondents attached significantly greater importance to marked trails and information boards as well as experiencing quietness and not seeing buildings or the influence of other people on the environment.

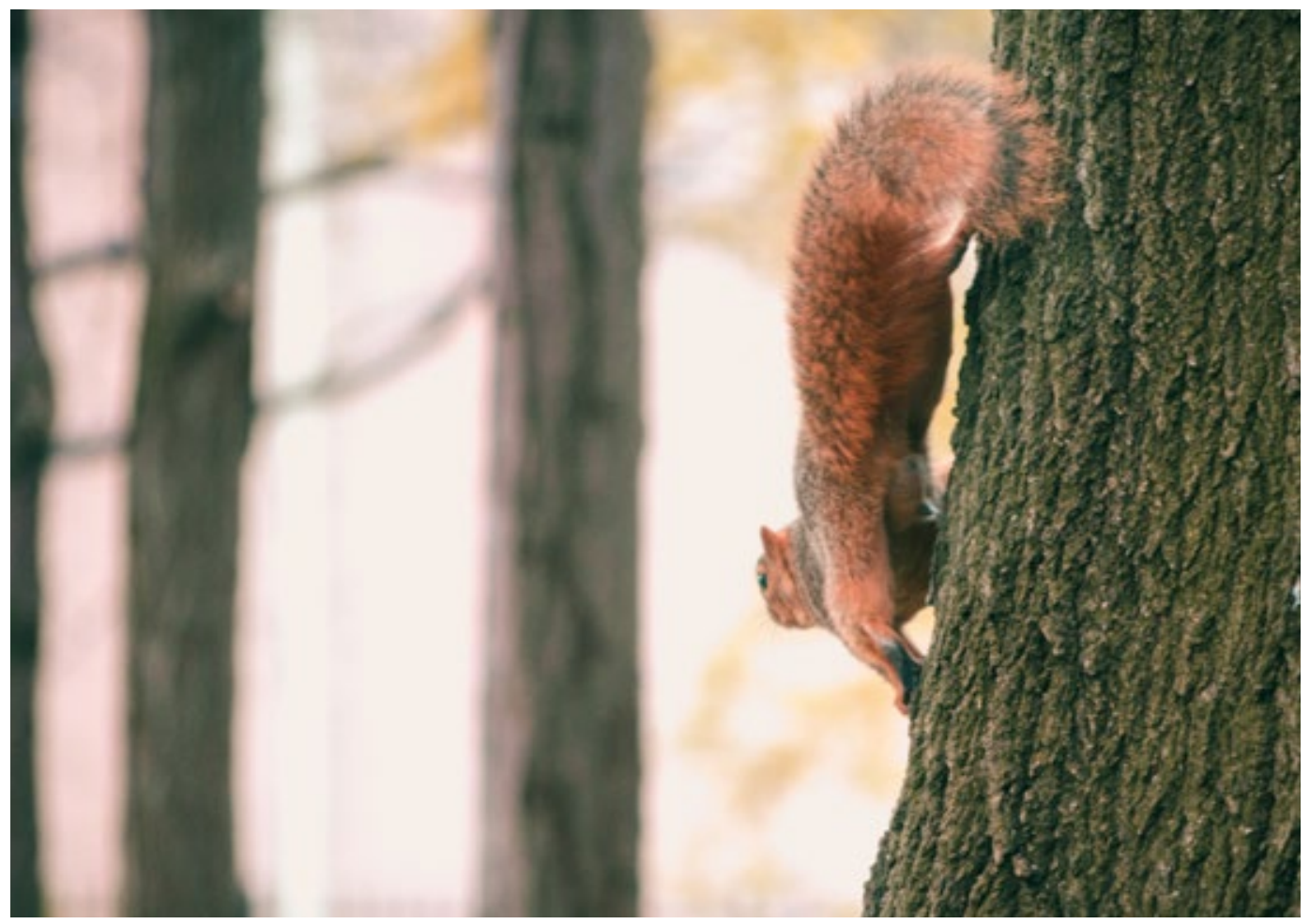

Photo by: @ Jonathan Meyer / Pexels 


\subsection{Perceptions of forestry and forest management}

This chapter investigates perceptions of forest conditions, management activities and forest attributes. This is important as different measures and activities change forests' characteristics and appearance, which might influence whether these forests are perceived as well managed by the general public.

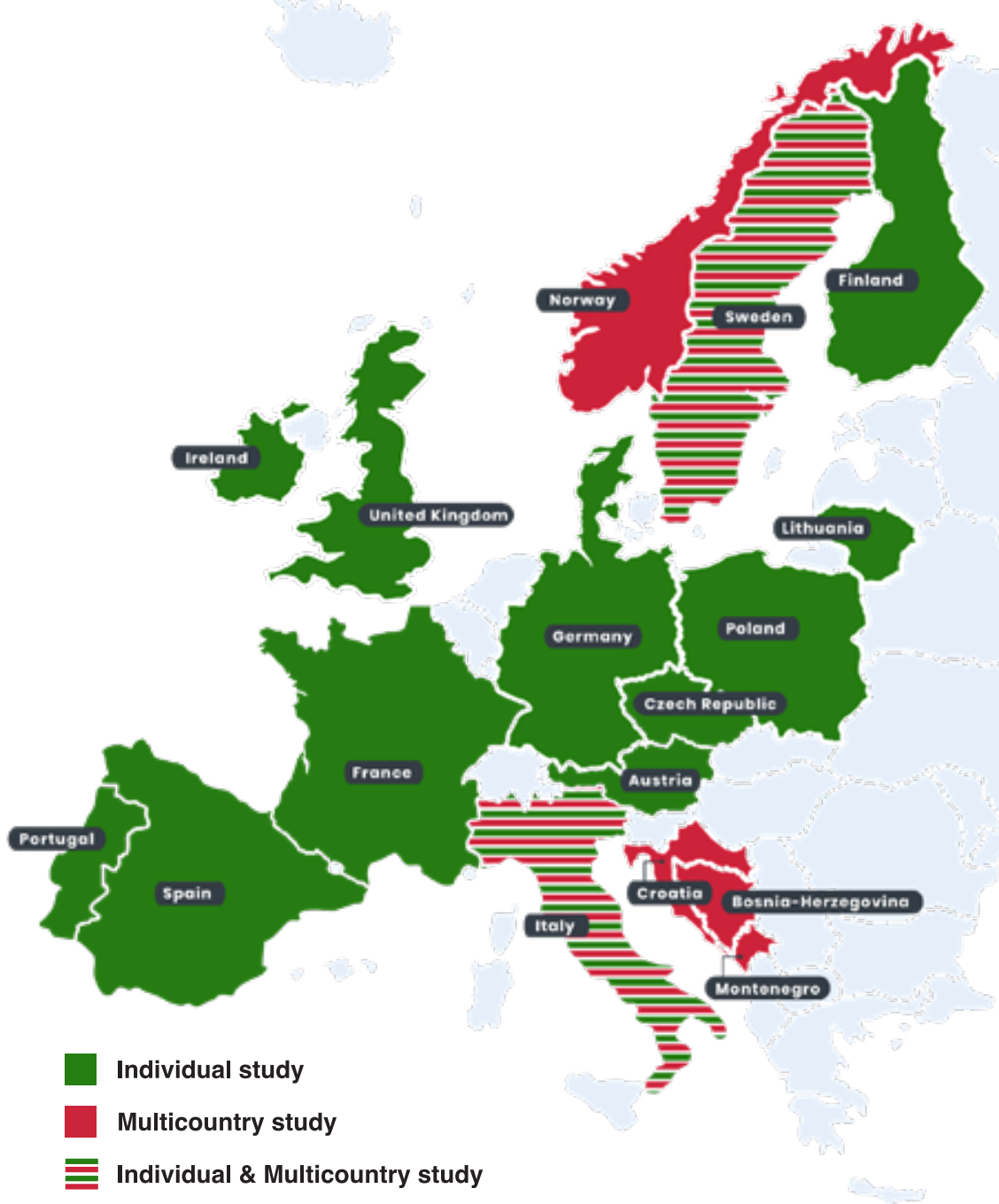

There are 32 studies in the following countries sorted alphabetically: Austria (1), Czech Republic (3), Finland (5), France (1), Germany (2), Ireland (1), Italy (3), Lithuania (1), Poland (2), Portugal (1), Spain (2), Sweden (3), United Kingdom (4) and three multi-country studies. 
The studies mainly covered the target groups of general public, forest visitors, and the local population (Figure 10a). Again, the studies mostly used convenience samples (Figure 10b). There are two qualitative studies and two mixed methods studies, which used addition qualitative methods in addition to their quantitative survey (e.g. expert interviews or focus groups with forest owners, industry representatives).

In Austria, Huber et al. (2017) used guided on-site interviews to survey forest visitors' ( $\mathrm{N}=51)$ reactions towards a harvesting operation and the moderating effect of information signs about the purpose and impact of a harvesting activity. Those forest visitors of the biosphere reserve in Vienna Woods (Biosphärenpark Wienerwald) in Vienna and Lower Austria who did not have the opportunity to read the signs put emphasis on the visual appearance (78\%) and worried about ecology and environmental compatibility (57\%).

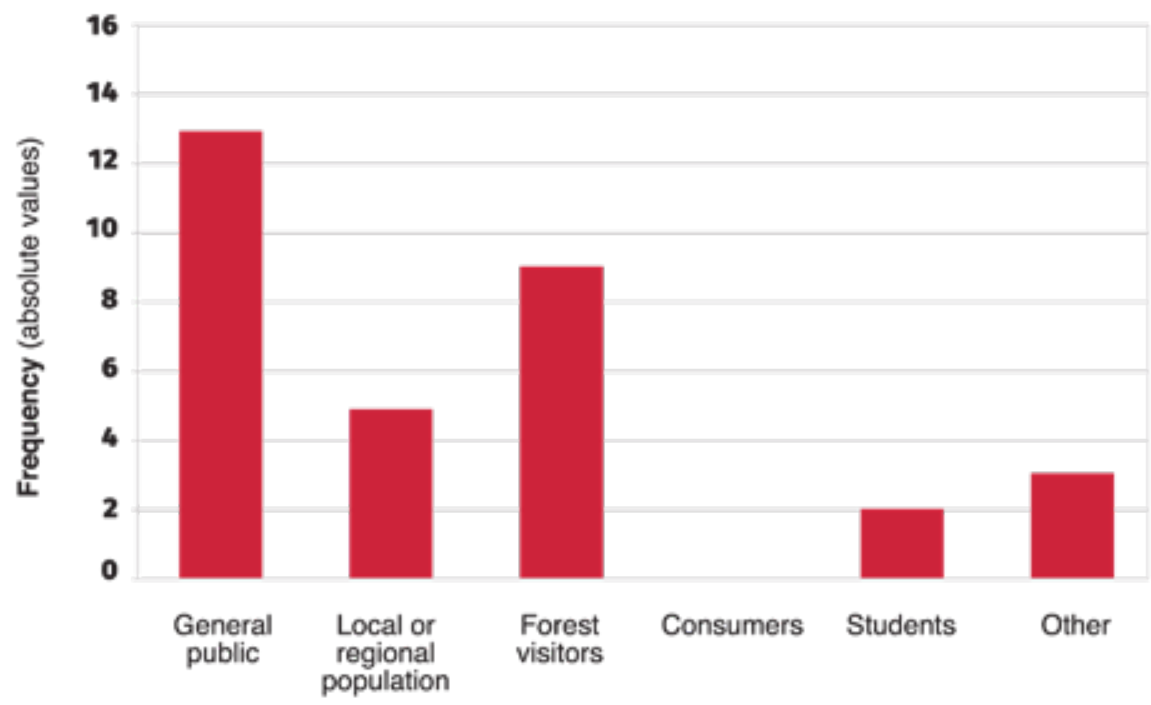

Figure 10a. Target groups of studies on forestry and forest management

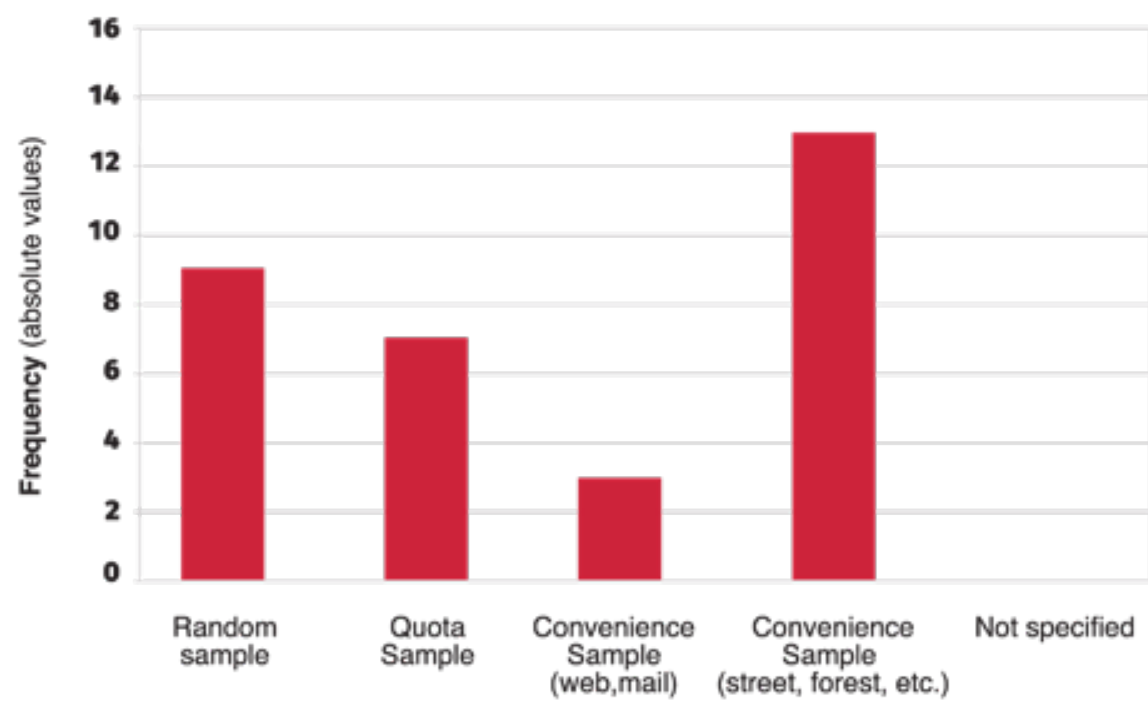

Figure 10b. Sampling procedures of studies on forestry and forest management 
For those who read the signs, visual appearance $(40 \%)$ and worries about ecology environmental compatibility $(20 \%)$ were of less importance, and answers were more diverse and centred around wood use. The results suggest that the information signs caused a shift in the topics mentioned by the forest visitors. Overall, the results show that the concern forest visitors feel about harvesting activity on a visual and ecological level can be reduced through information about the specific harvesting activity.

In the Czech Republic, Drábková et al. (2014) surveyed forest visitors reaching the top of the Velký Blaník hill, south of Prague $(\mathrm{N}=242)$, on site about forests and forestry. Regarding tree species composition, $48 \%$ of respondents preferred mixed forest while $35 \%$ had no opinion, $15 \%$ chose coniferous forest and only $2 \%$ chose broadleaved forest. On being asked which forests they prefer to travel to, $84 \%$ selected forests with variety, such as small "meadows, clear cuts, glades etc.". Regarding ease of passage and visibility, $44 \%$ preferred forests without undergrowth and $20 \%$ chose forest with undergrowth. When asked about their opinion of the fallen, old, rotting trunks left in the nature reserve, $82 \%$ of respondents considered this to be nature-oriented forestry. When asked about the meaning of "constantly sustainable forest management", $56 \%$ provided the correct answer, while 32\% were wrong and $11 \%$ did not know. However, it needs to be acknowledged that defining a technical term in a survey is difficult and may have biased the answers.

Krejčí et al. (2019) surveyed the general public $(\mathrm{N}=824)$ in an online survey about the most important topics regarding forests. Respondents mentioned forest conservation and protection (46\%), followed by environmental issues, forest health and air pollution (36\%) most frequently. The topics considered least important were deforestation (1\%) and recreation (2\%), while ecosystem services reached $7 \%$. When asked about the most important cause of damage and threats to forests, $61 \%$ respondents named harvesting and management damage. $31 \%$ named storms as the second most important cause of damage. Less than $10 \%$ named forest fires and wild animals as a forest threat. $52 \%$ of the respondents stated that the forest conditions of their permanent place of living are deteriorating, while only $18 \%$ said they were improving. Regarding significant differences, women were found to have higher preferences for forest conservation and the view on forest condition correlated with the forest density of a region.

Stachová et al. (2018) surveyed the Czech population $(\mathrm{N}=983)$ about their attitudes towards forests and forestry with quota sampling but details on how the data was collected are not available. The majority of respondents (77\%) believe that the polluted environment has a negative impact on Czech forests. $70 \%$ perceive clear cuts negatively, $48 \%$ state that the overpopulation of game has a negative effect on forests, and $45 \%$ believe that monocultures have a negative impact on forests. In general, the public, especially those with more education, prefer forest management that results in close-to-nature forest. Most people believe that the return of wild carnivorous animals to Czech forests is desirable (78\%). The same share of respondents also believes that cutting small groups of trees or individual trees, as opposed to the creation of large clearings, increases 
the resistance of forests to climate change. $54 \%$ of them consider it necessary to reduce game stocks in Czech forests. $76 \%$ of respondents believe that planting introduced tree species imported from other continents may have a negative impact on forests; $65 \%$ do not like forest clearings and $75 \%$ of respondents are of the opinion that the management of forests predominantly focuses on producing timber without sufficient respect for the environment. In addition, respondents more often considered non-productive, environmental functions of forests such as climate protection (68\%) and water and soil protection $(63 \%)$, biodiversity protection (55\%), and aesthetic function (52\%) as important, in comparison to production of forest fruits and mushrooms $(43 \%)$ recreation $(37 \%)$ and wood production (36\%). However, when asked to select only the three most important functions, biodiversity protection was rated as most important followed by climate protection and wood production.

In Finland, Hauru et al. (2014) surveyed forest visitors $(\mathrm{N}=287)$ on site in Helsinki about deadwood to investigate the effects of decaying logs on the aesthetic experience and acceptability. They differentiated between no logs, fresh logs and old logs. The results reveal the acceptability of the study sites as well as general acceptance of dead wood. The mean rating of general, non-sitespecific acceptability of dead wood across the whole dataset was high at 5.94 on a seven-point Likert Scale. Sites with old logs were considered messier and more chaotic than sites with fresh or no logs. Both old logs and fresh logs were rated higher regarding aesthetic diversity than no logs. Based on the results, the authors of the study suggest that decaying logs should be left in urban forests not only to increase biodiversity but also because they are accepted by, and aesthetically interesting to, forest visitors.

Juutinen et al. (2017) surveyed the general public $(\mathrm{N}=1241)$ in three regions regarding their preferences for recreation management in stateowned, commercial forests based on random and stratified random sampling using discrete choice experiments (mail, web, random selection). The attributes were width of scenic buffer zones along lakes and rivers, habitats for game birds and clear-cut areas visible along hiking trails. They found that the maintenance (or increase) of the scenic buffer zones along waters was a clear preference shared by all segments of respondents. The same more or less applies to the avoidance of clear cuttings along hiking trails. They found that forest visitors and those who practiced nature watching and fishing had higher monetary valuations for recreation-oriented management than had non-visitors. Overall, the majority of respondents were quite satisfied with the current management and the results do not seem to suggest any major management changes.

Matthies et al. (2018) surveyed Bachelors and Masters-level students of the Faculties of Agriculture and Forestry and Biological and Environmental Sciences at the University of Helsinki $(\mathrm{N}=165)$, during classroom hours, about forest management objectives differentiated in bioenergy, biodiversity, timber, climate, considering the students to be future environmental and forestry professionals. In general, the acceptance of biodiversity conservation and climate change mitigation objectives were higher than for timber and bioenergy. The perceived knowledge about the objectives was the highest for biodiversity and the 
lowest for timber and bioenergy production. These results show that in the context of ecosystem service management, positive consequences are more important than negative when evaluating bioeconomy objectives, and that consequences to humans were perceived as more important than consequences to the environment. Regarding significant differences, females endorsed the biodiversity and climate objectives more than males, whereas males endorsed timber objectives more than females. In addition, perceived harm and benefits to nature and humans reduced the acceptance of timber and bioenergy objectives and the perceived knowledge of timber increased the acceptance of the timber objective, whereas the perceived knowledge of the climate objective reduced the acceptance of the timber and bioenergy objectives.

Tyrväinen et al. (2017) surveyed forest visitors and tourists of Finnish Lapland $(\mathrm{N}=750)$ on site with convenience sampling to investigate the impact of forest management practices on visual quality by providing pictures showing different use intensity in summer and winter. The pictures depicted clearfelling, seed or shelter trees, sapling stands, young stands, mature stands and protected areas. Respondents rated the aspect of attractive scenery as the most important characteristic of the tourist area. The picture pair comparisons on suitability showed that the season has a clear impact on the perceived attractiveness of managed forests for recreational use: winter images were generally more appreciated than the corresponding summer images, especially in the case of regeneration areas that had no or only a few trees. The reason may be that, in winter, the snow covers disturbances so that fresh cutting looks natural and coherent. Summer images were rated more highly than winter images when they showed relatively dense forest stands. Thus, in the summer, tourists prefer mature, well-stocked stands and in the winter, far-views of sparsely stocked forests. From this point of view, intensive forest regeneration should be avoided in actively used forest areas, such as along trails and paths. Nevertheless, a positive finding is that conventional well-stocked commercial forest stands seem to be moderately suitable for tourism in both summer and winter.

Valkeapää et al. (2013) investigated citizens' views of the legitimacy of forest operations and Finnish forest policy, differentiating between forest owners and non-forest owners $(\mathrm{N}=1260)$ based on stratified random sampling. In general, forestry operations such as forest road construction and fertilisation ditching were, on average, evaluated positively while among forest owners the acceptance of forestry operations was higher. Forest owners accepted methods aimed at intensifying wood production, such as clear cutting, forest road construction and the ditching of peatlands, more often than other citizens. Clear cutting was the item with the least agreement with $76 \%$ of non-owners and $56 \%$ of forest owners disapproving of this method. Restoration of forests to a more natural state was more acceptable to non-owners than to forest owners. Forest owners agreed more often that they are satisfied with the way forest issues are managed in Finland. The acceptance of laws received generally positive scores from both groups, but forest owners considered forest-related laws to be less acceptable than other citizens, which suggests that the more people knew about forest policy, the less legitimate they considered it to 


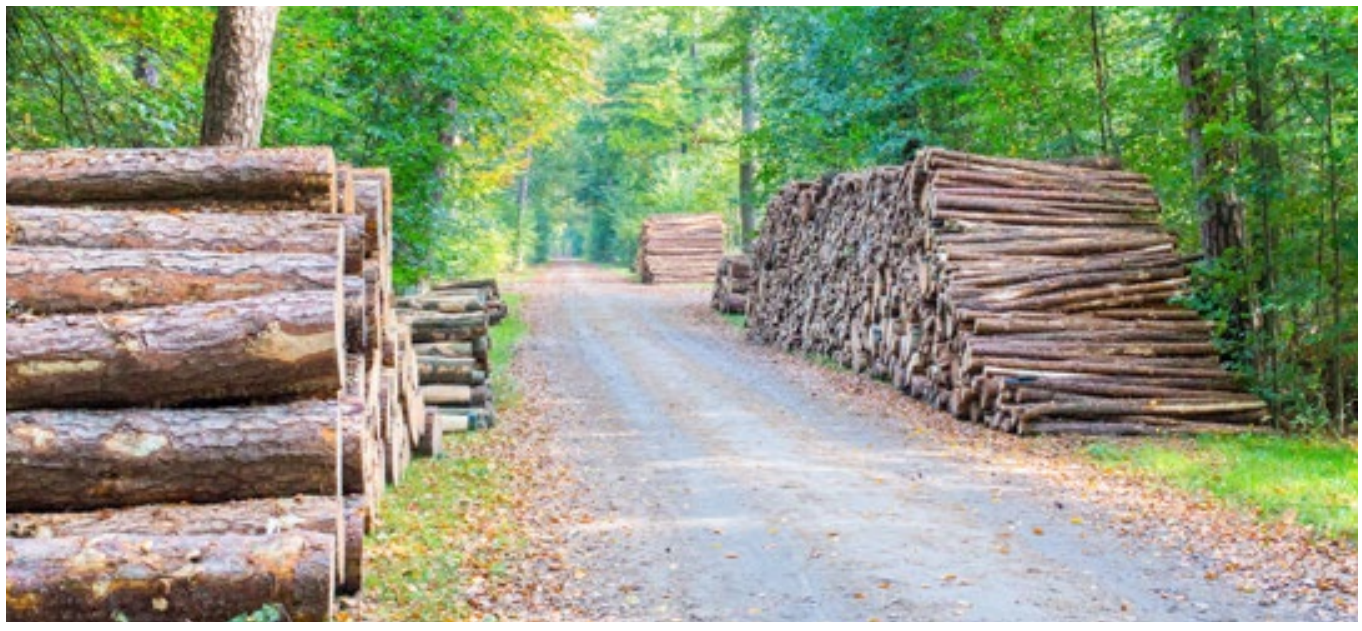

Photo by: ๑ benschonewille / Adobe Stock

be. Even-aged forest management was evaluated negatively by both groups. "Everyman's Rights", allowing berries to be picked in all forests, was the most positively evaluated statement in the whole questionnaire. Regarding significant differences, the acceptance of forestry operations was higher among forest owners, whereas acceptance of forestry laws and whether forest conservation is well managed and forests are well used was lower. The size of the forest estate also had a significant positive effect: the larger the forest, the more legitimate the forest policy was considered to be and wealthier citizens were more approving than poorer citizens. For non-owners, the acceptance of power relations had a statistically significant positive effect on legitimacy.

In France, Rambonilaza et al. (2016) surveyed the general public $(\mathrm{N}=1532)$ with quota sampling about non-market values of forest biodiversity using choice experiments. The different attributes measured are forest stand structure, tree species diversity, amount of deadwood and trees with ecological value. One group was provided with additional information that described the ecological process and value for biodiversity of each attribute. The results show that respondents hold higher values for "the diversity of forest stand structure" (11.79 EUR), "the diversity of tree species" (18.38 EUR) and "old-growth trees with high ecological value" (15.06 EUR) than for "deadwood and logging residues" (2.17 EUR). The provision of ecological information only had a positive effect on the willingness to pay (WTP) estimate for maintaining fallen deadwood. This shows that the public is not aware of the ecological importance of dead wood, and the study authors suggest that if individuals are informed about the ecological value of biodiversity measures they value it higher. Regarding significant differences, respondents' familiarity with the biodiversity concept positively correlated with their awareness of biodiversity loss.

In Germany Arnberger et al. (2018), surveyed visitors to the Bavarian Forest National Park, in south-east Germany $(\mathrm{N}=514)$ on site with discrete choice experiments regarding visual preferences for biophysical factors, such as bark beetle infestations, forest management practices, infrastructure and social factors. Using images, they found positive utility values for mixed and multi-layered forest stand, followed by monocultures of mature spruce 
trees without any beetle impacts, and a forest with first signs of beetle infestation. Artificial afforestation with spruce trees of the same age class, natural rejuvenation, clear cuts and buffer strip, as well as advanced bark beetle impact were negatively perceived by the respondents, indicated by negative utility values. Interestingly, respondents preferred artificial reforestation over natural rejuvenation. Negative utility values were also found for more than one person on the trail, forest roads as trail type, and five windmills nearby.

Gutsch et al. (2019) surveyed forest visitors on site at Teufelssee in southeast Berlin $(\mathrm{N}=554)$ regarding forest protection with pesticide application in Berlin forests. About half of the respondents felt informed about pests whereas this was only the case for one third regarding pest regulation methods. Respondents mostly agreed to measures of mechanical intervention (70\%) and the selected felling of infested trees (57\%) or host trees (43\%). Chemical interventions with pesticides and biocides, both on individual trees and extensive use, received the highest level of objections at $46 \%$ and $67 \%$ respectively. While about half of the respondents would agree to pest control measures if forest health and biodiversity is at stake, only a minority (less than 5\%) agree if economic damage or reduced aesthetic value are the reason. In general, respondents were interested in the topic as about half of the respondents said they would like to receive more information about it. Regarding significant differences, the application of pesticides was more acceptable to age classes older than 45 or respondents with a degree.

In Ireland Upton et al. (2012) surveyed the general public $(\mathrm{N}=996)$ with quota sampling using choice experiments to investigate preferred forest attributes regarding afforestation measures. Note, the study used the same survey data as Upton et al. (2015) but a different analysis was carried out. The study shows that the Irish public holds strong preferences and values for afforestation. In particular, gaining access to new forests is valued highly and, mixed forests were most preferred followed by broadleaf in comparison to conifer forests. In order to maximise the public's valuation of future afforestation, policies should aim to encourage the establishment of mixed species forest reserve areas without clear cuts. In addition, the public should have access to these forests and basic recreational facilities should be provided. Regarding significant differences, respondents with third level education were more likely to rank the forest benefits of employment lower and protection and conservation higher. Further, respondents from urban areas were more likely to rank recreation higher and timber lower.

In Italy, Paletto et al. (2017) surveyed visitors $(\mathrm{N}=201)$ to Monte Morello forest, a local peri-urban forest in Tuscany, face-to-face. Respondents reported tourism and recreation, biodiversity conservation, air quality and cultural values to be the most important benefits. Also, forests are perceived as important for carbon sequestration. Conversely, the economic benefits - provision of timber and fuelwood and creation of job opportunities - are considered as the least important benefits. When asked what kind of forest they consider as aesthetically pleasing, they preferred a mixed forest $(70 \%)$ with a random distribution of trees (55\%) and some preferred a completely untouched forest $(38 \%)$. When asked the same using pairwise comparison with 
forest images, they found that the respondents appreciate managed forests that employ selective thinning and traditional thinning over unmanaged peri-urban forests. Regarding significant differences, younger people were found to assign a lower importance to biodiversity and cultural values than the older ones. In addition, younger people showed a greater preference for broadleaves, while elderly preferred conifers.

Respondents with a university degree assign lower importance to air quality, timber and fuelwood provision and job opportunities compared to less educated people. Less educated people, with elementary school degree, assign higher importance to protection from natural hazards.

Paletto et al. (2013b) surveyed the general public $(\mathrm{N}=346)$ by targeting households with randomised stratified sample about forest management strategies. The majority preferred mixed forests $(66 \%)$, random distribution of trees with varying diameter (59\%), open crown cover density (82\%), and no undergrowth $(48 \%)$. Women and younger people preferred mixed conifer and broadleaf forests over conifer forests. Respondents ranked the unspoiled nature, paths and food vendors as the most important recreational resources in forests. Regarding the goods and services provided by the forest to society, respondents ranked as most important naturalness, landscape contemplation, hiking and relaxation, whereas economic benefits, such as firewood and non-wood forest products, were rated second. Regarding significant differences, people with no university degree assigned higher levels to all ecosystem services and women showed higher preference for uneven aged forests and open canopy. The right to harvest firewood from public forests was valued more highly by respondents living in mountainous areas.

Riccioli et al. (2018) surveyed forest visitors in Tuscany $(\mathrm{N}=248)$ on site regarding their willingness to pay (WTP) for different forest management systems. Respondents rated a coastal landscape with a maximum value of $65 \%$, followed by a rural landscape $(42 \%)$ and an urban landscape $(6 \%)$. High forest received the highest rating (75\%), while coppice received the second highest percentage (65\%). The respondents' choices reflected a high degree of importance placed on forests. Heterogeneous agricultural areas revealed a percentage equal to $48 \%$, followed by pastures (35\%) and crops (25\%). When analysing the simple means of the respondents' WTP, conversion to high forest attracted a WTP equal to $€ 8.64$ per person per year, followed by coppice (WTP equal to $€ 7.44$ per person per year) and natural evolution (WTP equal to $€ 6.52$ per person per year). The highest WTP was given to evolution to high forest (€7.60 per year), while respondents gave a lower WTP for natural conversion (€5.18 per year). This is likely due to the fact that natural evolution is perceived as impenetrable scrub, while coppice is less appealing (from an aesthetic point of view) due to frequent forest maintenance activities (i.e., thinning). This study confirms the existence of differences in users' WTP for forest recreational value according to the management systems. Regarding significant differences, educated individuals had a greater WTP for the recreational use of naturally evolved forest.

In Lithuania, Mizaras et al. (2015) surveyed the general public with stratified random sampling ( $\mathrm{N}=1003)$ and $57 \%$ of respondents said that 
forest cover is sufficient whereas $36 \%$ said it is too low. Also, $67 \%$ said forest cover in Lithuania decreased whereas $22 \%$ said it is unchanged. Regarding state of forests, $52 \%$ said state forests and $47 \%$ private forests are very good or good managed. About half of the respondents said the quality of forest regeneration is high and that forest protection against pests, diseases and fires is sufficient, whereas two thirds considered forest cutting levels too high. $74 \%$ of respondents would voluntarily give up cuttings for conservation of forests' ecological functions, but $62 \%$ of these respondents would do so only if income losses were compensated. For $35 \%$ the forest recreational facilities are sufficient. In addition, respondents had to rate the benefits of forest functions and $65 \%$ stated the ecological benefit is very important for the country and the people, and $47 \%$ found the economic benefit to be very important.

In Poland, Czajkowski et al. (2017) surveyed the general public $(\mathrm{N}=1001)$ to investigate a spatial pattern of willingness to pay with discrete choice experiments for a new forest management and protection programme for the national forest estate. The highest WTP was associated with reduction in the amount of litter in forests, followed by passive protection of all the most ecologically valuable forests and increase of tourist infrastructure. Regarding significant differences, they found that the further away from a forest one lives, the less one is willing to pay for the improvements, and the more forests there are where one lives, the lower is willingness to pay for enhancing the national forest estate. Having a predominance of conifer species always lowers WTP, while having a predominance of deciduous trees in local forests increases WTP for improvements to national forest environmental management. The presence of forests older than 120 years in the area where the respondent lives has a positive and highly significant effect on their WTP for conserving natural forests and removing litter, and for improving forest infrastructure. However, the authors cannot explain why there are spatial clusters of preferences for forest conservation.

Giergiczny et al. (2015) surveyed forest visitors ( $\mathrm{N}=1000)$ using choice experiments via mail regarding structural attributes such as species, silvicultural system, deadwood, infrastructure and residue, to model forest stand preferences. They used an internet panel maintained by a research company with computer-aided web interviews to get a representative sample of recreational forest visitors. Respondents preferred older stands that are diverse, with vertical layering and irregularly spaced trees. They considered that a higher number of tree species positively impacts recreational value and the presence of tourist infrastructure in the forest was appreciated. The level of forest management intensity had the greatest negative impact on respondents' choices: regardless of the management model (clear cut, shelter wood, seed trees), greater management intensity was associated with higher disutility. The same holds for residue from harvesting and thinning, which was disliked. Regarding significant differences, respondents with high level of education had lower preferences for ground vegetation, residue and clear cutting.

In Portugal, Carvalho-Ribeiro et al. (2011) surveyed the general public $(\mathrm{N}=379)$ in a street survey in the town centre of 14 municipalities within 
the Lima and Cavado watersheds of northwest Portugal. They were asked about preferred forest structure through verbal questions and ranking photos. In the verbal questions, $52 \%$ of the respondents considered a continuous forest to be more attractive than a patchy forest. Concerning stand structure preferences, $81 \%$ of interviewees said that they preferred uneven stands in terms of attractiveness. When asked about preferred management, $42 \%$ of respondents favoured continuous forests and $58 \%$ patchy forests. The image questions reveal a general trend for more fragmented forests to be regarded as less attractive. However, the photo showing some discontinuity of forest cover was ranked as both the most attractive and best managed. For stand structures the photo with an uneven structure and minimal ground cover by shrubs got the best attractiveness score, while a photo showing an even stand with no shrubs at all was rated best for management. The study authors argue that public preferences regarding forest cover and stand structure do not, in general, differ under attractiveness and management criteria. In addition, the results reveal some inconsistencies between responses to verbal and visual questions as the photo showing some discontinuity of forest cover was ranked as both the most attractive and best managed. One of the reasons for such a result is that respondents may have had different mental images of concepts such as "continuous forest", "patchy forest" or "even stands".

Regarding significant preferences, the user group influenced the perception of forest attractiveness and management. Respondents who regularly used the forests preferred photos showing discontinuous forest cover for both attractiveness and management. Further, respondents in urban areas preferred forest management

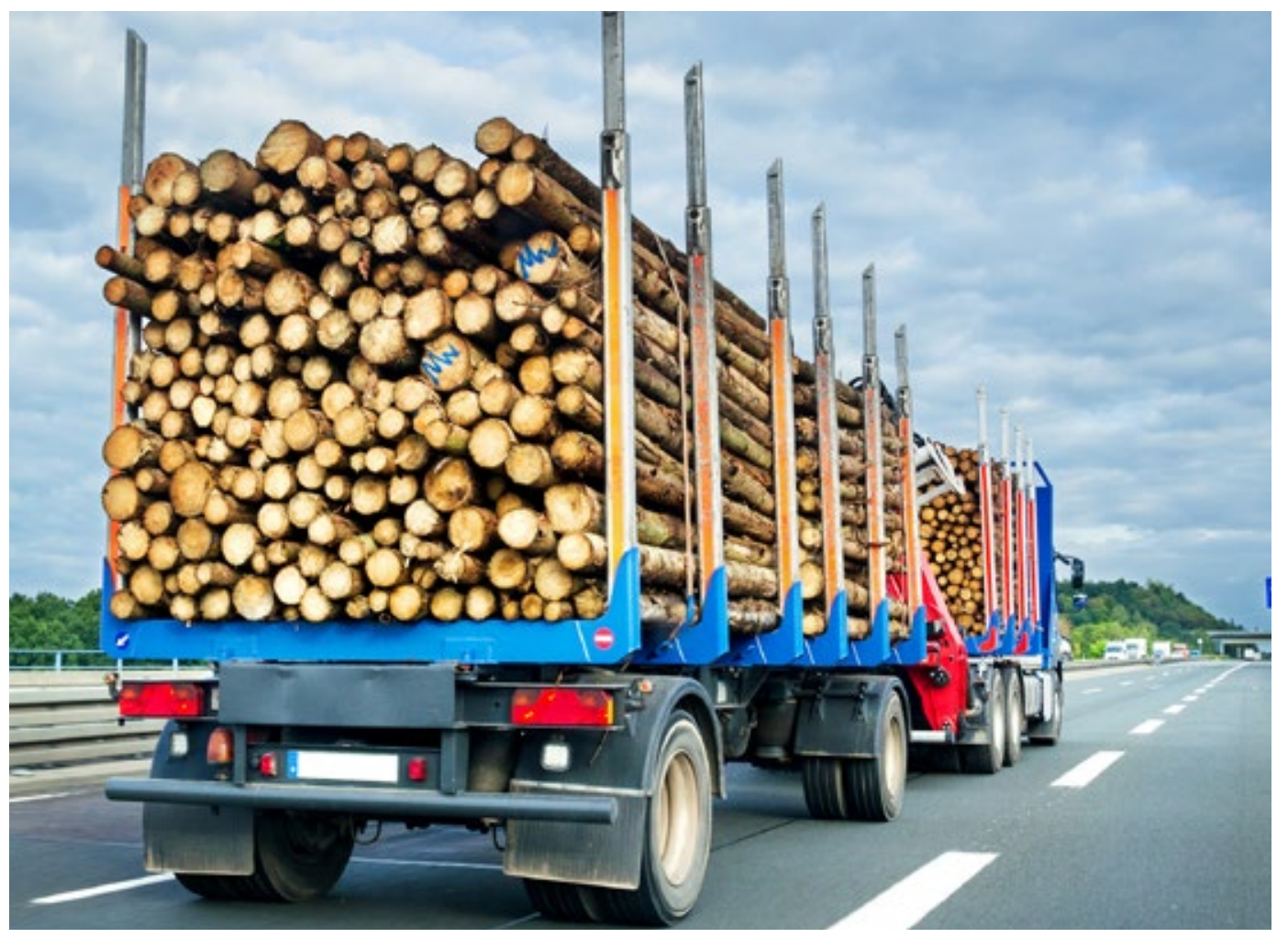

Photo by: (c) Petair / Adobe Stock 
focusing on recreation, whereas in rural areas respondents preferred fire management.

In Spain, Fabra-Crespo et al. (2012) surveyed the regional population in Valencia $(\mathrm{N}=823)$ about forestry issues with quota sampling through a telephone survey. The respondents prefer to improve existing forest areas through improved management (63\%), rather than to increase the current forest area through reforestation measures. $50 \%$ of respondents considered forest management by the municipalities as the preferred model for the Region of Valencia and administrative models involving private owners or non-governmental organisations were rejected. Half of the respondents were of the opinion that the owners should not have capacity for decision-making, but they could be economically compensated for this reduction in power: $75 \%$ of respondents agreed that private forest owners should get financial compensation for the services and externalities they provide to the rest of society for free. Thus, respondents agree to a compensation for sustainably managing their forests (e.g. storing $\mathrm{CO}_{2}$, fighting climate change, preserving biodiversity) and the implementation of a forest tax for funding forest conservation, for several specific forest uses (e.g. hunting, mushroom picking). In addition, the respondents said that more money should be invested in forest fire prevention strategies such as the use of wood and wood-like products from the forest (15\%) and maintenance of traditional mountain agricultural practices (16\%), surveillance to detect early forest fires (30\%), increase firewall structures, forest access and the water supply facilities (31\%), rather than suppression to increase the means of extinction such as fire brigades, airplanes etc. (9\%). Regarding significant differences, women had higher preferences for forest conservation and older age groups found fire suppression more important than younger age groups.

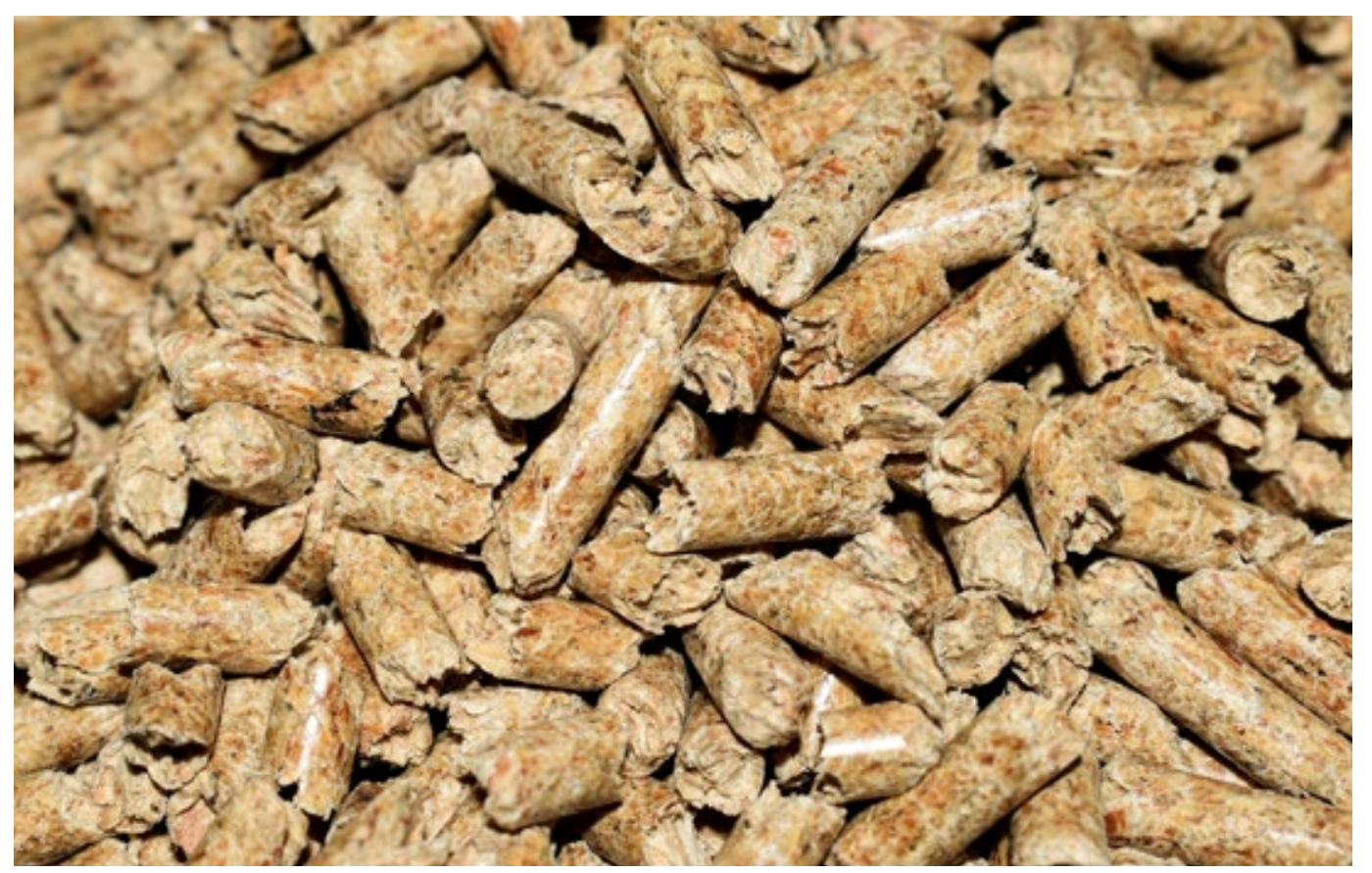

Photo by: ( ) Mrdidg / Pixabay 
Varela et al. (2017) surveyed a representative sample of Catalonian population $(\mathrm{N}=410)$ with choice experiments. They found biodiversity to be an important attribute in shaping people's preferences regarding forest management among the four nonmonetary attributes people had to trade off in this survey. These results are in accordance with studies showing that people hold a higher preference for the environmental value of forest (e.g. biodiversity protection, carbon sink) as the most preferred benefit over, for example, recreational value.

In Sweden, Eriksson et al. (2012) surveyed the general public $(\mathrm{N}=586)$ using a postal survey about their perceptions of urban fringe forests. The urban fringe forest was mostly perceived to be essential for personal wellbeing, followed by preservation and accessibility. Respondents emphasised ecological forest values (e.g. preserving the quantity of wildwood/natural forests) more than recreation (e.g. Increased number of areas for recreation) and production values (e.g. increased timber production). Regarding forest quality, the aspect of restoration (e.g. visiting the forest to experience peace and quietness) was rated higher than activities related to non-timber forest products (e.g. visiting the forest to pick berries and mushrooms). Regarding significant differences, a stronger ecological worldview also led to more emphasis on forest preservation and experiencing personal wellbeing in the forest. Women had higher preferences for forest conservation and accessibility. Respondents of older age classes with university degrees placed more emphasis on personal wellbeing, whereas easy access was more important for older ages classes. Stronger self- transcendence values resulted in an emphasis on preservation, easy access and personal wellbeing in relation to urban fringe forests. In addition, conservative values had a positive influence on urban residents' beliefs about easy access. Stronger ecological and recreation values and weaker production values resulted in a preference for preservation.

Eriksson et al. (2018) surveyed the local population using random sampling ( $\mathrm{N}=1026)$ from three counties in Sweden (Skåne, Västernorrland and Norrbotten) about the acceptability of forest risk management measures for storm, insects, fungi, native and new pests and pathogens. Respondents showed higher acceptance towards forest diversification regarding age, size without clear cutting, removal of infected trees and increased share of mixed forests. Least accepted were doing nothing, use of pesticides and cutting the tree earlier. Interestingly, agreement rates were a little higher when the pests were non-native or when the negative consequences of the pest were known. Regarding significant differences, stronger recreation values resulted in higher acceptability of both removing infected trees and removing trees from a large area. Stronger ecological values were furthermore associated with a more negative view of using pesticides. The study authors suggest that risk communication should focus not only on how the threat influences what people value in the forest but also on how the proposed strategies influence these values.

Hemström et al (2014), surveyed the population ( $\mathrm{N}=842)$ using random and random stratified sampling about intensive forestry practices such as fertilisation and cultivating exotics and clones. The results showed that the majority $(81 \%)$ of respondents thought that measures should be taken to 


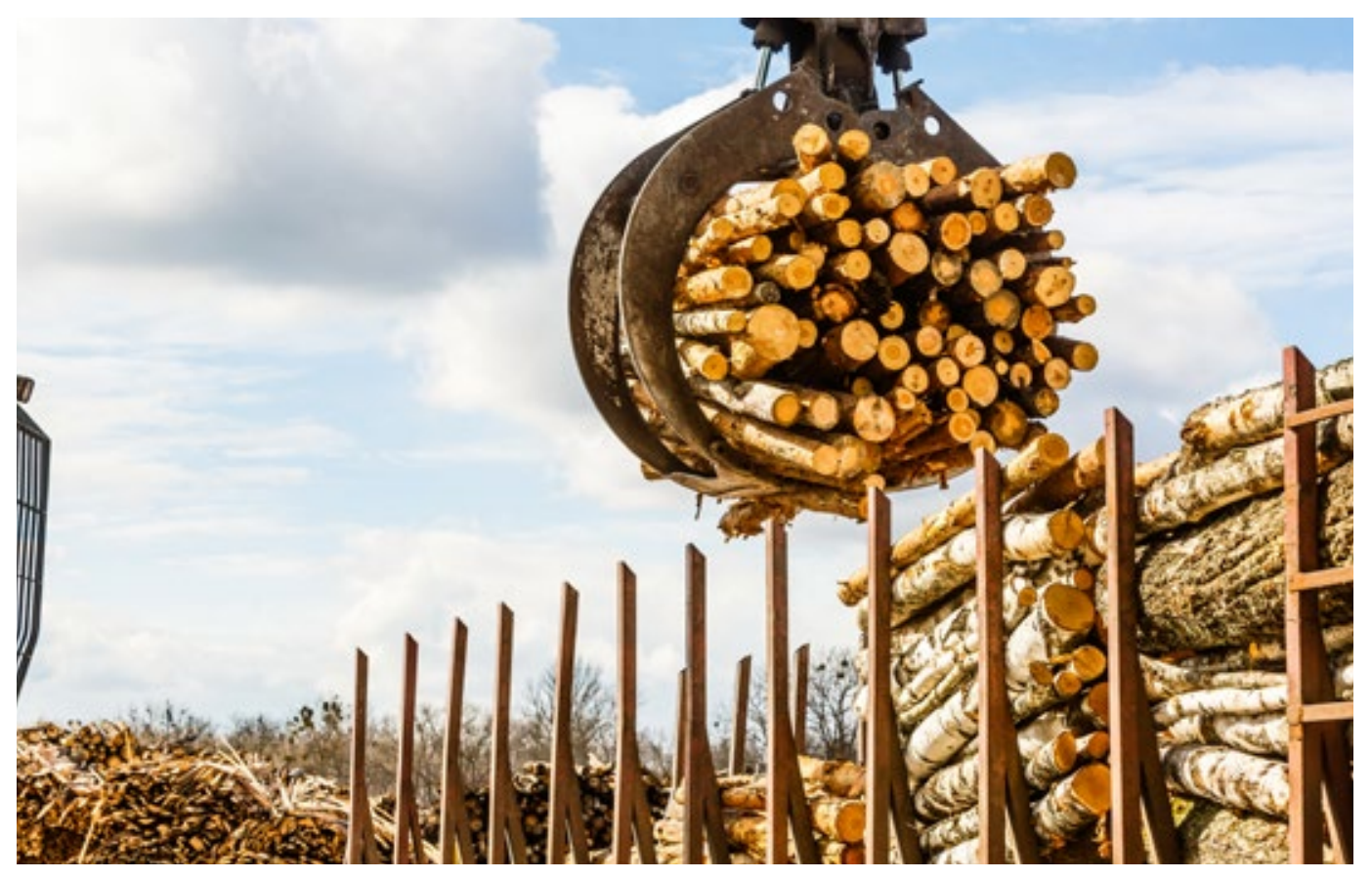

Photo by: @ A Angelov / Adobe Stock

increase forest growth in Sweden. A perceived need to increase forest growth influenced the acceptance of these measures. Nevertheless, more than half of the respondents opposed increasing forest growth through intensive forestry practices. The greatest opposition was found regarding the cultivation of clones, whereas fertilisation encountered the least opposition. Regarding significant differences, younger respondents were more likely to accept clones than older ones. Forest owners and respondents in southern or eastern Sweden accepted exotics to greater extent than northern respondents did. The acceptance of measures was also significantly influenced by the perceived economic, recreational and environmental consequences. The more positive the perceptions of an intensive forestry practice were with respect to these consequences, the greater the acceptance of the practice. No differences between these consequences were reported.
In the United Kingdom, Jepson et al. (2017a) surveyed individuals ( $N=1152)$ with regard to different tree-breeding solutions to fight ash dieback using quota sampling at different countryside and nature charity events. Around 90\% of respondents had heard about ash dieback and $83 \%$ said they would be concerned if ash trees disappeared from the British countryside. Before letting respondents know how much time is associated with each tree breeding option, breeding a native ash using conventional means was the firstchoice option for $69 \%$ and accelerated breeding of native ash the second choice for $56 \%$. When respondents were informed of the time scale (up to 25 years), the agreement rates for natural breeding dropped to $48 \%$ and $42 \%$ respectively. The third and fourth most popular options, as a first choice, were planting non-native ash trees to replace diseased native ash (19\%) and planting different native trees species to replace ash (18\%). For $55 \%$ no action and creating a disease-tolerant 
ash tree using trans-genetics were the least preferred options. The study shows that all tree breeding solutions, including genetic modification (GM), in particular cis-GM, had certain levels, although small, of public acceptability. Regarding significant differences, younger respondents were more likely to accept GM approaches whereas older and rural respondents were more likely to be in favour of traditional breeding techniques. Those more in favour of GM food and crops were more likely to support GM trees, both in forestry plantations and in natural woodland.

In a second study, Jepson et al. (2017b) surveyed the general public $(\mathrm{N}=2036)$ about ash dieback solutions by random sampling and conducted additional focus groups with the media, forest-based sector and policy representatives. The survey of the general public shows that again, breeding native ash using conventional means was the most preferred option selected by $40 \%$, followed by planting different native tree species (32\%) and accelerated (genomic) breeding (30\%). The survey revealed limited acceptability for planting non-native trees: the option of replacement with a non-native ash species appeared in the top three choices of just $17 \%$ of respondents and cross-breeding native and non-native ash trees in $18 \%$. A rather negative view of science in general was found to influence respondents' choice on how to deal with ash dieback. Nevertheless, the authors argue that the attitude towards genetically modified trees is better than towards food. Regarding significant differences, female respondents preferred less interventionist approaches (such as natural breeding, and planting of other native trees) compared with males and, again, younger respondents and those with university degrees were more likely to accept GM approaches.

Nijnik et al. (2016) explored stakeholder attitudes, including the general public, in Scotland towards benefits derived from forest ecosystems using $\mathrm{Q}$-methodology ( $\mathrm{N}=182)$. They found public support for woodland expansion as offering a range of benefits to the Scottish people and the environment. They identified three attitudinal groups. The productivists consider the creation of rural jobs as an important objective. The recreationists place importance on aesthetic values of landscapes and the right to enjoy landscape beauty, partly related to attracting tourists. The conservationists recognise the intrinsic value of nature and are primarily ecologically oriented. While other groups do not have strong prejudice against the enlargement of wooded areas at the expense of nonnative species, such as Sitka spruce, conservationists support extensive native woodlands regeneration and biodiversity conservation. Attitudes appeared to be dependent on age and living conditions and stakeholder group. For example, farmers belonged mainly to the productivist category, whereas scientists and researchers could largely be categorised as recreationists. Socioeconomic problems in remote rural areas are of primary concern to those respondents, who, accordingly, we named as productivists. These people consider timber production central and therefore would not really mind having forests dominated by Sitka spruce.

Sheremet et al. (2017) surveyed the general public $(\mathrm{N}=605)$ using random and stratified random sampling regarding preferences and willingness to pay for possible tree disease control measures and programmes. 
The results show that $69 \%$ of respondents have heard of tree diseases in the UK and they were relatively well informed about general tree disease-related issues, such as the causes, susceptible tree species and general measures taken to minimise the risk of disease spread, whereas knowledge about specific diseases was lower. The study shows that the general public is willing to pay for disease control in UK forests, but this willingness to pay depends on the ownership of affected forests, what benefits of the forest are most negatively impacted by the disease and what control measures are to be used. Regarding significant differences, older or lower income respondents tend to vote against supporting any disease control programmes. Higher income, better knowledge and awareness about tree diseases, and more frequent visits contributed to greater willingness to support tree disease control.

\section{In Croatia, Montenegro, Serbia,} Bosnia-Herzegovina, Nonić et al. (2014) surveyed university students from different faculties - Faculty of Forestry (University of Belgrade and University of Banja Luka), Faculty of Applied Ecology (Singidunum University) and Faculty of Agriculture (University of Novi Sad) - about their attitudes toward adoption of transgenic forest plants $(\mathrm{N}=325)$. The majority of respondents $(75 \%$ of forestry, $60 \%$ of applied ecology and $81 \%$ of agriculture students) agree with the idea of commercial planting of forest transgenic plants. A majority of them (72\% of forestry, $67 \%$ of applied ecology students, $87 \%$ of agriculture) would purchase final products (wood products, pulp, paper, etc) produced from transgenic forest plantations. Most of them ( $85 \%$ of forestry, $88 \%$ of applied ecology, $100 \%$ of agriculture), also agree that these final products should be labelled to indicate that they originate from genetically modified trees, with emphasis that such labelling should be legally mandatory $(90 \%$ of forestry, $92 \%$ of applied ecology, $94 \%$ of agriculture). Applied ecology students would, mostly, accept genetic modifications of forest trees in order to become more resistant to herbicides, while students of agriculture gave the highest rank to genetic modification that involves trees that are more stress tolerant and resistant to disease. On the other hand, the lowest level of acceptability for all groups of students was genetic modification that implies reduction of lignin content in trees in order to make the pulping process more efficient and create less pollution in the pulp mills. Forestry students' attitudes towards the importance of the benefits that would result through adoption of transgenic forest plants were: $74 \%$ said it is very important to have higher tree productivity. On the other hand, most of the applied ecology students $(67 \%)$ thought that "less herbicide treatments of forest plantations" is the most important benefit. The issue that mostly concerned the forestry (36\%) and applied ecology students $(33 \%)$, regarding the adoption of forest plants, is loss of biodiversity. Forestry students were also concerned that forest trees would become more vulnerable to viral diseases (14\%) and that this process would have adverse effects on biotrophic processes of host ecosystems (11\%).

In a multi-country study in Italy and Bosnia-Herzegovina, Pastorella et al. (2016) surveyed tourists on site in Geneva valley $(\mathrm{N}=273)$ and Sarajevo Canton regarding deadwood in mountain areas. The results show that tourists positively perceive the presence of deadwood in forest ecosystems. $60 \%$ of respondents 


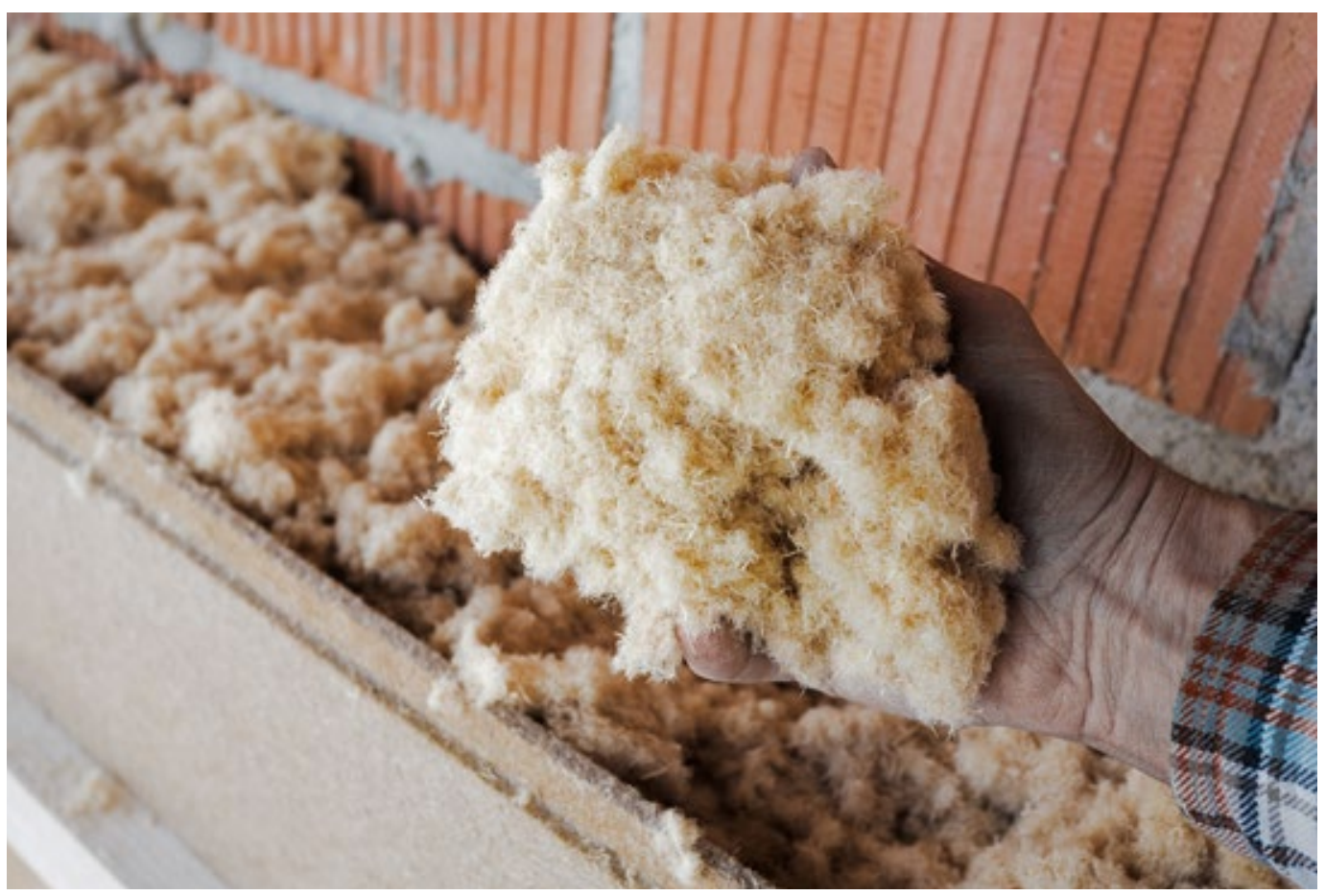

Photo by: ๑ Ingo Bartussek / Adobe Stock

prefer forests with a high level of naturalness such as unmanaged forests or close-to-nature managed forests, while the remaining $40 \%$ prefer forests that are managed in a more intensive way with low amounts of deadwood. These study shows that the majority of respondents prefer forests with a high level of naturalness, where deadwood is considered as an integral part of the forest ecosystem.

In a multi-country study in Sweden and Norway, Valasiuk et al. (2018) surveyed the general public $(\mathrm{N}=2531)$ via online panel survey using choice experiments. Half the respondents were willing to pay for passive protection by allowing natural aging of forest stands (i.e. no timber harvest) with the result that near-natural forests would be restored in 200 years and the restored areas would thus have the same biodiversity conservation potential as existing protected areas in terms of providing natural forest habitat for rare and endangered species. Additionally, over $60 \%$ of the respondents support spatially extended protection of the national park.

Therefore, the authors suggest that passive protection of transboundary forests aimed at forest landscape restoration is a socially desirable land management option. 


\subsection{Perceptions of the forest-based industry}

This chapter summarises studies on forest related and other value chain impacts, such as the overall sustainability of the sector. There were four studies with one study from Austria and three multi-country studies. The studies covered the target group of the general public and one study surveyed students using web-based convenience samples (Figure 11a and b) in its quantitative study designs.

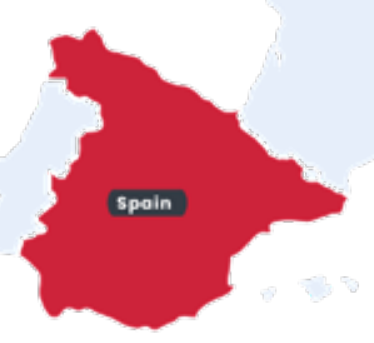

Individual study

Multicountry study

Individual \& Multicountry study
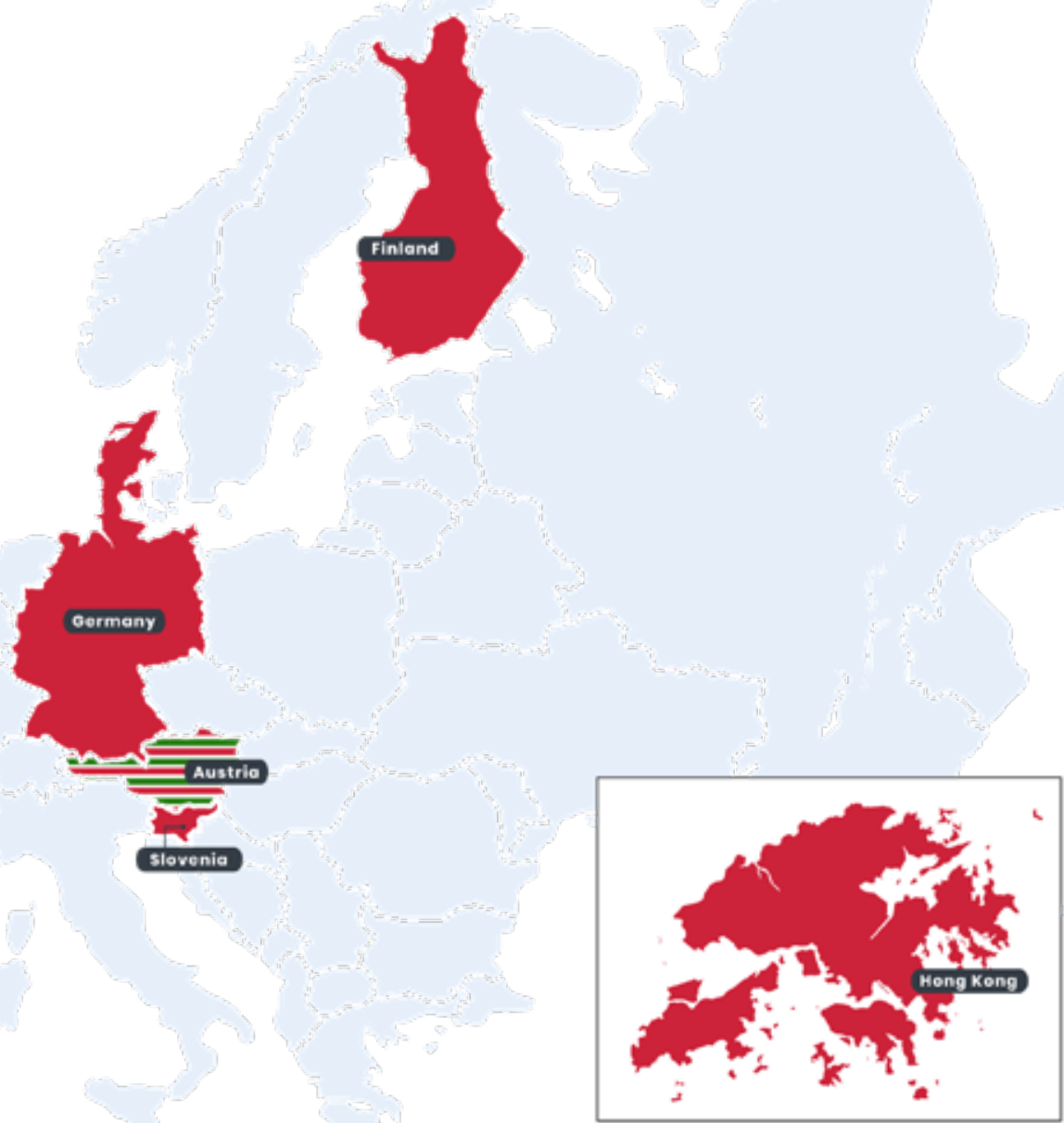
In an Austrian study, Ranacher and Stern (2015) evaluated forestbased sector communication about sustainable forest management by surveying the general public $(\mathrm{N}=204)$ with convenience sampling, differentiating them by their involvement in the forest-based sector by profession, education or forest ownership. Both involved and notinvolved respondents widely recognised that areas used for forestry provide protective functions against avalanches or erosion, and are a habitat for flora and fauna. Both involved $(79 \%)$ and not-involved $(64 \%)$ respondents agreed that foresters keep the forest healthy and strong and that foresters contribute to nature protection $(72 \%$ not-involved, $73 \%$ involved). Only $39 \%$ of not-involved respondents agreed that forest cover is increasing, and that wood produced in Austria comes from ecologically sound sources.

This rather low agreement rate and high levels of "I don't know" responses in comparison to involved respondents indicates respondents' scepticism of the economic role of forests and their responsible use. In addition, the question of whether wood processing companies in Austria mainly use certified wood (52\% involved, 39\% not-involved) or that they do not use illegally harvested wood (44\% involved, 35\% not-involved) received little agreement, and high rates of "don't knows" (up to 58\%).

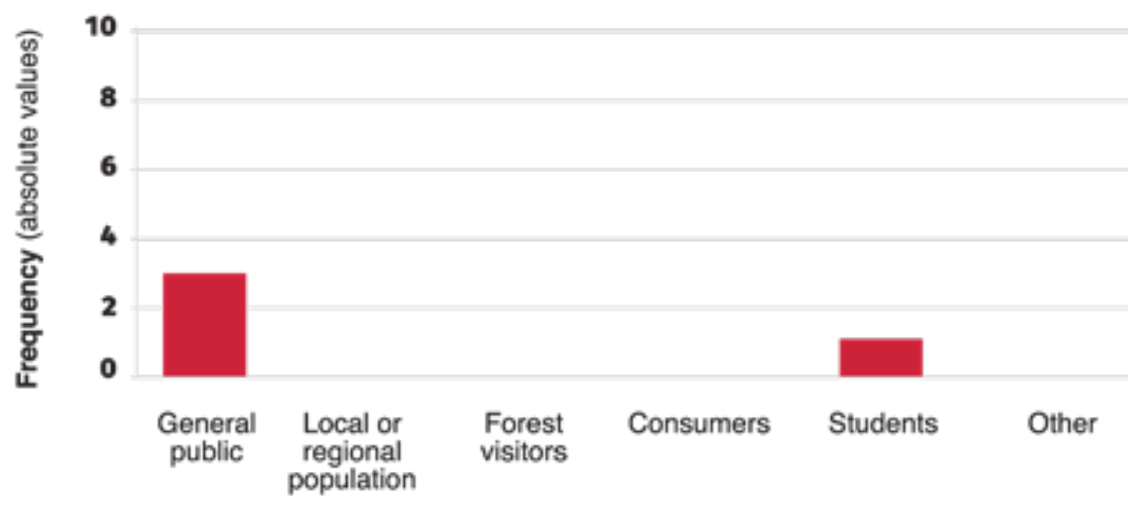

Figure 11a. Target groups of studies on the forest-based industry

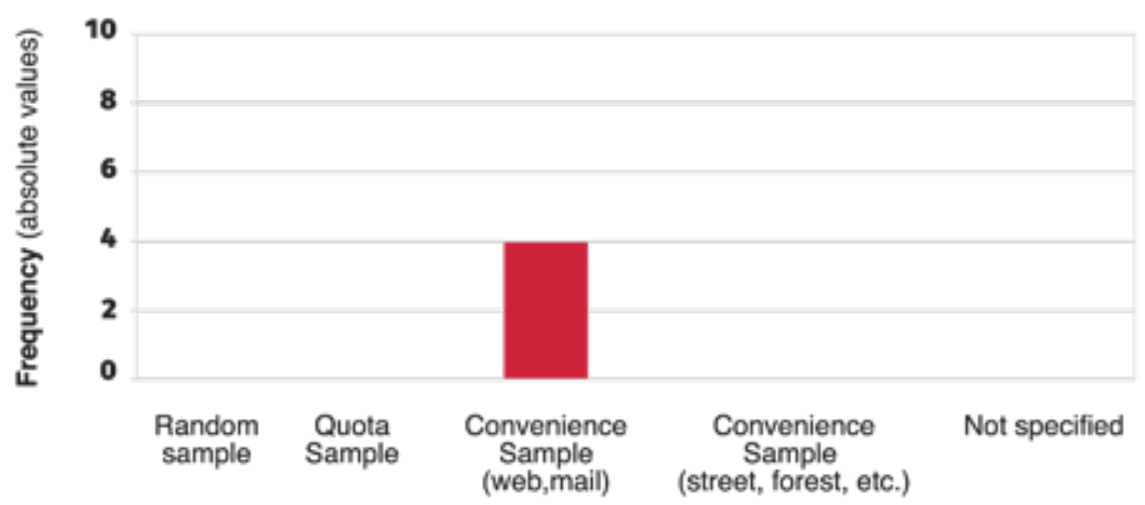


The not-involved respondents were more critical regarding the economic function of forests and the sustainability of the forest-based sector in Austria which was also statistically significant, whilst whether the forest is being taken care of was positively perceived by both groups.

In a multi-country study in Austria, Germany, Finland and Slovenia, Ranacher (2017a) surveyed the general public $(\mathrm{N}=219)$ on their perception of forest-based sector responsibility using an online survey and convenience sampling. Respondents mainly recognised regulating forest ecosystem services for air quality, water quality and climate change, as well as water cycling, soil health, fresh air and raw materials. Least agreement was found mainly for provisioning ecosystem services such as food and pharmaceuticals, with the exception of raw materials (i.e. wood), which scored high agreement. In addition, regarding bio-based chemicals, genetic resources and pharmaceuticals, there were a considerable number of "I don't know" answers. The study also compared information needs concerning impacts of the forestbased sector on ecosystems and the perceived level of responsibility. The respondents rated all items on information demand as having roughly equal importance, but "water nutrient contributions" was least important (75\%) and "threats to wildlife and fauna due to forest sector business activities" the most important (81\%). Respondents gave limited agreement and a substantial amount of "I don't know" and "undecided" responses (up to $23 \%$ ) to whether the forestbased sector acts responsibly, which indicates a potential lack of legitimacy for the sector. For example, 43\% agreed that the forest-based sector acts responsibly regarding habitat loss, and $52 \%$ regarding water pollution. The high number of "undecided" respondents indicate their perceived limited ability to make a judgement. As respondents differentiated little between the different impacts, the study authors suggest that the respondents have difficulty in locating precisely the various forms of ecosystem impacts or prioritising them in their detailed information needs. Regarding significant differences, consumable non-timber forest products (NTFP) were more important for female than for male respondents and respondents without involvement in the forest-based sector. Those respondents with higher perceived level of sector responsibility more often valued social and consumable NFTPs.

Another multi-country study in Austria and Germany (Ranacher et al., 2017b), evaluated forest-based sector communication in relation to its contribution to climate change mitigation, surveying the general public ( $N=194)$ with convenience sampling. The contribution of forests to positively influencing climate change by absorbing $\mathrm{CO}_{2}$ was widely recognised by more than $90 \%$ in both countries. However, the contribution of wood products to climate change mitigation was only partly perceived: $38 \%$ of respondents not involved in the sector, and $58 \%$ of respondents involved in the sector, through profession, education or forest ownership, agreed that the use of wood for energy purposes (e.g., burning pellets, wood chips or solid wood) positively influences the global carbon balance. Also, $47 \%$ of the not-involved respondents and $77 \%$ of the involved respondents agreed that the use of wood for construction such as for furniture or houses positively influences the global carbon balance. 
$51 \%$ of not-involved and $81 \%$ of involved agreed that if a tree is used for wood products (e.g. furniture), carbon is stored during the products' life cycle. Based on the study, the authors argue that the positive impact of forests is well understood, whereas the substitution effect and carbon storage effect of harvested products are only little perceived. The difference regarding sector involvement was statistically significant, with notinvolved respondents having lower agreement rates.

In a multi-country study in Finland, Hong Kong and Spain, Pätäri et al. (2017) surveyed university students (Lappeenranta University of Technology, University of Turku, University of Helsinki, Deusto University) using convenience sampling ( $\mathrm{N}=350)$ and considering them as potential consumers. They analysed how students perceive overall sustainability, the more specific concepts of the social and environmental performance of the forest-based sector, and its future in a bioeconomy. The respondents rated the sustainability performance with 4.82 on a scale from 1 to 7 with the latter being the highest. The social performance was rated higher (3.76) than the environmental performance (3.66). The future of the forest industry was rated with 4.08 and surveyed with items such as "In the future, wood will be used as a substitute for many currently oil-based products such as plastic." Regarding significant differences, Finnish students showed more positive views of the sustainability performance and more versatile future wood use by the forest industry. This may result from Finnish students' better general knowledge of the industry, which is a backbone for Finnish export, income and industrial jobs, or the
Finnish forest companies' long history in environmental communication. Also, the study programme and values were found to make a difference. Social science and humanities students gave lower ratings for sustainability performance than natural scientists. Respondents with higher egoistic values or higher corporate social responsibility (CSR) support gave higher sustainability scores regarding the sector's sustainability performance. General CSR support has a strong positive effect, indicating that students more committed to CSR in general give higher sustainability scores for the forest industry. 


\subsection{Perceptions of wood and wood-based products}

This chapter summarises studies relating to different product categories such as wooden houses, windows or furniture, bio-based innovations or the material itself regarding its technical, social and environmental performance, wood origin, appearance, health, and respondents' purchasing behaviour. The studies surveyed respondents' perceived performance of the products and/or which product attributes they consider important or value.

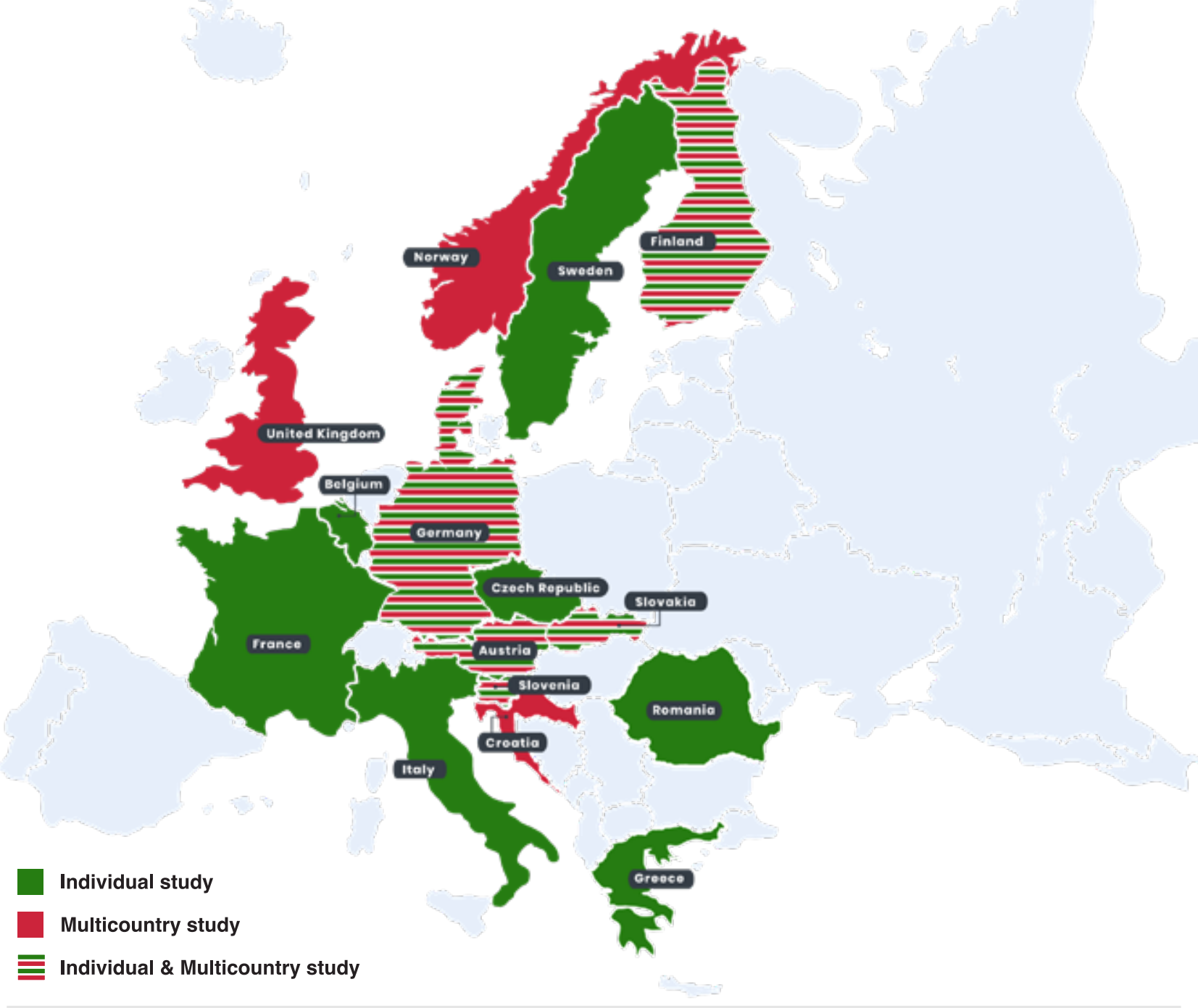

There were 27 studies that were conducted in the following countries, sorted by region: Austria (2), Belgium (1), Czech Republic (1), Finland (5), France (1), Germany (4), Greece (2), Italy (1), Romania (1) Slovakia (2), Slovenia (1), Sweden (1), and five multi-country studies. 
The studies mainly covered the target group consumers (Figure 12a). However, it should be noted that many studies surveyed the general public or the local population and considered them as consumers. Only few studies were conducted at actual shops. The studies mostly used web-based convenience samples and convenience samples collected at fairs or shops (Figure 12b). There is one qualitative study using focus groups and one mixed method study using additional qualitative methods next to the quantitative survey.

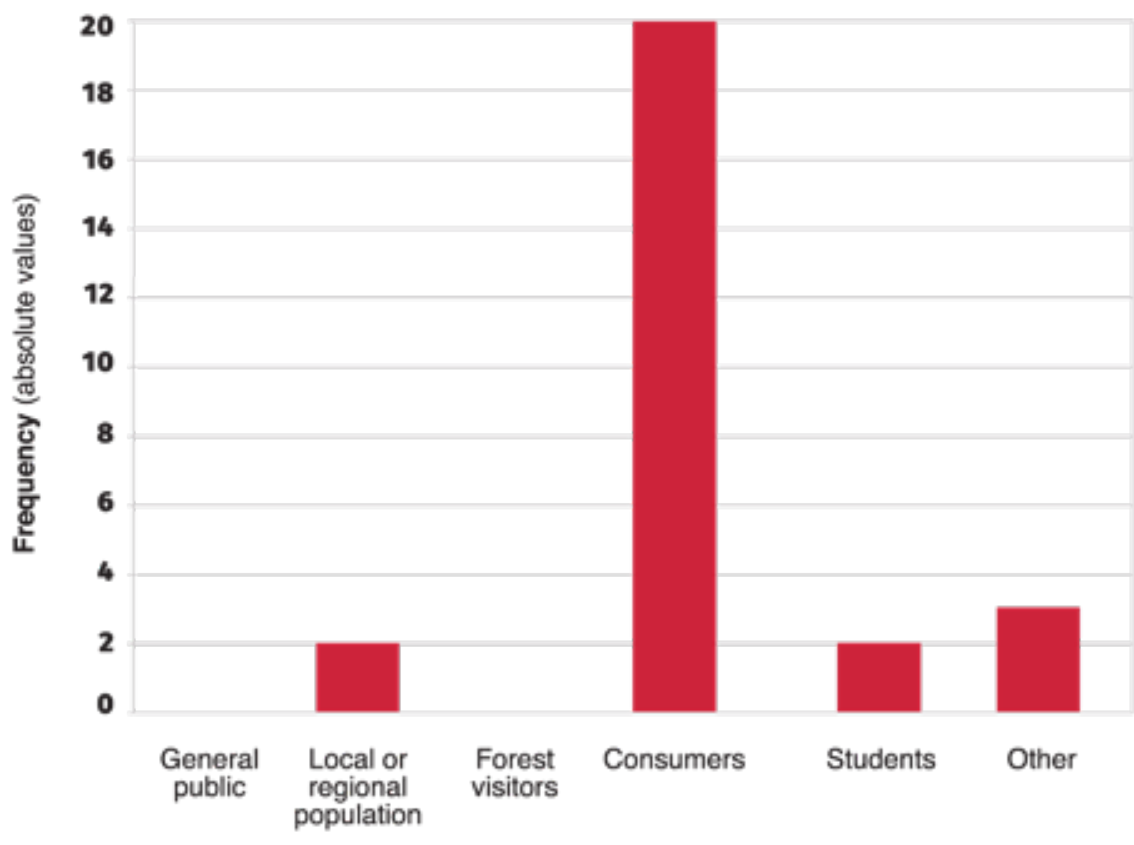

Figure 12a. Target groups of studies on wood and woodbased products

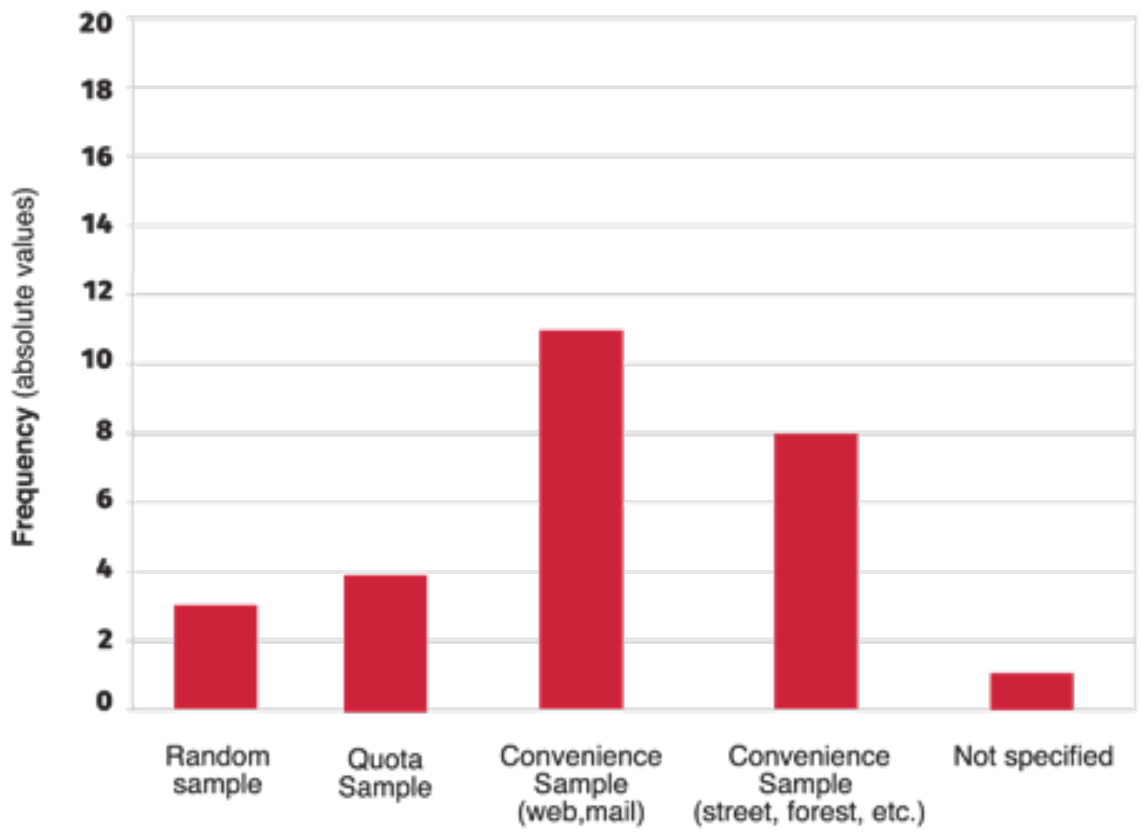


In Austria, Ranacher et al. (2018) conducted group discussions with future oriented, educated, urban individuals referred to as "future opinion leaders" $(\mathrm{N}=20)$ about their information demands regarding four wood-based innovations. The study shows that, in relation to the information categories provided in the introductory round, the results indicate that participants appeared to be slightly more interested in the benefits of innovation in comparison to scope of application, manufacturing process or characteristics. Regarding natural fibre reinforced composites, they found that this innovation was discussed in a controversial way among the participants. Most of the participants were already familiar with the concept. The most discussed topics were costs, possible applications and ecological issues regarding the recycling capability. Regarding nanocellulose, they found that this innovation was little known among the participants, which might be a reason why the level of interest was relatively low. Almost none of the respondents had ever heard of nanocellulose before. The participants often indicated that their opinions were based on guessing. The most discussed topics regarding nanocellulose were basic information, risks and environmental studies. The concept of biorefineries was perceived as a very interesting possibility to avoid the depletion of fossil-based resources. However, only a little knowledge existed among the participants, indicating a need for more basic information on the concept. Multi-story timber constructions were associated with high-quality wood features. Timber was favoured over concrete or steel constructions due to the positive aspects attached to wood such as health effects as well as societal benefits regarding climate change mitigation. The participants expressed concerns regarding safety and the technical performance of timber constructions. The participants mainly discussed safety aspects, costs and ecological aspects regarding the material, in comparison to concrete and steel constructions. Overall, the main points of discussion were about the feedstock that is used, basic knowledge regarding the products, and environmental issues. Information required by the respondents related to feed stock, (biomass) origin and environmental impact studies on biorefinery products.

Jiménez et al. (2015) surveyed the general public $(\mathrm{N}=92)$, targeting both experts and non-experts, by convenience sampling about psychological aspects of wooden floors and laminate. The results show that the sustainability and health aspects were rated substantially higher for wood than for laminate. The study suggests that, because wood is perceived as more sustainable and more exclusive, the consumers would also accept more deficiencies (for example availability, cost, etc.) for purchasing a wood product.

In Belgium, Van Dael et al. (2017) surveyed Hasselt University bachelor degree students and high school students from the Limburg province $(N=715)$ about bioenergy and how their perception of it is impacted when being given a lecture on this topic. They found that biomass and geothermal energy are less known renewable energy sources, in comparison to wind, water and solar. However, more than half of the respondents recognised these sources as being renewable. Most of the respondents agreed that an increased use of bioenergy could help to reduce the greenhouse gas effect $(74 \%)$ and replace fossil fuels (55\%). However, the majority of the respondents did not perceive wood 
as being environmentally friendly and did not perceive it as being one of Belgium's main sources of bioenergy in the future. Nevertheless, they indicated that the use of wood for energy production might be justified if the same amount of wood were replanted but perceived the use of waste streams as being a more environmentally friendly and important energy source in the future. While respondents were relatively positive about the future use of bioenergy, the possibility of a higher price decreased their intention to use it. Regarding significant differences, male respondents were found have higher knowledge than female respondents but women had more positive attitudes towards bioenergy. Students with more knowledge about bioenergy were more sceptical about its use.

In the Czech Republic, Olšiaková et al. (2016) surveyed consumers at an international furniture fair $(\mathrm{N}=696)$. They found that the most important parameters influencing consumers' purchase behaviour of wood products are mainly the quality and the material and not the price.

In Finland, Halder et al. (2011) surveyed high school students $(\mathrm{N}=459)$ in eight schools in North Karelia, situated in urban and rural areas, about their perceptions and attitudes of bioenergy. The study shows a critical perception among the students as they disagreed on most of the items about the environmental sustainability of bioenergy. Only $8 \%$ agreed that increased use of bioenergy can mitigate the global warming problems; $16 \%$ agreed that tree plantations should be established for bioenergy production, $25 \%$ agreed that production of bioenergy from forests is sustainable in Finland; 32\% agreed that production of energy from wood is environmentally friendly, and $40 \%$ agreed that cutting trees for energy production is justified. Next to the low agreement rates, students often chose the answer "do not know" (21-62\%), indicating that the questions were difficult to answer. However, the respondents were interested in bioenergy as they said they would like to discuss more about bioenergy with their parents $(45 \%)$ or teachers (42\%). Regarding significant differences, boys were more positive in their perceptions of bioenergy than girls.

Holopainen et al. (2014) surveyed consumers $(\mathrm{N}=208)$ in Finnish home and building material department stores in Helsinki and Joensuu, an eastern Finnish city, in an exploratory study regarding their value dimensions for sustainable wood products in home and building material departments. When asked which factors were important for their purchasing decisions, material durability was the most important $(95 \%)$, followed by the legal origin of the wood (80\%) and for $74 \%$ a responsible image of a product company is an important factor. $75 \%$ want to make sure that product materials do not contain any harmful components for health and $64 \%$ I want to make sure that no cheap labor force is used during production. For $69 \%$ the environmental impact of a wood product is an important factor, $55 \%$ would like to have more information concerning the environmental impact of wood products and $58 \%$ agree that certificates guarantee that wood products are from sustainably managed forests. However, $28 \%$ have chosen not to buy a product when uncertain about its sustainability and for half the respondents (47\%) low price is an important factor. Moreover, the study identified four factors - "information origin", "consumer activity", "product image", "quality" - of importance to consumers. 
Regarding significant differences, female respondents had a preference for "information and origin" and a tendency to "consumer activity" in comparison to male respondents. A higher income of the respondents positively influenced the perceptions of the value dimensions. Respondents older than 44 years had a higher preference for "information and origin" than those between 30 and 44 .

A recent study (Lähtinen et al., 2019) surveyed consumers $(\mathrm{N}=256)$ using random sampling to profile different types of consumers according to their stated views on the benefits of wood, especially timber construction. $73 \%$ of respondents agreed to "the use of wood enhances climate change mitigation, e.g. it can be considered as carbon storage", $74 \%$ agreed to "Manufacturing of timber products has less ecological impacts, e.g. compared to other materials such as bricks, concrete and steel" and $93 \%$ agreed "Wood is renewable material" and has positive impacts on human health. Furthermore, $88 \%$ agree to "Wooden structures are very long-lasting when designed and built properly" and $75 \%$ agree to "Wood has good acoustic properties, e.g. timber structures absorb well noise". At the same time, $48 \%$ agree to "Wood is a burning material, but simultaneously it is a fire-safe material" and $44 \%$ agree to "Wood is an antibacterial material, e.g. it prevents growth of hazardous microbes". Whilst technological and environmental properties of wood had no influence, valuing aesthetics and well-being were found to have a positive and statistically significant impact on preferences towards living in multi-storey houses with wooden structures.
Toivonen et al. (2012) surveyed consumers $(\mathrm{N}=147)$ in home retail centres selling building materials and the annual home construction fair about product value and quality. The results show that quality attributes related to the tangible product, such as technical quality, appearance and ease of care, are the most important for consumer. Intangible attributes such as quality of supplier and salespeople, and service and information, are also of value to the customer, but to a lesser extent. However, the environmental friendliness of wood products and domestic origin, which are also intangible product attributes, are less important. Consumers seem to consider environmental quality as being important but do not necessarily value it much, perhaps because of a lack of individual utilities. Considering significant differences, female respondents were grouped more often as environmentally friendly consumers.

Toppinen et al. (2013) surveyed consumers $(\mathrm{N}=227)$ regarding their perceptions of environmental and social sustainability attributes of wood products in home retail centres selling building materials. Overall, respondents found all sustainability aspects to be important or very important. Most important were product health and safety issues such as "the product has a safe surface treatment" and "the product is safe for health". Less important were social and environmental aspects such as "the wood used originates from sustainably managed forests" and "environmental impacts of production are being minimised". Using a factor analysis, the study identified two factors - general environmental and social impacts as well as specific health aspects to be important to consumers. From the wood product marketing point of view, the results suggest that there are two 
levels of environmental and social sustainability. The indirect, societal level such as generic environmental and social responsibility, and the specific impact directly at consumer level such as product safety and human health. Thus, the environmental and social sustainability of wood products includes not only concerns about biodiversity of ecosystems but also safety and healthiness of products. Regarding significant differences, elderly consumers (above 58 years) were more often included in the more environmentally sensitive group, whereas consumers in the two youngest age groups (less than 44 years) were more often identified as belonging to the less environmentally sensitive group.

In France, Costa et al. (2011) surveyed consumers $(\mathrm{N}=940)$ with quota sampling regarding their preferences for wood and vinyl windows. The results show that consumers' quality beliefs about windows and materials influence their consumption choice. Respondents perceived wood to be lower performing for thermal insulation and maintenance than vinyl but found wooden windows more attractive. Regarding significant differences, older people and those with higher incomes seem more likely to buy wooden windows than younger people. Higher environmental awareness and innovativeness positively impacted the perception of wood products and, interestingly, ecologically minded consumers tended to prefer vinyl windows rather than wooden windows.

In Germany, Knauf (2015) surveyed potential furniture customers $(\mathrm{N}=1000)$ by means of a representative online panel about the product attributes of finish surface, certification and weight for honeycomb boards and did some additional interviews and observations in a shop. The finish was rated as very important by $85 \%$ of respondents, the base material by $66 \%$ and the weight by $15 \%$, thus only of minor importance compared to other material attributes. Respondents did not recognise any ecological benefits from honeycomb boards due to material efficiency or a smaller carbon footprint for shipping and transportation. The study indicates that $78 \%$ of respondents are willing to purchase lightweight furniture at an equivalent price if the functionality was guaranteed and the furniture had the same visual appearance. For example, respondents who indicated that they are familiar with this light wood furniture material estimated that the weight is significantly lower.

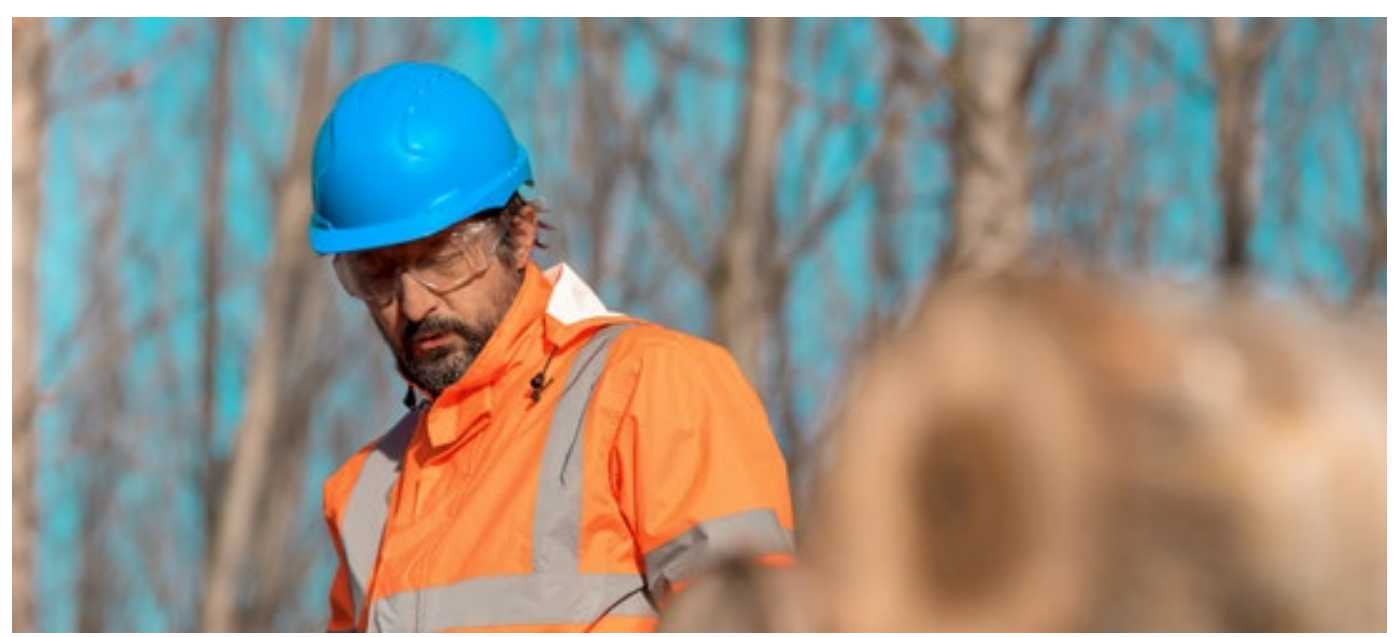


Osburg et al. (2016a) surveyed a representative sample of population $(\mathrm{N}=357)$ about Wood Plastic Composites (WPC). The study shows that respondents who perceived the advantages of WPC and valued the benefits also intended to buy WPC products. Specifically, attitude towards environmental product aspects, attitude towards innovative product aspects and the subjective norm emerged as significant predictors of the behavioural intention. Therefore, marketing should promote both an eco-friendly and innovative image of WPC. The subjective norm was found to significantly influence purchasing behaviour.

Osburg et al. (2016b) surveyed young consumers $(\mathrm{N}=205)$ with an online survey and convenience sampling about wood product information demands regarding origin, environmental impact and material. Participants mainly demanded information about the country and region, sustainable forest management and carbon footprint, type of wood, as well as additives and health effects of additives. However, the list of product information reached a medium relevance concerning the purchase decision, compared with other purchase decision drivers, such as quality, appearance, durability and price. Nonetheless, the authors recommend the provision of information because it can lead to an increase in consumers' product trust and purchase intentions and, in the long run, to market success of the sustainable products.

In a third study, Osburg et al. (2016c) surveyed the general public ( $N 1=198$, $\mathrm{N} 2=357$ ) with two online surveys to gauge consumer acceptance of Wood Plastic Composites (WPC). The study shows that participants preferred solid wood over full plastic, while WPC remained in the centre position. The higher the respondents environmental concern, the stronger the preference for solid wood over full plastics. The authors suggest that the purchase intention for WPC is located around the middle of solid wood and full plastics. Consumer segments with high environmental concern and innovation are important target groups as they evaluate WPC better than the average consumer. Contrary to the assumptions, environmentally concerned consumers did not downgrade, but even upgraded to WPC. Consumer segments with high environmental concern and innovation significantly evaluated WPCs better than the average consumer.

In Greece, Tsourgiannis et al. (2013) explored consumers' purchasing behaviour towards wood products from transgenic plantations using face-to face interviews ( $\mathrm{N}=418)$. Respondents showed positive perceptions towards products from these resources. They agreed that the establishment of forest transgenic plantations can contribute to the increase of job flexibility, reduction of production cost, or increase of farmers' income and reduction of production losses. Thus, the study suggests that there might be potential buyers of wood products originating from transgenic plantations.

In a second study Tsourgiannis et al. (2015) again surveyed consumers $(\mathrm{N}=450)$ about wood products from transgenic forest plantations with faceto face interviews at supermarkets and/or malls located at the capital/ seat of each region. The study shows that most consumers were interested in the quality of the products and believe that the establishment of transgenic forest plantations will increase job opportunities and the 
farmers' income alongside reducing the production cost and output losses. However, they also believe that the establishment of such plantations could have a negative impact on wild native species and, in general, could harm the biodiversity of ecosystems. By segmenting the consumers into different groups with cluster analysis they identified four groups of potential consumers of products from genetically modified trees with similar purchasing behaviour: (a) those interested in the quality of products; (b) those oriented towards lower prices; (c) those influenced by curiosity and labelling issues; and (d) consumers interested in health safety issues and environmental impacts. They found that potential consumers mostly showed purchasing behaviour driven by economic issues (price, quality, labelling and branding). Regarding significant differences, most consumers interested in the quality of products were 65 or older, retired, did not have children and attended high school, whereas most consumers orientated towards lower prices were 30-44 years old and had children.

In Italy, Panico et al. (2018) surveyed consumers $(\mathrm{N}=371)$ about their intention to purchase sustainable wood products using an online survey and convenience sampling with the aim of offering insights into predicting consumption behaviour. The majority of respondents $(72 \%)$ said they were going to buy wood products labelled as environmentally sustainable. Also, $44 \%$ said they had a good knowledge of wood certification labels. Nearly $38 \%$ and $19 \%$ of the sample claimed to have seen at least one of the FSC or PEFC labels on wood products, respectively. Among the socio-demographic variables, income and age were found to increase the likelihood to buy certified products and suggests that older individuals and those with higher levels of income have a stronger preference towards certified wood products. Also, respondents with a full knowledge of the certification schemes are $18 \%$ more likely to buy the certified wood products. Regarding the individual sustainability orientation, only the social dimension was found to influence purchasing intention, while the other two dimensions, economic and ecological, are not statistically significant.

In Romania, Orzan et al. (2018) surveyed consumers $(\mathrm{N}=268)$ online about preferences for eco-packaging using convenience sampling. The results show that the preferred ecopackaging is from wood (74\%) and that people want to buy products in organic packaging and want to be informed about this. Also noteworthy is that they pay attention first to the product label and the information on it. Most of the respondents mentioned that the first source of information on product packaging is the product label followed by producers' and distributors' information campaigns and the internet. Regarding significant differences, only the level of income determined the choice of environmentally packaging but no further information was provided.

In Slovakia, Moresová et al. (2019) surveyed the general public $(\mathrm{N}=728)$ with an online survey with a sampling procedure aimed at representativeness. The most positively viewed factors regarding wooden houses were: natural and ecological material $(71 \%)$, feeling of peace and wellbeing in the house $(69 \%)$, house liquidation (64\%), and the size of utility space in relation to the built-up area (44\%). Wood is considered a suitable construction material for a family house (40\%) and the term wooden construction or 
house is most frequently understood as a traditional wooden cottage (33\%), timber house $(31 \%)$ or as a wooden house as a construction, the skeleton of which is built from wood (21\%).

Švajlenka (2018b) surveyed wooden house owners und users $(\mathrm{N}=25)$. The first part of the survey focuses on the priority of the selected criteria for users before the procurement of a wooden building and the second part on overall perception on construction quality. It found users attach the greatest significance to the operating costs of the building and time of construction. Less significance was observed for quality and comfort of living and construction technology, while least significance was put on ecological aspects.

In Slovenia Kitek et al. (2010) surveyed consumers $(\mathrm{N}=628)$ using telephonebased random sampling about their opinion of wooden buildings. They found mostly positive perceptions: $90 \%$ of the respondents agreed that the government should allocate more funds towards ecological constructions; $73 \%$ agree that wood is a suitable material for construction, $62 \%$ agree that wood enables healthier living.

In Sweden, Lindberg et al. (2013) surveyed individuals' $(\mathrm{N}=30)$ perception of tactile attributes of wood and woodbased composites, with respondents' vision and hearing blocked. The reason is that most perception studies focus on visual aspects or combined tactile and visual attributes. However, as people frequently touch furniture and interior applications, it is essential for the industry to know more about the tactile qualities of the materials. The respondents rated the samples as natural, exclusive, eco-friendly, rough, inexpensive, reliable, warm, modern, snug and solid. The most significant differences between the samples, and in particular between wood and oriented strand board and composites, were for the descriptors natural, ecofriendly and reliable. The solid wood pieces were perceived as particularly natural and eco-friendly or exclusive. The composite materials presented a greater variation in terms of perceived attributes than the wood specimens.

Stern et al. (2018) surveyed the public $(\mathrm{N}=218)$ using convenience sampling on the importance of forestbased sector innovations in Austria, Germany, Finland and Slovakia. The respondents mostly agreed that the forest-based sector has, since the year 2000, produced innovations for wood building systems, construction materials and composites. The lowest awareness was associated with the development of new marketing channels and recognised brands, as well as forestry services and paper products. As for the next 20 years, it was perceived that the sector should continue to focus on wood construction-related innovation efforts, whereas the development of woodbased biofuels and paper products gained the lowest level of support. Regarding nanocellulose, it is notable that over one-third of the respondents were incapable of evaluating past as well as future innovation activity, indicating that they lacked awareness regarding this innovative material. People not involved in the sector have significantly lower levels of innovation recognition and often have high rates of "I don't know" answers. Regarding significant differences, respondents not involved in the sector mainly recognised innovations in traditional use such as building systems, wood construction materials, biofuels, and material substitution and considered the environmental impacts of forestry and industry more often as important 
in the future. When comparing the mean values of respondents for past innovation performance and future expectations of innovation, it was evident that the respondents have higher expectations for future innovation, with the only exception of biofuels for which the future importance is perceived to be clearly lower than the performance in the past. (significant decrease at $1 \%$ level).

Burnard et al. (2015) surveyed the general public $(\mathrm{N}=111)$ using convenience sampling in Finland, Norway and Slovenia regarding perceived building material naturalness. The survey was conducted at Oslo (Norway), Espoo (Finland), Ljubljana and Koper (both in Slovenia). In Espoo, Ljubljana and Koper, students, faculty, and staff of local universities (Aalto University, University of Primorska and the University of Ljubljana) were considered to be the general public. Pine was ranked as the most natural material in all countries by $98 \%$ of all respondents. In general, respondents consistently rated and ranked the materials with less apparent transformation, such as solid wood, stone and brick, as being more natural than materials with much greater degrees of transformation such as metal, plastic and fabric. Significant differences were found regarding respondents' nationality with Finish and Norwegian respondents giving lower ratings regarding naturalness than the Slovenian respondents.

In a multi-country study in Slovenia and Croatia, Kuzman et al. (2012) surveyed the representative sample of general public $(\mathrm{N}=743)$ with telephonebased interviews. According to the study, respondents have positive perceptions towards wood construction and wood furniture as they agree that the government should increase expenditure for environmentally friendly construction, wooden buildings enable healthier living, and that wood is a suitable material for construction. However, they also agree that environmentally friendly construction is expensive. The main reason to have more solid wood furniture at home was "I like it" and "quality", whereas environmental friendliness was less important.

In Slovakia and Croatia, Paluš et al. (2012) used snowball sampling to survey consumers $(\mathrm{N}=848)$ about consumer preferences for wooden furniture. The study shows that Slovak and Croatian respondents have similar preferences for interior furniture made of solid wood, wood composites (woodbased panels), and a combination of materials. Manufacturing quality was of the greatest importance when making a purchasing decision (78\% of Croatian and $85 \%$ Slovak respondents), whereas the environmental attributes of furniture were only important to $38 \%$ of the Croatian and $29 \%$ of Slovak respondents. Almost 70\% of the Croatians preferred interior furniture made of environmentally certified wood, while this was found to be the case for $46 \%$ of the Slovaks. Significant differences regarding preferences were found regarding respondents' nationality.

\section{In the United Kingdom and Norway,} Solberg et al. (2011) surveyed consumers $(\mathrm{N}=590)$ in furniture stores in Birmingham and Oslo about eco-labelling of furniture to identify eco-oriented customers. They identified four factors to be important for consumers: environmental consciousness, price consciousness, design consciousness and wood-type consciousness. 
onses?

E sile

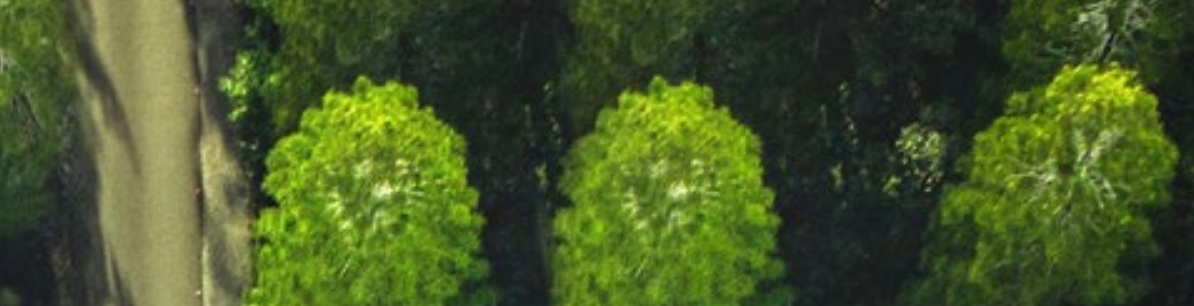

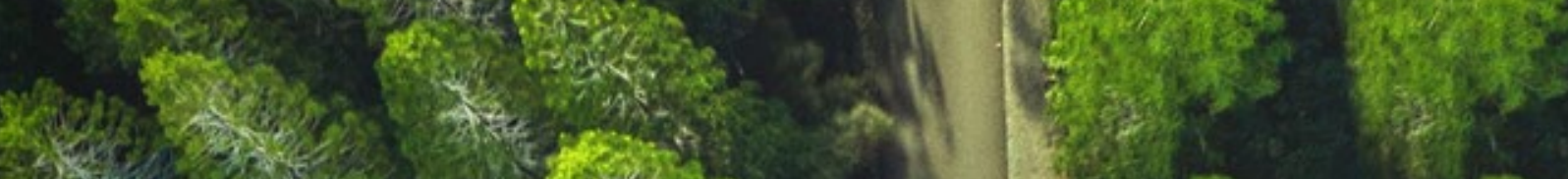
20

$\frac{12}{4}$

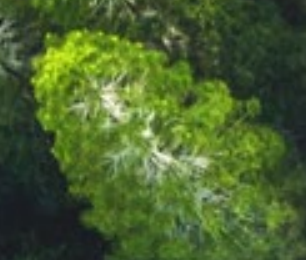

forment

(4)

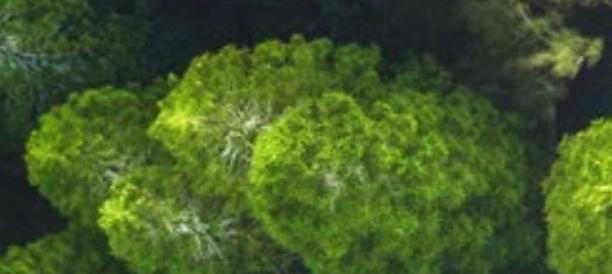

2. 320,70 3. 270

1285.
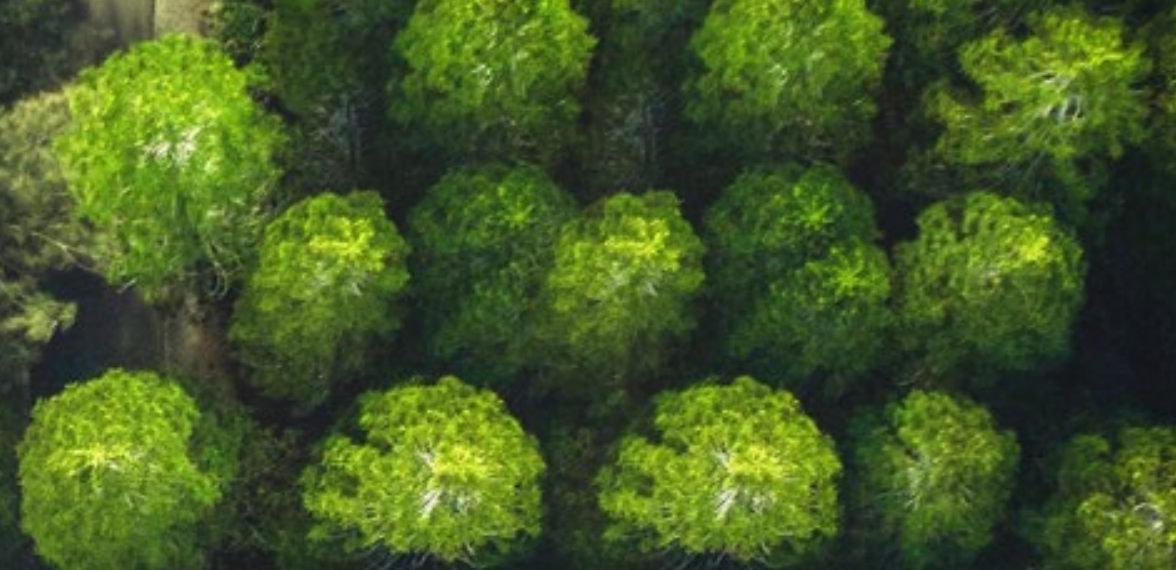

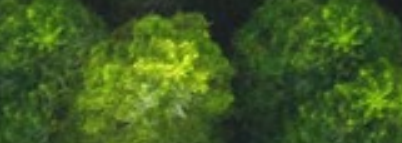

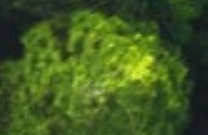

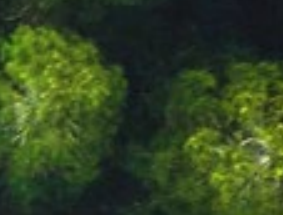

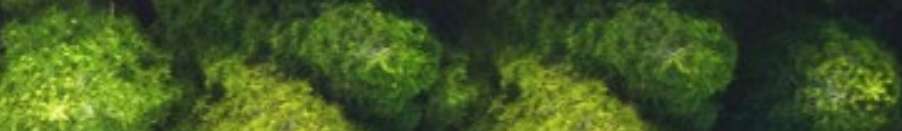

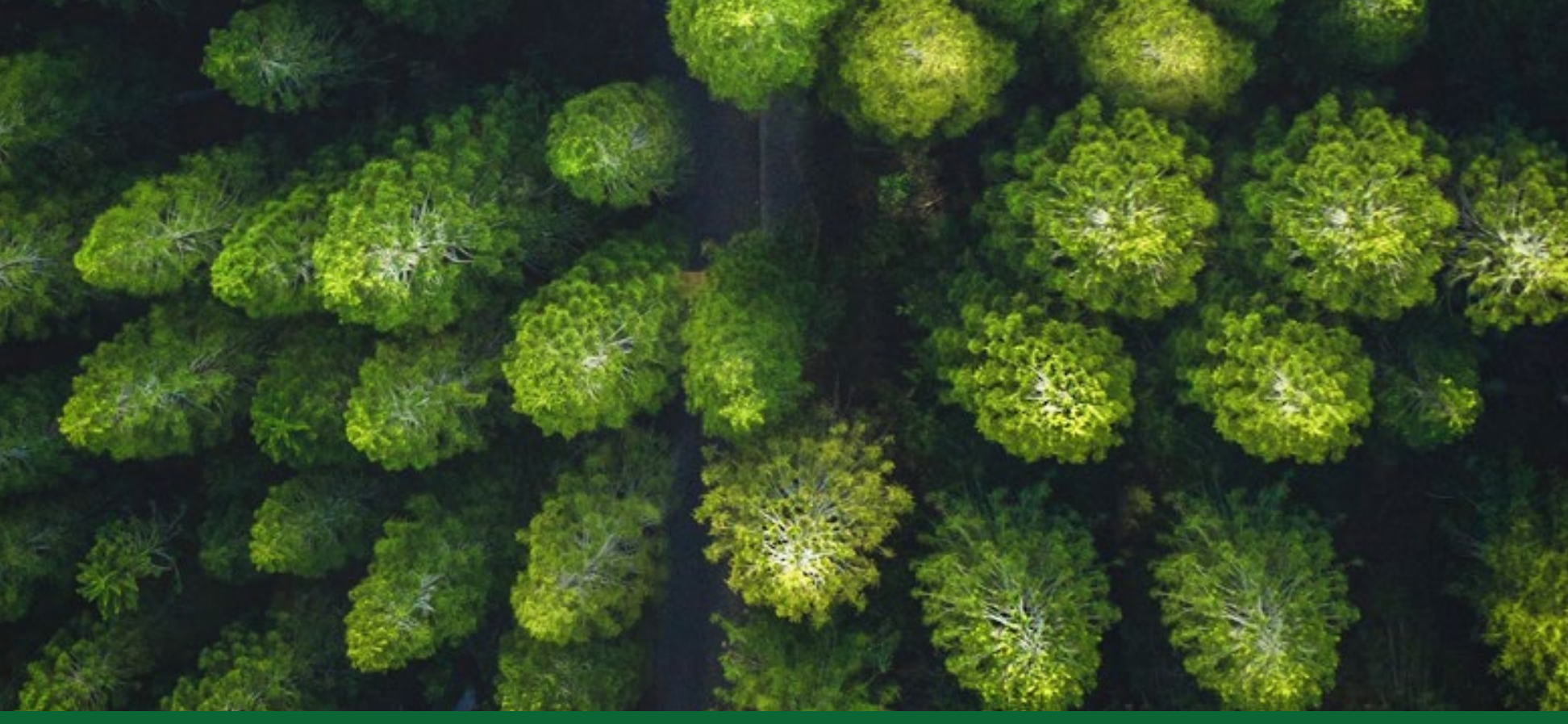

CHAPTER 4

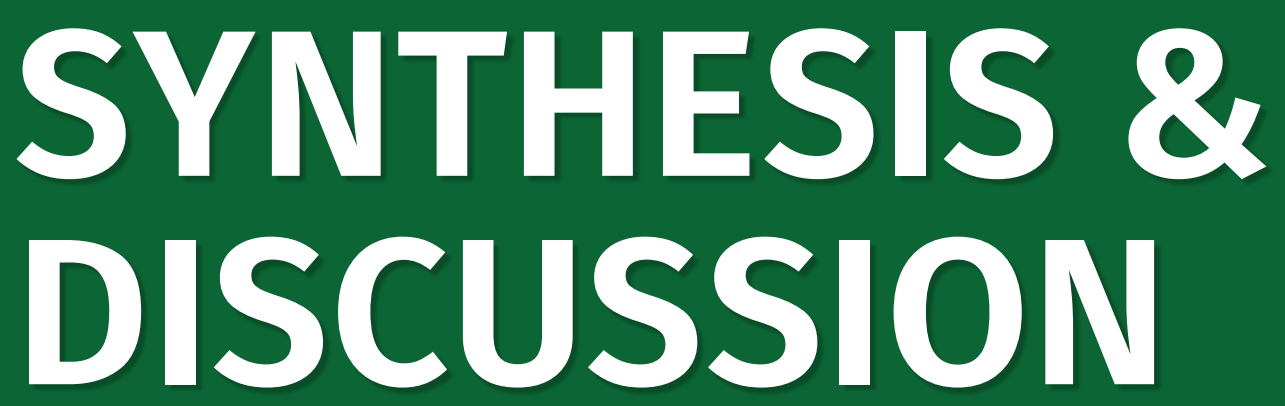




\title{
4.1 Forest ecosystem services are highly valued
}

\author{
64 The public has a high awareness of forest ecosystem services, often \\ referred to as "forest benefits", "forest functions" or "forest values".

The identified studies indicate that the public has a high awareness of forest ecosystem services, often referred to as "forest benefits", "forest functions" or "forest values". The studies used different conceptualisations of forestecosystems services. In some cases, they used the advanced structure from the Millennium Ecosystem Assessment (2005) or differentiated into environmental, social and economic benefits. To improve comparability, we used the latter conceptualisation. Thus, the environmental benefits include positive impacts for climate, habitat for flora and fauna, and protection of soil and water. The social benefits include recreational, cultural and spiritual aspects. The economic benefits include the provision of timber and associated benefits but also other job opportunities (such as tourism). In all studies, the environmental and recreational benefits were rated higher than economic benefits.

Regarding the environmental benefits, respondents recognised and valued the positive impacts of forests on the global climate. For example, statements such as "forests are important to mitigate climate warming" and "carbon sequestration" received high agreement in Germany, Sweden and Austria (Nordlund et al., 2017; Lupp et al., 2016; Ranacher et al., 2017b). Similarly, the biodiversity benefits such as "forests ensure a broad variety of plants and animals" and "conservation of plants and animals" were highly rated. For example, in Ireland the biodiversity benefits of having forests to ensure a broad variety of plants and animals were held as the most important benefits by $85 \%$ of the respondents (Howley et al., 2011) and forest conservation of plants was ranked first by $37 \%$ of respondents (Upton et al., 2015). In Germany (Almeida et al., 2018) respondents perceived mixed forest to perform better on environmental functions and monocultures better on economic functions.

Regarding the social benefits, respondents mainly referred to recreational activities and experiencing nature. For example, in Italy, respondents ranked as most important naturalness, landscape contemplation, hiking and relaxation but put also emphasis on firewood and non-wood forest products, which is found with other surveys conducted in the Alpine region (Paletto, 2013b). In the Czech Republic more than half of respondents valued forest for its aesthetic and landscape-forming function and $43 \%$ for the production of forest fruit and mushrooms (Stachová et al., 2018). In Germany, hiking and observing plants and wildlife were preferred activities, whereas meditating received only little agreement (Almeida et al., 2016). In general, engaging in physical activity or collecting non-timber forest products such as mushrooms, plants or hunting were considered less important than ecological functions but were nevertheless valued and carried out by respondents. Interestingly, the provision of ecosystem 
services was not found to influence pathway choice in Germany and rather was a decision of personal habit and existing infrastructure (Meyer et al., 2016). No visible influence of other people on the environment, such as littering, forestry activities or forest damage while also having public access to forests were important and a high frequency of other visitors was negatively perceived in all studies, which is found with previous studies (e.g. Rametsteiner and Kraxner, 2003).

\section{G G While timber production was considered to be an important function of the forest, it was not the most important one. \\ פ}

The economic benefits were considered least important. While timber production was considered to be an important function of the forest, it was not the most important one. For example, in Italy the provision of timber and fuelwood and creation of job opportunities were considered as the least important benefits (Paletto, 2013a). In Ireland timber production was perceived to be an important function of the forest by $70 \%$ but this was still less than the other reported benefits (Howley et al., 2011). In Sweden, production values and business-related aspects received least agreement (Nummelin et al., 2017; Eriksson et al., 2012).

In the previous studies (Rametsteiner et al., 2009; Rametsteiner and Kraxner, 2003), the ecological function "biodiversity/habitat" was rated as the most important function and forests' capability to tackle climate change emerged as an important topic, and this has changed a little. The latter is now perceived as the most important benefit. However, both functions are almost equally perceived and ranked by the survey respondents and the role of forests in providing fresh air was rated highest among provisional functions. Similarly, as in the previous studies, forests are perceived as "nature". However, one must consider that those studies which did on-site surveys in forests may have experienced difficulties in surveying forest visitors engaging in sport activities, and so that group could therefore be underrepresented. While the review shows that the public is highly aware that forests provide wood, they do not consider the economic function of forests to be very important. This is in line with a previous study (European Commission, 2002) in which the economic function of forests providing the raw material for woodbased industries was little perceived.

The reviewed studies show a wide recognition of forest ecosystem services in all countries. The Eurobarometer 440 survey (European Commission, 2016) further confirms that European citizens rate environmental functions higher than recreational and economic functions. When asked "what do you think are the most important benefits provided by forests?, $66 \%$ of the respondents mentioned absorbing carbon dioxide to fight climate change and its detrimental effect and $63 \%$ said providing animals' natural habitats, preserving the different types of animals and plants and conserving nature. Together with "protecting people from natural disasters such as floods and avalanches" (40\%), these were the functions most often mentioned as the most important benefits in all countries. At least one in five EU citizens believe the benefits forests provide include supplying renewable energy such as using wood as fuel (24\%), providing wood to produce furniture and other products (22\%) and providing healthy leisure activities (20\%). Fewer respondents (16\%) felt "contributing to jobs and rural development" is an important benefit that forests provide (European Commission, 2016). Thus, 
the findings from the earlier review (Rametsteiner et al., 2009) suggesting that forests are mainly perceived from the perspective of nature and landscape quality and less as a source of economic activity or a carrier of services, is partially supported, as the review reveals a high and diversified recognition of forest ecosystem services.

\section{We identified some statistically} significant relationships of socioand psychographic variables regarding this topic. Respondents with forestbased sector involvement or farming households were more likely to rank timber higher and recreation and conservation outputs lower than other respondents (Howley et al., 2011). Respondents who did not own any private forest lands were more likely to believe environmental ecosystem services are higher in mixed forests than the private forest owners (Almeida et al., 2018). Gender and education were found to play a significant role. Female respondents expressed more positive attitudes and knowledge towards ecosystem services than male students (Torkar et al., 2019; Ranacher et al., 2017). People with lower education assigned higher levels to all ecosystem services (Paletto, 2013b), whereas those with third level education were more likely to rank employment lower and protection and conservation higher (Upton et al., 2015). Regarding location, respondents from urban areas were more likely to rank recreation higher and timber lower (Upton et al., 2015). Other significant variables were visitor group and personal values. For example, ratings for forest benefits differentiated between sport groups valuing sport and health and families, with the latter rating time with family and friends and fresh air higher (Lupp et al., 2016). A stronger ecological worldview also led to more emphasis being given to preservation and personal wellbeing (Eriksson et al., 2012).
Summarising, the reviewed studies show that respondents perceived the forest as a place of "nature" which can be used to experience quietness and wilderness during a walk. The aspect of experiencing nature and wilderness is in line with the strong valuation of the ecological functions of forests, especially regarding its positive impact on the global climate. In the context of a forest-based bioeconomy, the studies clearly show the recognition of forests in contributing to climate change mitigation and preserving biodiversity and across all countries. However, the economic function of forests in providing a livelihood for the local community (through e.g. timber production, tourism) is little perceived and respondents are less aware of the economic contribution of forests and the forest-based sector, such as generating income in rural areas. The strong perception of environmental values is important for the support of sustainable forest management and nature protection but may also pose a risk for the acceptance of forest management activities aimed at wood production.

\section{G Respondents perceived the forest as a place of "nature" which can be used to experience quietness and wilderness during a walk.}
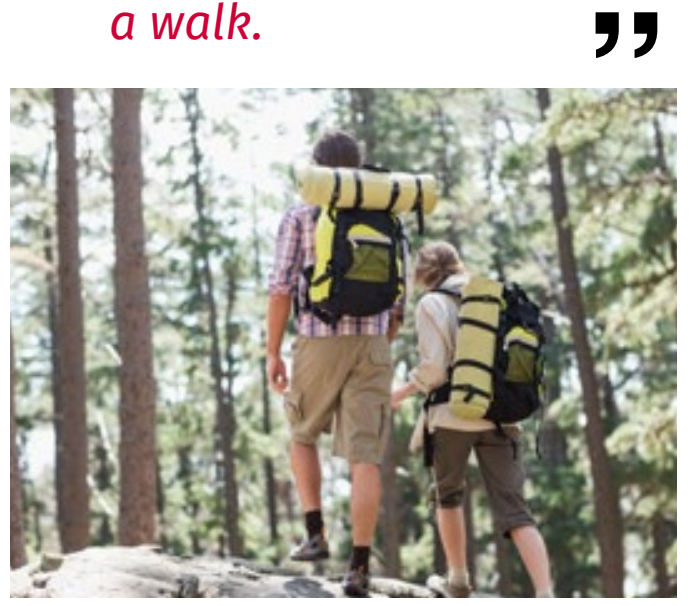

Photo by: (C) WavebreakMediaMicro / Adobe Stock 


\subsection{Preference for forest protection and diversity}

Several studies indicated respondents' concern about forest conditions and their support for forest protection and conservation activities. Regarding forest conditions, the review shows that forest conditions are perceived to be deteriorating in the Czech Republic (Krejčí et al., 2019) and threatened by environmental problems such as environmental pollution and climate change in Germany, Sweden and Czech Republic (Nordlund et al., 2017; Stachová et al., 2018).

Harvesting and management damage were also perceived as a threat and respondents in Lithuania approved voluntarily giving up cuttings to improve forests' ecological functions when income losses are compensated (Mizaras et al., 2015). There were several respondents agreeing that forest cover is decreasing in Lithuania and Austria (Mizaras et al., 2015; Ranacher and Stern, 2016). Again, respondents' perception of forest conditions is similar to previous studies but the issue of "forest dieback", a prominent issue in the past, was not identified (Rametsteiner et al., 2009; Rametsteiner et al., 2003). However, the review did not identify forest fires or storms to be a central concern or damage, as was the case in these previous studies, which could be bias from not using the key word "forest". Interestingly, the negative aspects of climate change on forests and adaption measures (e.g. planting different tree species) only marginally appeared in the reviewed studies. The quality of forest management (Mizaras et al., 2015; Dobsinska et al., 2016; Pacurar et al., 2018) and forest conservation (Valkeapää et al., 2013) is perceived to be good to medium and foresters are perceived to positively impact forest health (Ranacher and Stern, 2016; Upton et al., 2015) in Lithuania, Slovakia, Romania, Finland, Austria and Ireland. Thus, the review indicates a certain ambiguity among the public towards forest management activities. While the review shows that respondents perceive forests to be well managed, results also show that forests are seen to be vulnerable and threatened. The Eurobarometer study 501 (European Commission, 2020) shows that $36 \%$ consider the decline and extinction of species and habitats and natural ecosystems such as forests as a very serious problem, next to air pollution (46\%) and marine pollution (40\%).

Regarding management activities, respondents were found to be interested in the way forests are managed and agreed that citizens should have more opportunities to decide how forests are managed in Ireland (Upton et al., 2015). In Spain, the municipality was preferred to be responsible for forest management in comparison to forest owners and respondents preferred to 


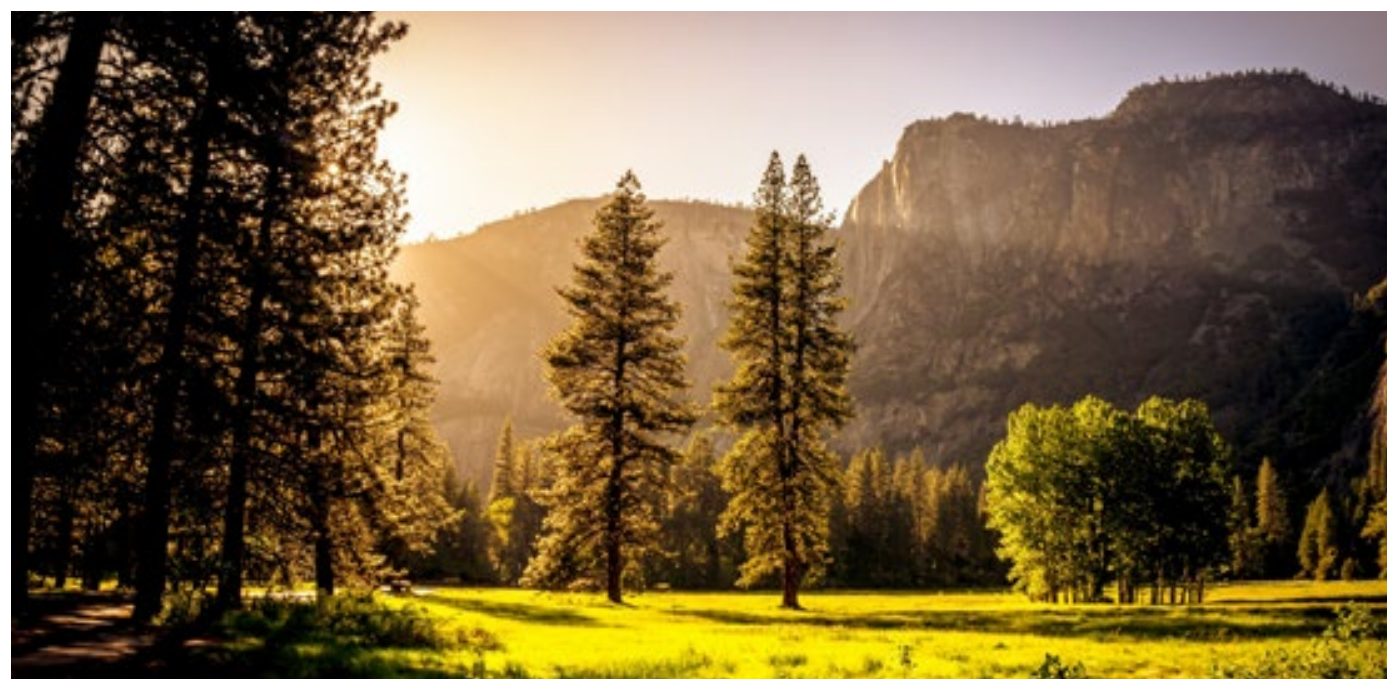

Photo by: (c) André Cook / Pexels

improve the management of existing forest areas rather than to increase forest cover (Fabra-Crespo et al., 2012). Sources of financing non-market services of publicly owned forest in the Czech Republic should mainly come from timber sales or the state (Šišák et al., 2011). In Finland, the forest management objectives for biodiversity conservation and climate change were more accepted than those for timber and bioenergy (Matthies et al., 2018). In the Czech Republic, the forestry operations of tree planting, tree protection, road maintenance and water stream protection were perceived as more important than timber transport or timber harvesting (Šišák et al., 2011). Similarly, this was also found for Finland (Valkeapää et al., 2013), with forest road construction and forest restoration receiving higher agreement rates than clear cutting. Forest protection and conservation measures also received high agreement in Sweden, Norway, Spain, Romania, Czech Republic, Slovenia and Poland (Valasiuk et al., 2018; Varela et al., 2017; Pacurar et al., 2018; Krejčí et al., 2019; Torkar et al., 2011; Czajkowski). Afforestation was positively perceived in Ireland and using broadleaved or mixed forests were preferred (Howley et al., 2011; Upton et al., 2012). These positive perceptions are an interesting result as the Irish government seeks to increase forest area on agricultural land, which has been also publicly criticised (Ni Dhubháin et al., 2019). A study from the United Kingdom identified three groups - productivists, recreationists and conservationists - of which the latter support the expansion of forest cover with native species (Nijnik et al., 2016). Similarly, the study from the Forestry Commission $(2019,2017)$ reveals that the majority of respondents (88\%) agreed that "A lot more trees should be planted" and "Different types of trees should be planted that will be more suited to future climates" (78\%). However, only a small number of people agreed that "No action is needed; let nature take its course" $(26 \%)$ and "Trees should not be felled in any circumstances, even if they are replaced" (29\%).

Regarding pests, respondents in Ireland, Sweden and Germany are aware of these and approve mainly of mechanical intervention (Upton et al., 
2017; Eriksson et al., 2018; Gutsch et al., 2019) or the planting of native trees in the United Kingdom (Jepson, 2017a; Jepson, 2017b). The reviewed studies show respondents' good awareness of calamities, pests and pest control and a general support of measures. In addition, the Forestry Commission (2019) indicates a high awareness of pests in the United Kingdom and found that $85 \%$ of respondents agree that action should be taken by authorities and woodland managers to protect trees from damaging pests and diseases. There was some level of acceptance regarding the use of genetically modified trees that would be more resistant to herbicides or diseases and to increase productivity in Croatia, but concerns regarding biodiversity exist (Nonić et al., 2016). While respondents agreed to increase forest growth in Sweden, cultivating clones encountered the greatest, whereas fertilisation encountered the least opposition (Hemström et al., 2014). Two studies in the United Kingdom (Jepson et al., 2017a,b) found that creating a disease tolerant ash tree using trans-genetics was the least preferred option to fight ash dieback.

\section{GG Women showed higher preferences for forest conservation, protection and easy forest access and endorsed biodiversity and climate objectives \\ 95}

Regarding preferred forest attributes, there was an overall preference for mixed forests with random distribution of trees regarding age class/multi layered in Italy, Germany, Czech
Republic, Poland, Germany, France, and Ireland (Paletto et al., 2013b; Arnberger et al., 2018; Stachová et al., 2018; Drábková et al., 2014; Giergiczny et al., 2015; Paletto et al., 2017b; Almeida et al., 2018; Rambonilaza et al., 2016; Upton et al., 2012). Thus, regarding structural attributes, little has changed compared to previous studies (eg Rametsteiner, 2003). The removal of ground vegetation received a high level of agreement for good management in Portugal because of the threat of forest fires and some inconsistency between verbal statement and images was found (Carvalho-Ribeiro et al., 2011). High forest was preferred over natural evolution and coppice in Italy (Riccioli et al., 2018). One German study based on pictures (Arnberger et al., 2018) shows that artificial reforestation was preferred over natural rejuvenation, which indicates some uncertainty among the public about what certain management activities look like. Deadwood was perceived as nature-oriented forestry in the Czech Republic (Drábková et al., 2014) and aesthetically pleasing in Finland (Hauru et al., 2014). However, there was also some indication that the removal of deadwood was preferred in some cases in Italy (Paletto et al., 2017; Pastorella et al., 2016). In France, willingness to pay for deadwood as an ecological measure was found to be the lowest among all measures but could be significantly improved through the provision of information on its ecological value (Rambonilaza et al., 2016). The level of management intensity had an impact on recreational values. This review supports the findings from previous studies (e.g. Rametsteiner, 2009) about the negative perception of forest-based sector activities regarding harvesting and clear cuts. Clear cutting was overly negatively perceived in the 
Czech Republic, Germany, Poland, Sweden and Finland (Stachová et al., 2018; Arnbeger et al., 2018; Giergiczny et al., 2015; Nordlund et al., 2017; Juutinen et al., 2017). In Austria, harvesting activities led concerns regarding visual appearance and ecology and nature but were reduced by providing information at the site (Huber et al., 2017).

\section{We found several statistically} significant relationships for this topic regarding gender, age and education. Women showed higher preferences for forest conservation, protection and easy forest access (Eriksson et al., 2012; Fabra-Crespo et al., 2012; Krejčí et al., 2019) and endorsed biodiversity and climate objectives (Matthies et al., 2018). Respondents with higher levels of education were more likely to rank employment lower and protection and conservation measures higher (Upton et al., 2015) and preferred the recreational use of naturally evolved forest (Riccoli et al., 2018). Stronger ecological and recreation values and weaker production values resulted in highlighting preservation of forests (Eriksson et al., 2012). Female respondents preferred less interventionist approaches (such as natural breeding and planting of other native trees) compared with males (Jepson et al., 2017b). In general, older, lower income, less aware respondents tend to vote against supporting any disease control programmes (Sheremet et al., 2017). Also, the application of pesticides was more accepted by older age classes and lower education levels (Gutsch et al., 2019). Younger, more educated respondents and those with sector involvement were more likely to accept exotic tree species, clones or GM approaches whereas older respondents were more likely to be in favour of traditional breeding techniques (Hemström et al., 2014; Jepson et al., 2017a, b). Women showed higher preference for uneven aged forests and open canopy (Paletto, 2013b). Younger people showed a greater preference for broadleaves, while the elderly preferred conifers (Paletto et al., 2013a, b) and put more emphasis regarding easy access of forests and personal wellbeing (Eriksson et al., 2012).

\section{G G Forest visitors seek intangible attributes such as nature, wilderness, wellbeing and quietness in a forest while the ecological benefits of forests in providing habitat for biodiversity and environmental processes is strongly perceived.

Summarising, the review shows that, despite the fact that forests are considered to be well managed, a certain level of threat is perceived. Intensive forest management activities, such as using exotic tree species and clones and conducting clear cuts, are negatively perceived, which suggests a conflict between increased raw material production and respondents' expectations regarding recreation and ecology. Overall, the review suggests that forest visitors seek intangible attributes such as nature, wilderness, wellbeing and quietness in a forest. Again, this shows that the ecological benefits of forests in providing habitat for biodiversity and environmental processes is strongly perceived. 


\title{
4.3 Scepticism towards the environmental performance of industry
}

\author{
G6 There are only a few studies that investigated the public's \\ perception of the forest-based sector as an industry and thus \\ this topic is underrepresented.
}

This chapter addresses the perceived sustainability of the sector and whether its activities contribute to a bioeconomy and climate change mitigation. Regarding forest related impacts, we found little agreement around whether wood processing companies in Austria use certified wood and do not use illegally harvested wood (Ranacher and Stern, 2016).

Similarly, there was scepticism of the sector's level of environmental responsibility regarding different impacts along the value chain among respondents from Austria, Germany, Finland, Slovenia (Ranacher et al., 2017a). While the overall sustainability performance of the forest industry was rated to be good, it was rated higher than the social and the environmental performance in Finland, Hong Kong, Spain (Pätäri et al., 2017). While respondents considered information about forest sector impacts as important, they could not prioritise them, also suggesting a limited understanding of forest-based sector activities and thus its responsibility (Ranacher et al., 2017a). Regarding the forest-based sector contribution to climate change mitigation in Austria and Germany, respondents perceived the forest to be good for the climate but were sceptical whether this true for wood and wood-based products, especially regarding the "carbon storage effect" often claimed by the industry (Ranacher et al., 2017b), a finding also supported by previous results (Rametsteiner et al., 2007).

Regarding significant differences we found that nationality had an impact (Pätäri et al., 2017) with Finnish respondents having more positive attitudes. The main difference was sector involvement, with those without involvement being more critical (Ranacher et al., 2017a, b; Ranacher and Stern, 2016). Study programme and personal values were found to make a difference with social science and humanities students giving lower sustainability scores than natural scientists (Pätari et al., 2016). 
In general, the review shows that there are only a few studies that investigated the public's perception of the forestbased sector as an industry and thus this topic is underrepresented. A possible explanation for this may be that the general public was found to have a hazy notion about the sector, its value chain and its activities (European Commission, 2002) and is therefore difficult to survey. The (few) studies suggest that the beginning of the value chain (i.e. wood sourcing) is more sceptically perceived than impacts that occur through the processing of the material and other impacts, (e.g. socioeconomic aspects) and the general public has little awareness of the activities of the forest-based sector.

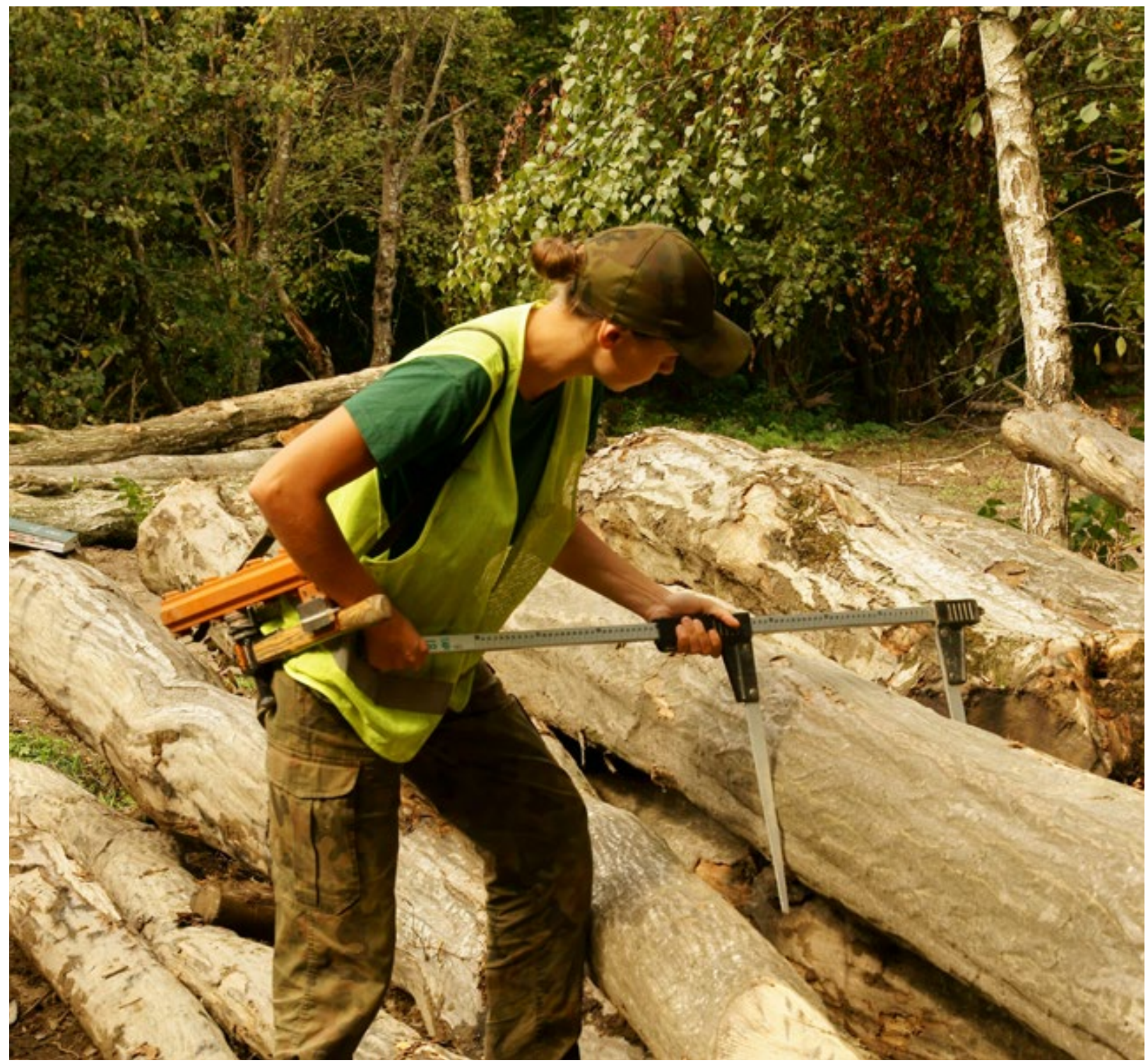

Photo by: ๑ Szymon Bartosz / Adobe Stock 


\title{
4.4 Wood products perceived as environmentally friendly
}

\author{
G6 Studies mostly focused on wood products such as furniture, \\ floorings, or construction with few studies identified for new, \\ wood-based products, such as composites, fibres, biofuels, textiles \\ or biochemicals, as envisioned in a forest-based bioeconomy. Ig
}

With a few exceptions the studies mostly focused on wood products such as furniture, floorings or construction. We did not identify many studies for new wood-based products such as composites, fibres, biofuels, textiles or biochemicals, as envisioned in a forest-based bioeconomy.

While wood buildings and housing elements were perceived to be of high quality, the review identified doubts about their safety and technical performance, which may reflect the rather traditional perceptions of wood houses - and wood products - among the respondents in Italy, Austria, Slovenia, Croatia and Finland (Costa et al., 2011; Jiménez et al., 2015; Kuzman et al., 2012; Lähtinen et al., 2019; Ranacher et al., 2018). For example, $48 \%$ of respondents in Finland agreed that "Wood is a burning material, but simultaneously it is a fire-safe material" and $88 \%$ agreed that "Wooden structures are very long-lasting when designed and built properly" (Lähtinen et al., 2019). The technical performance of wood-based innovations such as composite materials was questioned in Austria (Ranacher et al., 2018). As indicated in Rametsteiner et al. (2007), EU citizens seem to need more reassurance if they are to appreciate wood as a construction material as they have some reservations regarding its technical performance, such as strength, durability and fire resistance.

In the majority of reviewed studies, wood was perceived to contribute to a healthy living environment in the form of mental and physical health (see e.g. Slovakia (Moresova et al., 2019) and health in Finland (Lähtinen et al., 2019). At the same time, the review shows that respondents are worried about additives. For example, they have the highest information demands for product safety around the health effects of additives or surface treatments in Germany and Finland (Osburg et al., 2016b; Toppinen et al., 2013).

Regarding appearance, wood products were considered to be of high aesthetic and emotional value. In general, solid wood and wood products were perceived to be more natural and attractive than technically modified 
or non-wood products in Sweden, Finland, Norway, Slovenia and France (Lindberg et al., 2013; Burnard et al., 2015; Costa et al., 2011).

Regarding environmental performance, wood products were perceived as environmentally friendly. There are some recent studies that confirm the positive perception of wood construction for climate change mitigation, which was stronger perceived in Finland than in Austria and Germany (Lähtinen et al., 2019; Ranacher et al., 2017b). Environmental benefits resulting from substitution and carbon storage effect was questioned in Austria and Germany (Ranacher et al., 2017b; Ranacher et al., 2018). In general, biofuels from forest resources were positively perceived but their environmental sustainability and contribution to climate change mitigation was scrutinised in Finland, Austria, Germany and Belgium (Halder et al., 2011; Van Dael et al., 2017; Ranacher et al., 2017b). Woodbased packaging, such as paper, is perceived as environmentally friendly, which was also found to be an important attribute for consumers in Romania (Orzan et al., 2018). The scepticism towards bioenergy and the positive perception of wood-based packaging material aligns with previous findings (Rametsteiner and Kraxner, 2003; Rametsteiner et al., 2007). In general, the review shows that respondents had a limited awareness of forest-based sector innovation, but positive perceptions around further pursuing them, especially regarding environmental aspects of industrial production and sustainable forest management (Stern et al., 2018) in

Austria, Germany, Slovenia and Finland. However, the review further shows that respondents in Germany did not recognise any ecological benefits from material efficiency or a smaller carbon footprint for fewer transport costs (Knauf et al., 2015).

Regarding purchasing decision, results suggest high agreement that consumers buy products that are environmentally sustainable, which results from leading questions such as "Are you going to buy wood products labelled as environmental sustainable?" There was a high level of willingness $(70 \%)$ to pay price

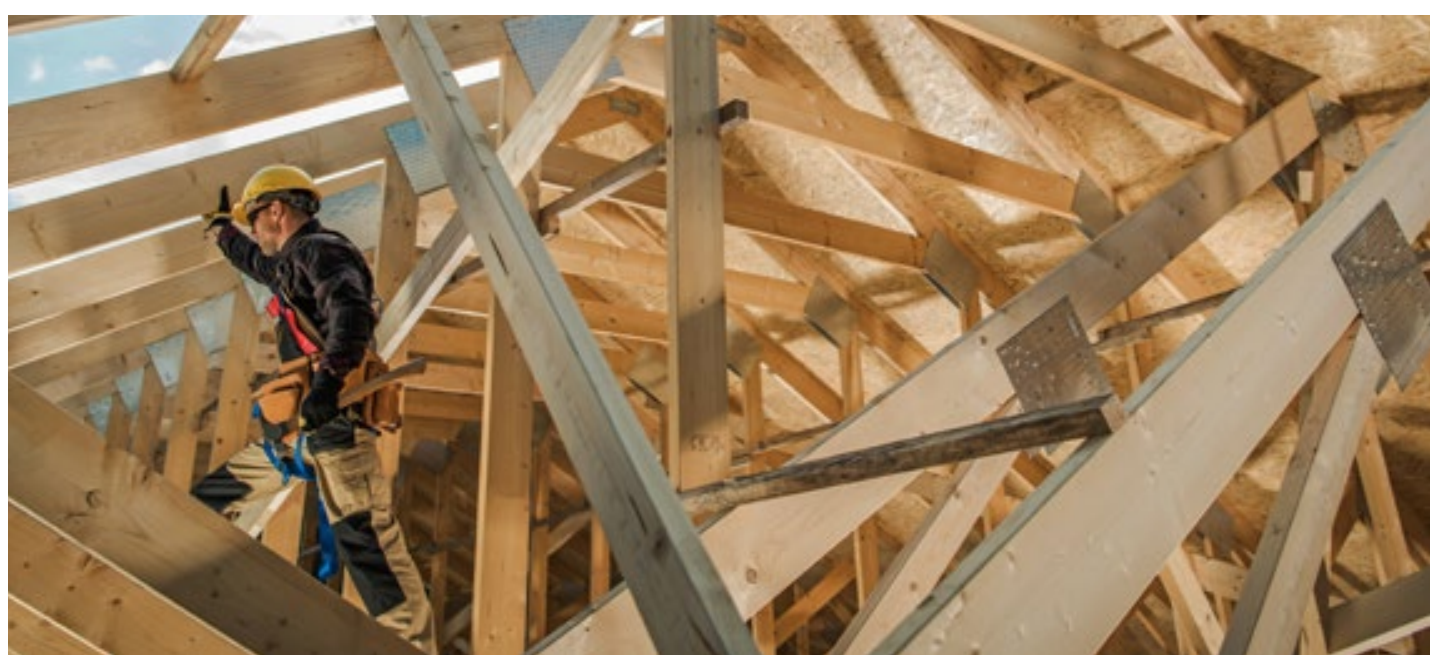

Photo by: @ Tomasz Zajda / Adobe Stock 
premiums for environmental or social product characteristics in Finland (Toppinen et al., 2013). At the same time, environmental attributes were found to play a minor role, whereas other attributes such as appearance, technical performance and price were more important in Finland, France, Slovenia, Slovakia, Croatia (Lähtinen et al., 2019; Costa et al., 2011; Holopainen et al., 2014; Kuzman et al., 2012; Paluš et al., 2012; Švajlenka, 2018; Toivonen et al., 2012). While environmental attributes were not as important in comparison to quality, price and technical performance, a study in Austria shows that, when it comes to innovation, focus group participants were specifically interested in the economic and environmental aspects of wood-based innovation. A reason might be that in the focus groups they answered as citizens and not as consumers, which is commonly known to shift preferences (see e.g. Nyborg, 2000).

The review shows that wood origin (legal, forest management model or region) was an important product attribute in Finland and Germany (Holopainen et al., 2014; Osburg et al., 2016b; Toppinen et al., 2012; Tsourgiannis et al., 2013). In Croatia and Greece respondents agreed they would purchase final products (wood products, pulp, paper, etc.) from transgenic forest plantations but prefer that they are labelled as such and environmental concerns, regarding biodiversity, remained (Tsourgiannis et al., 2013, 2015; Nonić et al., 2014). Studies showed preference for, and willingness to purchase, environmentally sustainable certified wood in Croatia and Italy (Paluš et al., 2012; Panico et al., 2018). In the past, wood origin regarding territory and forest management model used was found to be of importance for consumers; they are aware of forest certification and a high level of knowledge and awareness (Rametsteiner et al., 2009) was also confirmed in this study.

Social aspects referred to all aspects addressing social sustainability issues such as labour conditions and impact on the region but these were only marginally researched. The responsible image of a product company, using no cheap labour and respecting social aspects in production (e.g. needs of local people, no child labour) were important product attributes in Finland (Holopainen et al., 2016; Toppinen et al., 2013). In Greece the improvement of job opportunities and farmers' income was important for the use of products from transgenic forest plantations (Tsourgiannis et al., 2013).

We found several statistically significant relationships for this topic. Female respondents were more positive regarding the perceived environmentally friendliness of the products and rated the environmental attributes to be more important than males did (Holopainen et al., 2014; Toivonen et al., 2012; Halder, 2011; Van Dael et al., 2017). Those with sector involvement had more positive perceptions regarding the environmental performance as well as greater recognition of innovation (Ranacher et al., 2017b; Stern et al., 2018). Older people seem to be more likely to buy high-quality wood products than younger people (Costa et al., 2011). Respondents with a full knowledge of the certification schemes are more likely to buy certified wood products but income and age were also important (Panico et al., 2018; Holopainen et al., 2016; 
Toppinen et al., 2013). Regarding psychographic factors we found that higher environmental awareness and innovation positively impact the perception and purchasing of wood and wood-based products (Costa et al., 2011; Osburg et al., 2016c).

\section{G While the use of different wood and wood-based products or bioenergy was perceived to be environmentally friendly in all studies, the review shows ambiguity as to whether their use contributes to climate change mitigation.

As the large majority of EU citizens are concerned about climate change (European Commission, 2020), using wood products and pursuing a forestbased bioeconomy is an opportunity for the forest-based sector. While the use of different wood and wood-based products or bioenergy was perceived to be environmentally friendly in all studies, the review shows ambiguity as to whether their use contributes to climate change mitigation with higher ratings for wood construction than bioenergy. However, as the respondents of the reviewed studies see forest area as decreasing and scrutinise the sustainability of products, this opportunity is limited. At the same time as most Europeans are worried about the decrease in biodiversity and decline of forests, with forests valued as an important place for biodiversity (European Commission, 2013b, 2020), they are also worried about forest conditions and question the sustainability of wood products. The review shows that the perception of social and socio-economic aspects along the value chain are only little researched, while being considered important. This highlights the demand for an accompanying assessment of innovative processes and products to achieve sustainable and competitive products in line with the vision of future of a forest-based bioeconomy.

Note that the majority of reviewed studies research which product attributes are important to consumers and not how they actually perceive these products and their contribution to a bioeconomy. Where the studies investigate these attributes, such as importance of product information or sustainability aspects, the studies fail to overcome the attitude-behaviour gap to allow statements of purchasing behaviour.

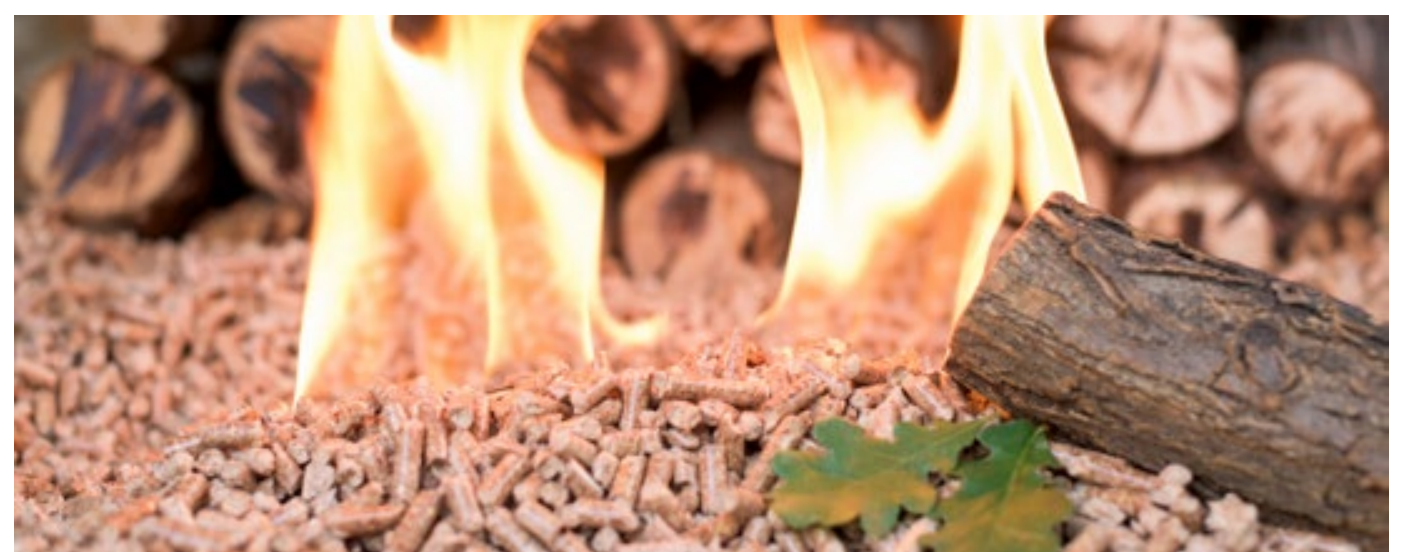

Photo by: (c) tchara / Adobe Stock 


\subsection{Limitations of the review}

\section{The way the study was carried out was necessary to stay within the boundaries of the time, personnel and budget resource available. Therefore, we acknowledge that the study comes with limitations.}

First, only studies published in scientific journals have been reviewed. Thus, there might be other studies, within the thematic scope of this study, that have been published elsewhere (e.g. business surveys, project reports).

Second, only the Scopus database was used, with an awareness that it covers most - but not all - of the relevant journals (e.g. Forest Policy and Economics). In addition, the country limitation used in the search is automatically applied to the affiliation of the authors and thereby excluded studies. Furthermore, we only included studies in the English language, thus we had to exclude some of the studies listed in Scopus. Note that the increase of time span would probably not increase the likelihood of generating new results as the last review was done in 2009 (Rametsteiner et al., 2009) and would generate a sample size unsuitable for content analysis (Holsti, 1969).

Third, the selection of search terms influenced the results, as by using the term "forest" there will have been some more studies related to forestry, which could not be done within the given time frame and resources. By not including the search term "forest" the study takes a forest management and economic perspective and excludes available studies on the perception of forests from another perspective e.g. recreational or environmental. The exclusion of this search term was done primarily as a vast array of studies was found in SCOPUS (e.g. "perception"” AND forest* resulted in more than 4000 studies for the time period 2010-2019), most of them not in scope of the study, and we were not able to review them. Many of the studies identified with the search term "forest" focused on forest attributes and forest visitors' preferences for recreational purpose, for which a recent review has been published (Ciesielski and Stereńczak, 2018). Nevertheless, we reported on these preferred attributes and perceived forest condition, as they have a forestry aspect, but acknowledge they are incomplete.

Finally, by focusing only on primary survey data collected from the general public, local or regional population, forest visitors and consumers, we excluded literature surveying other groups or investigating public perception with other methods (e.g. by media analysis). In addition, our categorisation of target groups based on how they were defined in the study is limiting as they are not mutually exclusive. However, we chose this categorisation to reveal how current studies are conducted. 
While there are many studies on the perception of forest ecosystem services, forestry and forest management, and wood and wood-based products, there is only a limited amount of studies about the perception of the forest-based industry or the concept of the forestbased bioeconomy and its products. Up until 2020, no studies about the public perception of the concept of a forestbased bioeconomy were published, but publications are coming up or have recently been published (e.g. Masiero et al., in press; Navrátilová et al., 2020 ). A reason could be that the general public is more interested and able to make statements regarding forests, forestry and wood products than on the forest-based sector, which was already the case in a previous study (European Commission, 2002). Surveys on forest-based sector innovation are, with a few exceptions (e.g. Stern et al., 2018), not published. A reason may be that those surveys conducted remain confidential to secure business advantages and are not aimed at a scientific audience. Nevertheless, communicating the (potential) benefits of innovation for gaining public support is crucial in early phases of development to get access to resources (Kriechbaum, 2018).

The conditions for data collection vary strongly across all countries. Even when the same topic was surveyed, questions have not been phrased in the same way. In addition, many questions are phrased, unintentionally or intentionally, as leading questions. Such questions (e.g. "Are you going to buy wood products labelled as environmentally sustainable?") can result in higher, biased measurements and thus overestimations of positive perceptions in real life. We agree with the recent findings of another review study (Stevanov et al., 2016) that argues that, in some cases, the methodology could have been more carefully applied and there needs to be a stronger theory foundation of survey-based articles. However, to further assess the quality differences in the survey questions goes beyond the scope of the paper.

Thus, we highlight that a direct comparison of results across country and time is limited. The results reported in the study may vary in different geographical regions across Europe, partly as a result of differently phrased questions and objectives of the different studies and different sampling procedures used. Nevertheless, studies that do not aim for representativeness (e.g. when using convenience sampling) can also be of value if they particularly seek to identify differences between different groups of individuals or items. Convenience sampling was mostly used, probably because it is a lowcost method that makes it possible to specifically target e.g. forest visitors or shop visitors.

Acknowledging these shortcomings regarding comparability, the review still shows some patterns in the different countries. For example, the perceptions of forest ecosystem services, preferred forest management activities and wood products are quite coherent. The environmental aspects of forests were ranked highest, mixed forest and close to nature management was preferred and wood products' attributes were appreciated while concerns regarding their environmental impact remained. This is unexpected given that forests underlie different environmental conditions and forest policies. However, this may relate to the general public's awareness of global environmental problems and international value chains sourcing and processing their raw materials in different places. 


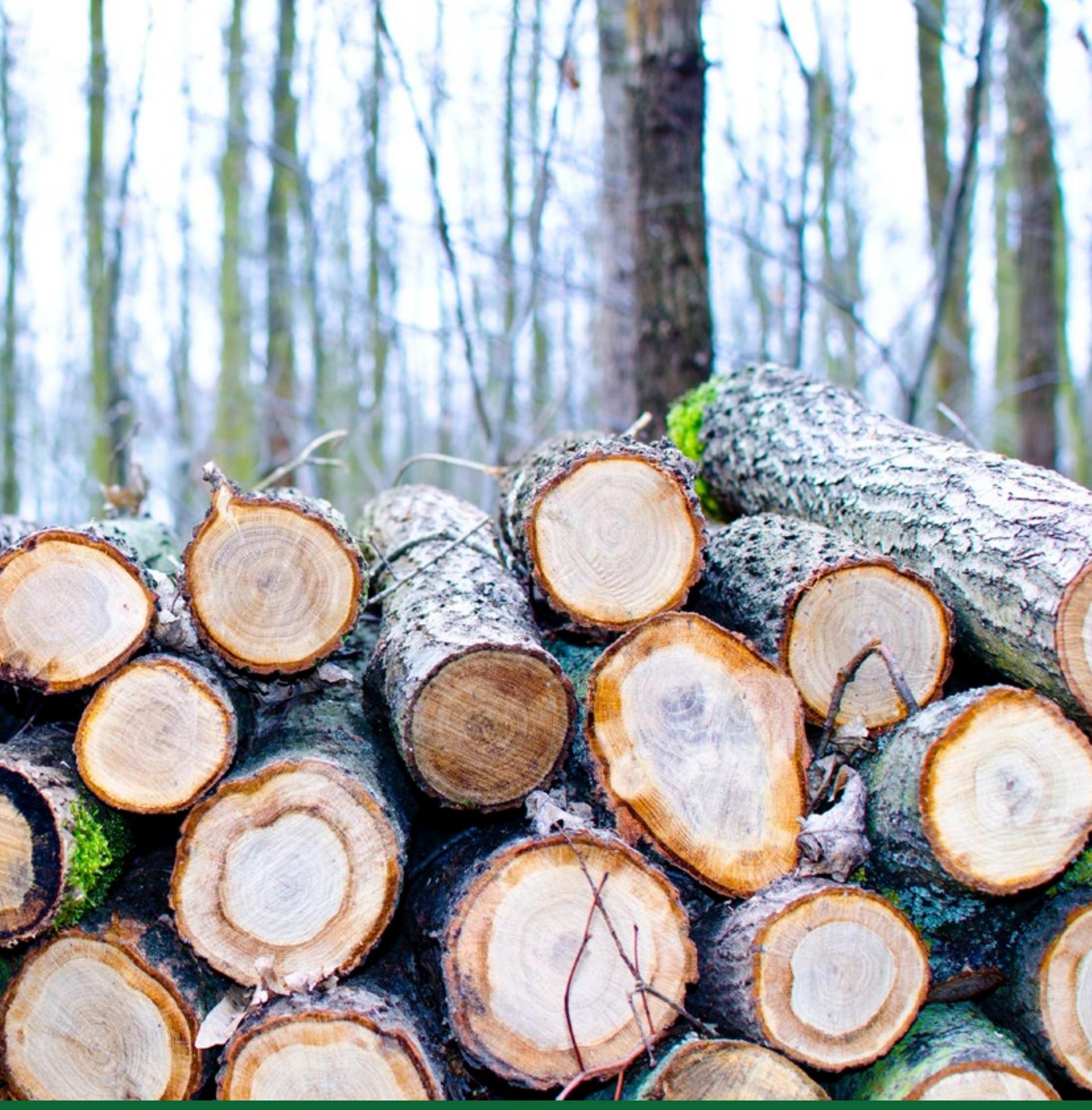

\section{CHAPTER 5}

\section{CONCLUSIONS \& \\ RECOMMENDATIONS}



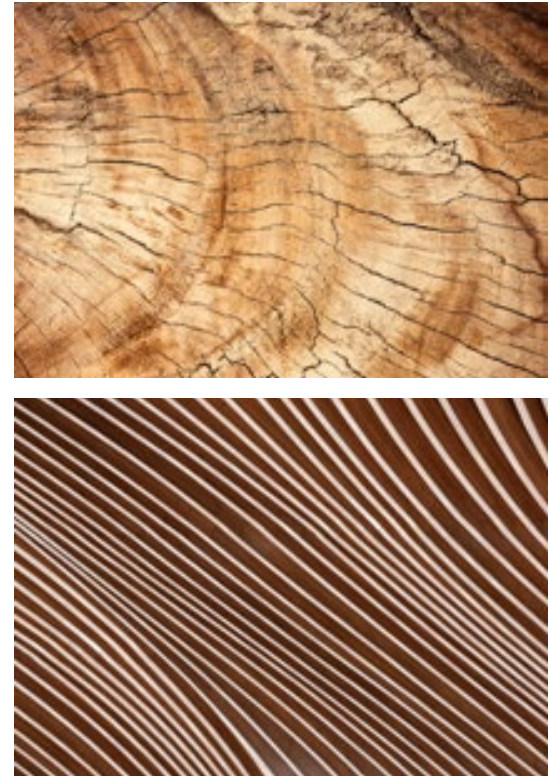

(top) Photo by: ๑ FWStudio / Pexels (down) Photo by: @ Alberto Masnovo / Adobe Stock
This review shows that there is a decent amount of literature available to investigate the public perception of forestry and the forest-based bioeconomy. While there are many studies available on forest ecosystem services and forest management activities, there is a research gap regarding the perception of forest-based bioeconomy innovations and the forest-based industry.

In all four topic categories - forest ecosystem services, forestry and forest management, forest-based industry, wood and wood-based products - quantitative surveys using convenience sampling were the most frequently used method. Studies of forest ecosystem services, as well as forestry and forest management, cover many different target groups. Thus, a research need is to address the importance of forest ecosystem services, management systems and forest sector responsibility from a consumer perspective as well. To allow generalised statements for a wider population, sampling methods aimed for representativity could be used.

Socio-demographic and psychographic characteristics play a significant role regarding public perceptions. The majority of differences were related to age, gender and education. However, other variables such as sector involvement also played a role, whereas respondent location (urban, rural) was not significant. There were several relationships regarding respondents' awareness or knowledge of a topic, their attitudes and personal values. For example, women were found to place more importance on forests' environmental benefits and protection. This was also the case for urban respondents and those with higher ecological and recreational values. Younger, more educated or urban people showed more acceptance regarding the use of non-native species. Older or male 
respondents showed more acceptance regarding invasive pest management measures. In general, acceptance of management activities was more often related to the level of education or involvement in the forest-based sector. Higher levels of income, education and prevalence of environmental awareness led to higher valuation of quality and environmental attributes of wood products and purchasing decision.

In comparison to the studies reported in previous meta studies on public perception about forest, forestry and forest-based sector (e.g. Rametsteiner et al., 2007; Rametsteiner et al., 2009; Rametsteiner and Kraxner, 2003), there appears to be a quantitative and qualitative increase in studies that have been published in a wide array of peer reviewed journals in the fields of forest and environment sciences. There are also more studies using a wide range of different, elaborated survey methods. Nevertheless, many of the findings from these previous studies were also confirmed in this review, such as the perception of forests' environmental benefits and ambiguity regarding the sustainability of wood product and the forest-based sector. We highlight that this review of public perception in the EU can only be indicative, due to our research design, but also the vast diversity in how the studies were carried out. While acknowledging the country and regional specific environmental conditions and policy frameworks, the following key messages regarding the public perception of forestry and forestbased bioeconomy are deduced from the study:

- Primarily, European citizens perceive forests to be beneficial for the climate, as a place of biodiversity and to experience nature and recreation in the forest.

- Mixed forests and diversity of stands are preferred and perceived as being "more natural".

- The economic role of forests, specifically as provider of raw materials and for generating regional income - central aspects in bioeconomy - was less recognised.

- Forest management activities, especially clear cuts, the use of exotic tree species and the application of chemicals for productivity or pest measurement, receive little acceptance.

- The public has a limited understanding of the activities related to forestry and the forestbased industry.

- Wood and wood-based products have a positive image. Yet the positive impact on climate change mitigation, especially of new woodbased products, is questioned.

- Sustainable wood sourcing (country and legal origin) is an important piece of product information. Yet consumers assign similar or even more importance to product quality and prices and little is known about the actual purchasing decisions of consumers.

- European citizens are fond of forest-based sector innovation, despite having little awareness of them and few studies being available.

- Respondents' characteristics, such as socio-demographics and psychographics (e.g. values, beliefs, attitudes), influence their perceptions of forestry and the forest-based bioeconomy.

The review further shows that there are no transnational studies that monitor public perception of forests 
in the European Union on a regular basis. The only exceptions are the Eurobarometer studies, which sometimes contain forestry related questions. As forests and their use is a very emotional topic for the general public, surveying these perceptions is recommended in the future to develop socially accepted forest policy and forest-based value chains. Overall, to support forestry and foster a forestbased bioeconomy we suggest addressing the following issues in the future:

- Acknowledge and integrate the general public's preference for forests' environmental benefits (e.g. providing biodiversity) and specific forest attributes into forest management practices and forest policy.

- Improve communication on sustainable forest management by addressing the sensitive topic of wood harvest and communicate trade-offs between the use of different forest ecosystem services.
- Acknowledge consumers' demand for product information (e.g. wood origin, health) and integrate it into sector communication about products.

- Investigate how purchasing decisions regarding forest-based bioeconomy innovation are formed and can be influenced by communicating environmental attributes or addressing respondents' environmental concern and values.

- Communicate the technical, social, economic and environmental performance of existing and future innovations as well as guiding their development through sustainability assessment.

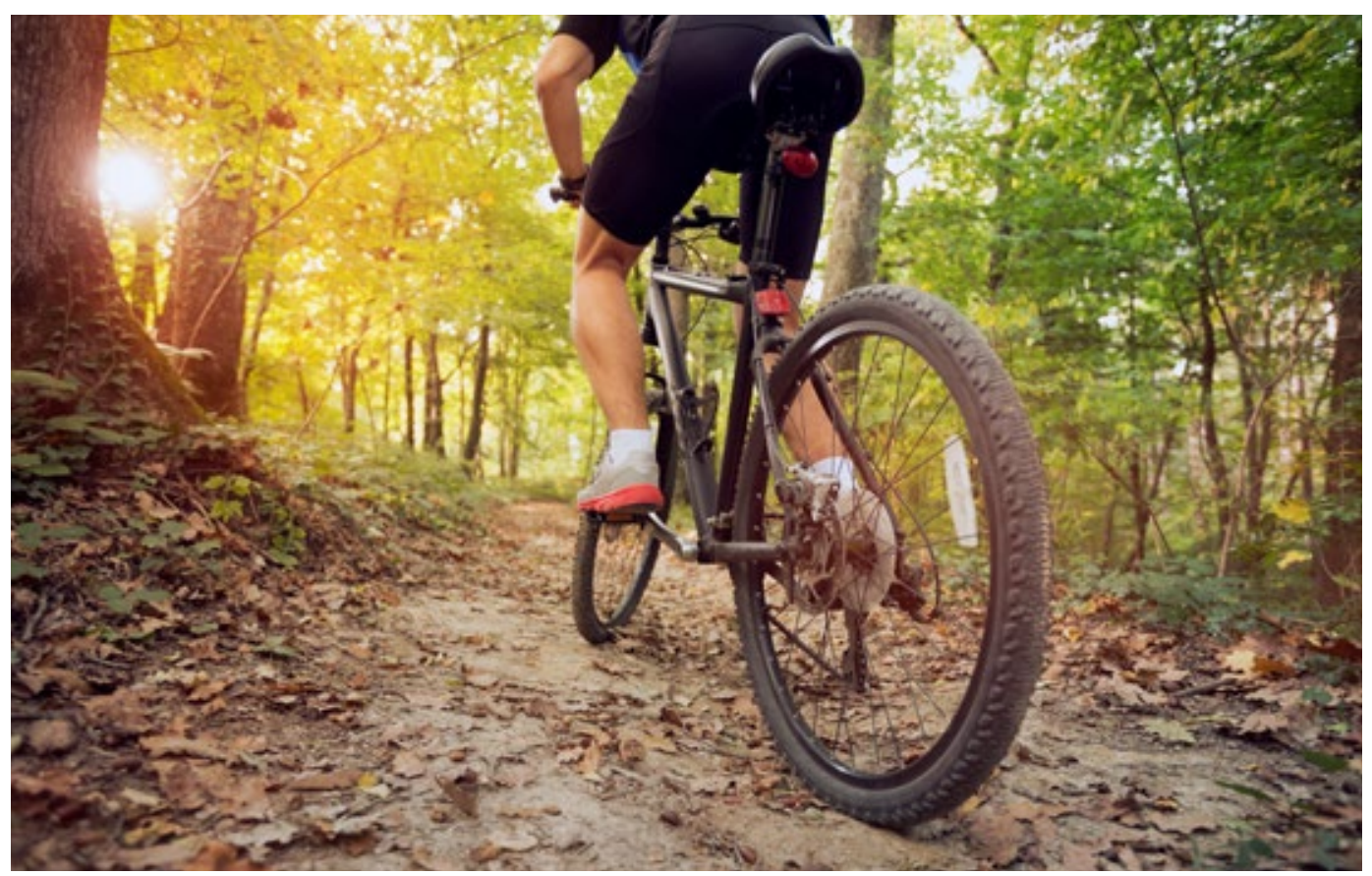

Photo by: (c) luckybusiness / Adobe Stock 


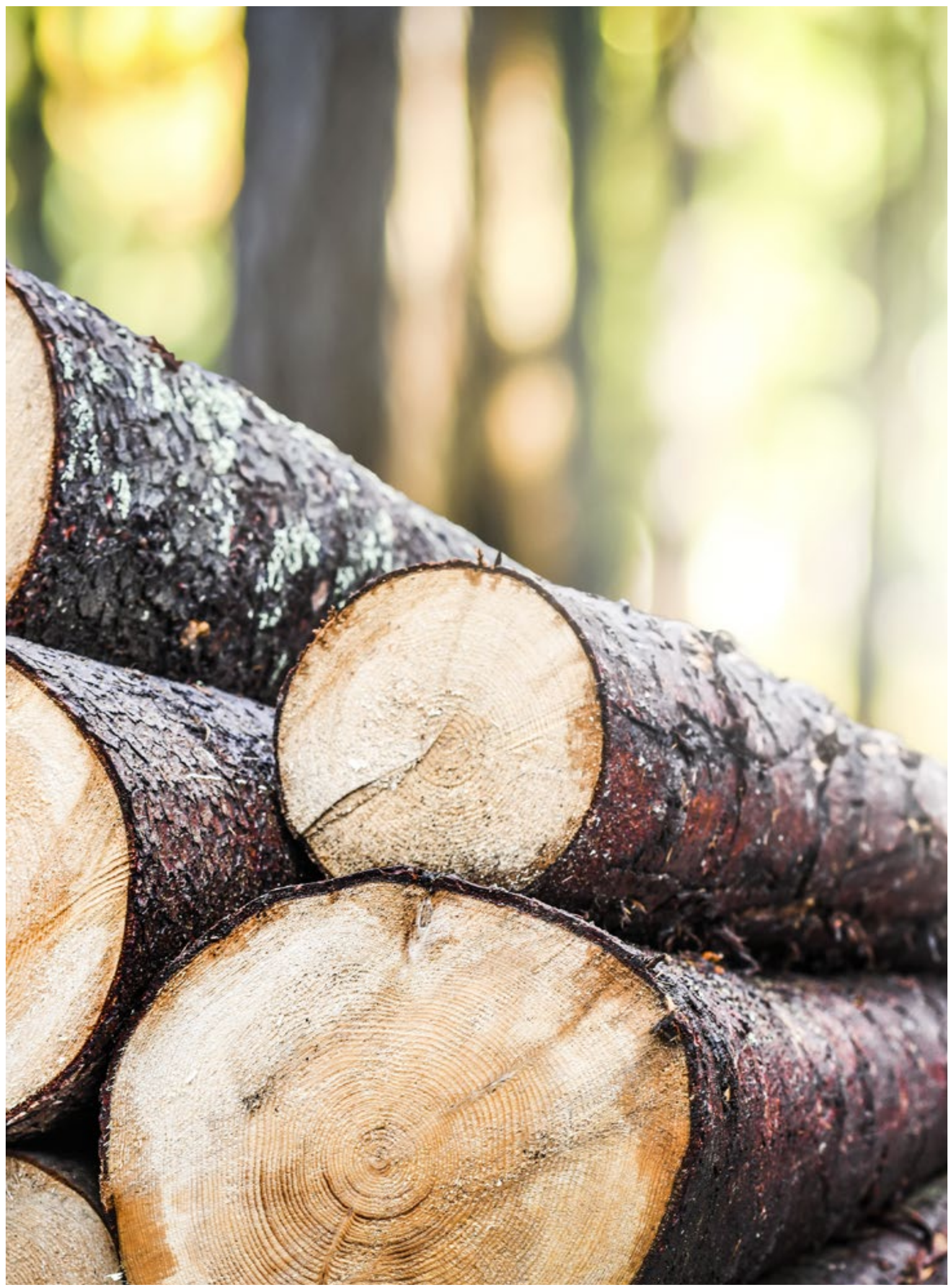




\section{References}

Aghaei Chadegani A., Salehi H., Yunus M. M., Farhadi H., Fooladi M., Farhadi M. and Ale Ebrahim, N. (2013). A comparison between two main academic literature collections: Web of Science and Scopus databases. Asian Social Science, 9(5), pp. 18-26. https://doi.org/10.5539/ass.v9n5p18

Assefa, G., \& Frostell, B. (2007). Social sustainability and social acceptance in technology assessment: A case study of energy technologies. Technology in Society, 29(1), 63-78. doi: https://doi.org/10.1016/j.techsoc.2006.10.007

Bethmann, S., Simminger, E., Baldy, J. and Schraml, U. (2018). Forestry in interaction. Shedding light on dynamics of public opinion with a praxeological methodology. Forest Policy and Economics, 96, pp. 93-101.

https://doi.org/10.1016/j.forpol.2018.08.005

Braun, M., Fritz, D., Weiss, P., Braschel, N., Büchsenmeister, R., Freudenschuß, A., Gschwantner, T., Jandl, R., Ledermann,T., Neumann, M., Pölz, W., Schadauer, K., Schmid, C., Schwarzbauer, P. and Stern, T. (2016). A holistic assessment of greenhouse gas dynamics from forests to the effects of wood products use in Austria. Carbon Management, 7(5-6), pp. 271-283.

https://doi.org/10.1080/17583004.2016.1230990

Bryman, A. (2012). Social Research Methods. Vol. 4. Oxford: Oxford University Press.

Ciesielski, M. and Stereńczak, K. (2018). What do we expect from forests? The European view of public demands. Journal of Environmental Management, 209, pp. 139-151.

https://doi.org/10.1016/j.jenvman.2017.12.032

Cook, E and Eurostat (2020). Agriculture, forestry and fishery statistics: 2019 edition. Luxembourg: Publications Office of the European Union, p. 88. https://doi.org/10.2785/798761

Edwards, P., Lacey, J., Wyatt, S. and Williams, K. J. H. (2016). Social licence to operate and forestry - an introduction. Forestry: An International Journal of Forest Research, 89(5), pp. 473-476. https://doi.org/10.1093/forestry/cpw036

European Commission (2002). Perception of the wood-based industries. Luxembourg: Office for Official Publications of the European Communities. ISBN 92-894-4125-9.

European Commission (2012). Innovating for sustainable growth: A bioeconomy for Europe. Luxembourg: Publications Office of the European Union. https://doi.org/10.2777/6462

European Commission (2013a). Communication from the commission - A new EU forest strategy: for forests and the forest-based sector. https://eur-lex.europa.eu/legal-content/ EN/TXT/?uri=CELEX\%3A52013DC0659 [last accessed 29 May 2020].
European Commission (2013b). Flash Eurobarometer 379: Attitudes towards biodiversity. Luxembourg: DirectorateGeneral for Communication. https://data.europa.eu/euodp/en/ data/dataset/S1103_379 [last accessed 29 May 2020].

European Commisson (2016). Special Eurobarometer 440: Europeans, agriculture and the CAP. Luxembourg: DirectorateGeneral for Communication. https://data.europa.eu/euodp/en/ data/dataset/S2087_84_2_440_ENG [last accessed 29 May 2020].

European Commission (2017). Special Eurobarometer 468: Attitudes of European citizens towards the environment. Luxembourg: Directorate-General for Communication. https://data.europa.eu/euodp/en/data/dataset/ S2156_88_1_468_ENG [last accessed 29 May 2020].

European Commission (2020). Eurobarometer 501: Attitudes of European citizens towards the environment. Luxembourg: Directorate-General for Communication. https://data.europa.eu/euodp/en/data/dataset/ S2257_92_4_501_ENG [last accessed 29 May 2020].

Forestry Commission (2017), Public Opinion of Forestry. Edinburgh: Forest Research. https://www.forestresearch.gov. uk/tools-and-resources/statistics/statistics-by-topic/publicopinion-of-forestry/ [last accessed 29 May 2020].

Forestry Commission (2019), Public Opinion of Forestry. Edinburgh: Forest Research. https://www.forestresearch.gov. uk/tools-and-resources/statistics/statistics-by-topic/publicopinion-of-forestry/ [last accessed 29 May 2020].

Giurca, A. (2020). Unpacking the network discourse: Actors and storylines in Germany's wood-based bioeconomy. Forest Policy and Economics. Amsterdam: Elsevier, 110, 101754. https://doi.org/10.1016/j.forpol.2018.05.009

Hetemäki, L., Hanewinkel, M., Muys, B., Ollikainen, M., Palahí, M. and Trasobares, A. (2017). Leading the way to a European circular bioeconomy strategy. From Science to Policy 5. European Forest Institute. https://doi.org/10.36333/fs05

Hetemäki, L., Hoen, H. and Schwarzbauer, P. (2014). Conclusions and policy implications. In: L. Hetemäki, ed. Future of the European forest-based sector: Structural changes towards bioeconomy. What science can tell us 6 . European Forest Institute, pp. 95-108.

Hetemäki, L. (2017). Future of forest industry in bioeconomy. Lecture in 'Managerial economics and business strategy in forest industry' (course), University of Helsinki, 16 February 2017. https://doi.org/10.13140/RG.2.2.25828.78727 
Hodge, D., Brukas, V. and Giurca, A. (2017). Forests in a bioeconomy: bridge, boundary or divide? Scandinavian Journal of Forest Research, 32(7), pp. 582-587. https://doi.org $/ 10.1080 / 02827581.2017 .1315833$

Hurmekoski, E., Jonsson, R., Korhonen, J., Jänis, J., Mäkinen, M., Leskinen, P. and Hetemäki, L. (2018). Diversification of the forest industries: Role of new wood-based products. Canadian Journal of Forest Research, 48(12), pp. 1417-1432. https://doi.org/10.1139/cjfr-2018-0116

Hurmekoski, E., Lovrić, M., Lovrić, N., Hetemäki, L. and Winkel, G. (2019). Frontiers of the forest-based bioeconomy A European Delphi study. Forest Policy and Economics, 102, pp. 86-99. https://doi.org/10.1016/j.forpol.2019.03.008

Kleinschmit, D., Lindstad, B. H., Thorsen, B. J., Toppinen, A., Roos, A. and Baardsen, S. (2014). Shades of green: A social scientific view on bioeconomy in the forest sector. Scandinavian Journal of Forest Research, 29(4), pp. 402-410. http://dx.doi.org/10.1080/02827581.2014.921722

Korhonen, J., Giurca, A., Brockhaus, M. and Toppinen, A. (2018). Actors and politics in Finland's forest-based bioeconomy network. Sustainability, 10(10), p. 3785. https://doi.org/10.3390/su10103785

Kriechbaum, M., López Prol, J. and Posch, A. (2018). Looking back at the future: Dynamics of collective expectations about photovoltaic technology in Germany \& Spain. Technological Forecasting and Social Change, 129, pp. 76-87. https://doi.org/10.1016/j.techfore.2017.12.003

Leskinen, P., Cardellini, G., González-García, S., Hurmekoski, E., Sathre, R., Seppälä, J., Smyth, C., Stern, T. and Verkerk, P. J. (2018). Substitution effects of wood-based products in climate change mitigation. From Science to Policy 7. European Forest Institute. https://doi.org/10.36333/fs07

Lovell, R. and O'Brian, L. (2009). Wood you believe it? Children and young people's perceptions of climate change and the role of trees, woods and forests. Farnham: Forest Research.

Masiero, M., Secco, L., Pettenella, D., Da Re, R., Bernö, H., Carreira, A., Dobrovolsky, A., Giertlieova, B., Giurca, A., Holmgren, S., Mark-Herbert, C., Navrátilová, L., Pülzl, H., Ranacher, L., Salvalaggio, A., Sergent, A., Sopanen, J., Stelzer, C., Stetter, T., Valsta, L., Výbošt'ok, J. and Wallin, I. (in press). Bioeconomy perception by future stakeholders: hearing from European forestry students. Ambio: A Journal of the Human Environment. Royal Swedish Academy of Sciences.

McCormick, K. and Kautto, N. (2013). The Bioeconomy in Europe: An Overview. Sustainability, 5(6), 2589-2608. https://doi.org/10.3390/su5062589
Millennium Ecosystem Assessment (2005). Conceptual framework. In: R. M. Hassan, R. J. Scholes, N. Ash and Millennium Ecosystem Assessment, eds. Ecosystems and human wellbeing: Current state and trends findings of the Condition and Trends Working Group of the Millennium Ecosystem Assessment. Washington D. C.: Island Press.

Mustalahti, I. (2018). The responsive bioeconomy: The need for inclusion of citizens and environmental capability in the forest based bioeconomy. Journal of Cleaner Production, 172, pp. 3781-3790.

Näyhä, A., Hetemäki, L. and Stern, T. (2014). New products outlook. In: L. Hetemäki, ed. Future of the European forestbased sector: Structural changes towards bioeconomy. What science can tell us 6. European Forest Institute, pp. 43-54.

Näyhä, A., Pelli, P. and Hetemäki, L. (2015). Services in the forest-based sector - unexplored futures. Foresight, 17(4), pp. 378-398. https://doi.org/10.1108/FS-08-2013-0034

Ni Dhubháin, A., Stoettner, E., Ballweg, J. and Garcia, S. (2019). The socio-economic impact of forestry in Co. Leitrim. Dublin: Department of Agriculture, Food and the Marine. https://www.agriculture.gov.ie/media/migration/forestry/ publications/The\%20Socio-Economic\%20Impact\%20of\%20 Forestry\%20in\%20Co.\%20Leitrim\%20Final\%20Report.pdf [last accessed 3 June 2020].

Nyborg, K. (2000). Homo Economicus and Homo Politicus: interpretation and aggregation of environmental values. Journal of Economic Behavior and Organization, 42(3), 305-322. https://doi.org/10.1016/S0167-2681(00)00091-3

Paletto, A., Giacovelli, G. and Pastorella, F. (2017a). Stakeholders' opinions and expectations for the forest-based sector: A regional case study in Italy. International Forestry Review, 19(1), pp. 68-78(11). https://doi.org/10.1505/146554817820888654

Petticrew, M. and Roberts, H. (2006). Systematic reviews in the social sciences. A practical guide. Oxford: Blackwell Publishing. https://doi.org/10.1002/9780470754887

Pülzl, H., Kleinschmit, D. and Arts, B. (2014). Bioeconomy - An emerging meta-discourse affecting forest discourses? Scandinavian Journal of Forest Research, 29(4), pp. 386-393. https://doi.org/10.1080/02827581.2014.920044

Rametsteiner, E. and Kraxner, F. (2003). Europeans and their forests: What do Europeans think about forests and sustainable forest management? A review of representative public opinion surveys in Europe. Vienna: Ministerial conference on the protection of forests in Europe, Liaison Unit Vienna. 
Rametsteiner, E., Oberwimmer, R. and Gschwandtl, I. O. (2007). Europeans and wood. What do Europeans think about wood and its uses? A review of consumer and business surveys in Europe. Warsaw: Ministerial Conference on the Protection of Forests in Europe, Liaison Unit Warsaw.

Rametsteiner, E., Eichler, L., Berg, J., Aggestam, F., Zane, E. B. and Plumet, C. (2009). Shaping forest communication in the European Union: Public perceptions of forests and forestry. Rotterdam: European Commission - DG Agriculture and Rural Development.

Ranacher, L., Lähtinen, K., Järvinen, E. and Toppinen, A. (2017a). Perceptions of the general public on forest sector responsibility: A survey related to ecosystem services and forest sector business impacts in four European countries. Forest Policy and Economics, 78, pp. 180-189. http://dx.doi.org/10.1016/j.forpol.2017.01.016

Roos, A. and Stendahl, M. (2016). The emerging bioeconomy and the forest sector. In: R. Panwar, R. Kozak and E. Hansen eds. Forests, business and sustainability. New York: Earthscan, p. 179

Šimunović, N., Hesser, F. and Stern, T. (2018). Frame analysis of ENGO conceptualization of sustainable forest management: Environmental justice and neoliberalism at the core of sustainability. Sustainability, 10(9).

https://doi.org/10.3390/su10093165

Šimunović, N., Stern, T. and Hesser, F. (2019). Is sustainable forest management enough? Insights from a frame analysis of European environmental nongovernmental organizations. Austrian Journal of Forest Science, 136(2), pp. 87-140. Retrieved from https://www. scopus.com/inward/record.uri?eid=2-s2.0-85074327744\&pa rtnerlD $=40 \& \mathrm{md} 5=5 f 29 \mathrm{~d} 255 \mathrm{e} 4 \mathrm{bc} 638 \mathrm{fd} 0 \mathrm{c} 6 \mathrm{~b} 6 \mathrm{~d} 8 \mathrm{f} 4 \mathrm{f} 232 \mathrm{f} 8$

Stein M., Giurca, A. and Kleinschmit, D. (2018). „Wir sind die Bioökonomie" - Perspektiven von Akteuren aus dem deutschen Forst- und Holzsektor. Allgemeine Forst und Jagdzeitung.

Stern, T., Ledl, C., Braun, M., Hesser, F. and Schwarzbauer, P. (2015). Biorefineries' impacts on the Austrian forest sector: A system dynamics approach. Technological Forecasting and Social Change, 91, pp. 311-326.

Stern, T., Ploll, U., Spies, R., Schwarzbauer, P., Hesser, F. and Ranacher, L. (2018). Understanding perceptions of the bioeconomy in Austria: An explorative case study. Sustainability, 10(11). https://doi.org/10.3390/su10114142

Stevanov, M., Dobšinska, Z. and Surový, P. (2016). Assessing survey-based research in forest science: Turning lemons into lemonade? Forest Policy and Economics, 68, pp. 105-117. http://dx.doi.org/10.1016/j.forpol.2015.07.004
UNECE, FAO (2016). Forest Products Annual Market Review 2015-2016. United Nations Publications.

Winkel, G. ed. (2017). Towards a sustainable European forestbased bioeconomy - assessment and the way forward. What science can tell us 8 . European Forest Institute.

Wüstenhagen, R., Wolsink, M., \& Bürer, M. J. (2007). Social acceptance of renewable energy innovation: An introduction to the concept. Energy Policy, 35(5), 2683-2691. doi: https://doi.org/10.1016/j.enpol.2006.12.001 


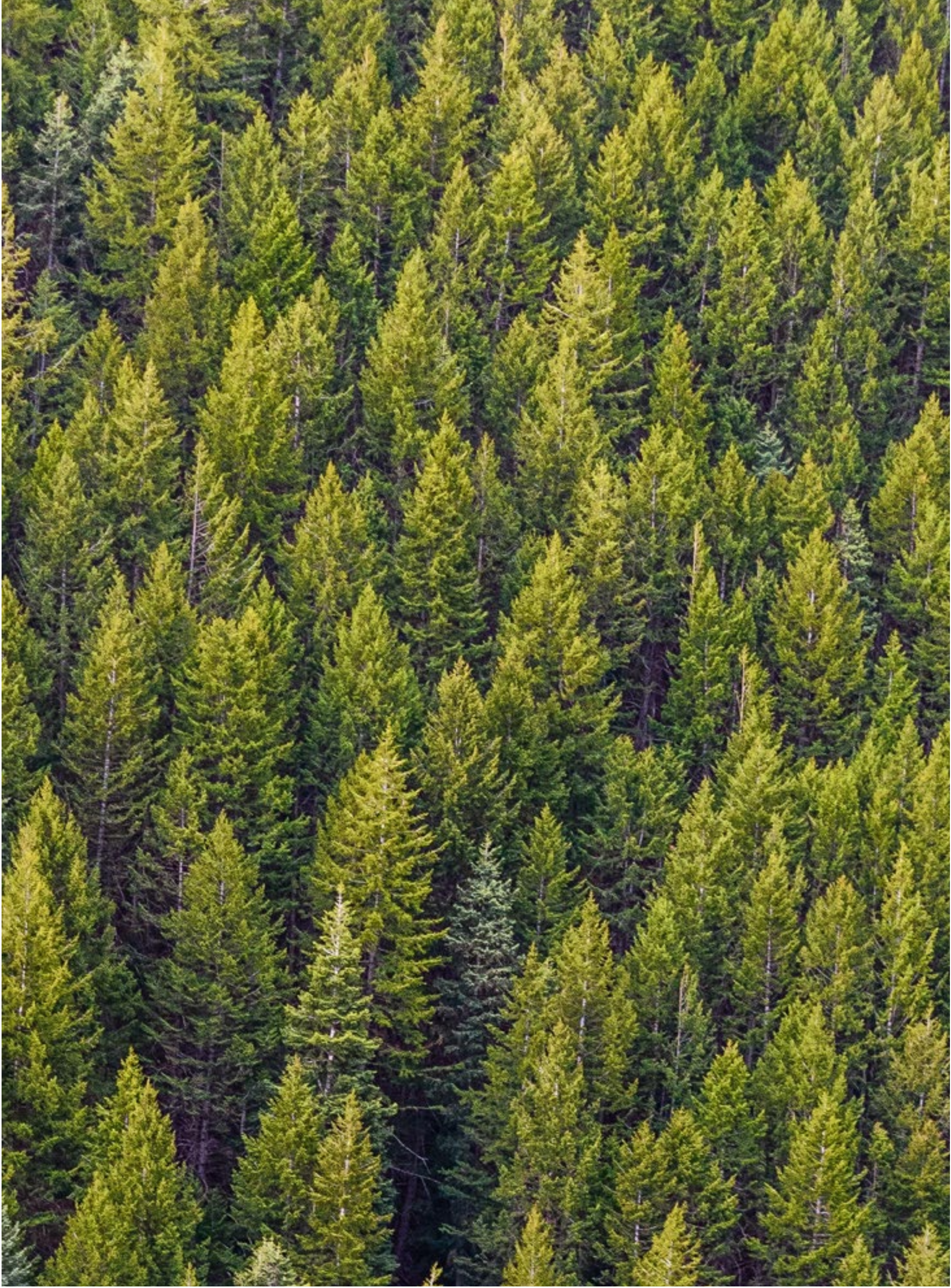




\section{List of reviewed studies}

Almeida, I., Rösch, C., and Saha, S. (2018). Comparison of ecosystem services from mixed and monospecific forests in Southwest Germany: A survey on public perception. Forests, 9(10). doi:10.3390/f9100627

Arnberger, A., Eder, R., Allex, B., Preisel, H., Ebenberger, M. and Husslein, M. (2018). Trade-offs between wind energy, recreational, and bark-beetle impacts on visual preferences of national park visitors. Land Use Policy, 76, 166-177. doi:10.1016/j.landusepol.2018.05.007

Burnard, M. D., Nyrud, A. Q., Bysheim, K., Kutnar, A., Vahtikari, K. and Hughes, M. (2015). Building material naturalness: Perceptions from Finland, Norway and Slovenia. Indoor and Built Environment, 26(1), 92-107. doi:10.1177/1420326X15605162

Carvalho-Ribeiro, S. M. and Lovett, A. (2011). Is an attractive forest also considered well managed? Public preferences for forest cover and stand structure across a rural/urban gradient in northern Portugal. Forest Policy and Economics, 13(1), 46-54. doi:10.1016/j.forpol.2010.09.003

Costa, S., Garcia, S. and Ibanez, L. (2011). Do taste and quality perception influence consumer preferences for wood? An econometric model with latent variables. Forest Science, 57(2), 89-101.

Czajkowski, M., Budziński, W., Campbell, D., Giergiczny, M. and Hanley, N. (2017). Spatial Heterogeneity of Willingness to Pay for Forest Management. Environmental and Resource Economics, 68(3), 705-727. doi:10.1007/s10640-016-0044-0

Dobsinska, Z., and Sarvasova, Z. (2016). Perceptions of forest owners and the general public on the role of forests in Slovakia. Acta Silvatica et Lignaria Hungarica, 12(1), 23-34. doi:10.1515/aslh-2016-0003

Drábková, A. (2014). Opinions and preferences of forest visitors to the Protected Landscape Area Blaník. Scientia Agriculturae Bohemica, 45(2), 110-116. doi:10.7160/ sab.2014.450206

Eriksson, L., Björkman, C. and Klapwijk, M. J. (2018). General public acceptance of forest risk management strategies in Sweden: Comparing three approaches to acceptability. Environment and Behavior, 50(2), 159-186. doi:10.1177/0013916517691325

Eriksson, L., Nordlund, A., Olsson, O. and Westin, K. (2012). Beliefs about urban fringe forests among urban residents in Sweden. Urban Forestry and Urban Greening, 11(3), 321-328. doi:10.1016/j.ufug.2012.02.004
Fabra-Crespo, M., Mola-Yudego, B., Gritten, D. and RojasBriales, E. (2012). Public perception on forestry issues in the region of Valencia (Eastern Spain): Diverging from policy makers? Forest Systems, 21(1), 99-100. doi:10.5424/ fs/2112211-11309

Giergiczny, M., Czajkowski, M., Zylicz, T. and Angelstam, P. (2015). Choice experiment assessment of public preferences for forest structural attributes. Ecological Economics, 119, 8-23. doi:10.1016/j.ecolecon.2015.07.032

Goodwin, S., Brogaard, S. and Krause, T. (2019). Values held by Swedish primary school students towards forest ecosystems and the relevance for a nature's contributions to people approach. Ecosystems and People, 15(1), 331-346. do i:10.1080/26395916.2019.1687585

Gutsch, M., Larondelle, N. and Haase, D. (2019). Of bugs and men: How forest pests and their management strategies are perceived by visitors of an urban forest. Urban Forestry and Urban Greening, 41, 248-254. doi:10.1016/j.ufug.2019.03.003

Halder, P., Havu-Nuutinen, S., Pietarinen, J. and Pelkonen, P. (2011). Bio-energy and youth: Analyzing the role of school, home, and media from the future policy perspectives. Applied Energy, 88(4), 1233-1240. doi:10.1016/j. apenergy.2010.10.017

Hauru, K., Koskinen, S., Kotze, D. J. and Lehvävirta, S. (2014). The effects of decaying logs on the aesthetic experience and acceptability of urban forests - Implications for forest management. Landscape and Urban Planning, 123, 114-123. doi:10.1016/j.landurbplan.2013.12.014

Hemström, K., Mahapatra, K. and Gustavsson, L. (2014). Public perceptions and acceptance of intensive forestry in Sweden. Ambio, 43(2), 196-206. doi:10.1007/s13280-0130411-9

Holopainen, J. M., Häyrinen, L. and Toppinen, A. (2014). Consumer value dimensions for sustainable wood products: Results from the Finnish retail sector. Scandinavian Journal of Forest Research, 29(4), 378-385. doi:10.1080/02827581.201 4.925138

Howley, P., Ryan, M., and Donoghue, C. O. (2011). Forestry in Ireland: An examination of individuals' preferences and attitudes towards the non-market benefits of forests. Irish Geography, 44(2-3), 291-302. doi:10.1080/00750778.2011.6 43392

Huber, J., Ranacher, L., Stern, T. and Schwarzbauer, P. (2017). Forest management or greed of gain?-An information experiment on peri-urban forest visitors' attitudes regarding harvesting operations. Urban Forestry and Urban Greening, 27, 214-220. doi:10.1016/j.ufug.2017.08.005 
Jepson, P. and Arakelyan, I. (2017b). Exploring public perceptions of solutions to tree diseases in the UK: Implications for policy-makers. Environmental Science and Policy, 76, 70-77. doi:10.1016/j.envsci.2017.06.008

Jepson, P. R. and Arakelyan, I. (2017a). Developing publicly acceptable tree health policy: public perceptions of treebreeding solutions to ash dieback among interested publics in the UK. Forest Policy and Economics, 80, 167-177. doi:10.1016/j.forpol.2017.03.002

Jiménez, P., Dunkl, A., Eibel, K., Denk, E., Grote, V., Kelz, C. and Moser, M. (2015). Evaluating psychological aspects of wood and laminate products in indoor settings with pictures. Forest Products Journal, 65(5-6), 263-271. doi:10.13073/ FPJ-D-14-00003

Juutinen, A., Kosenius, A. K., Ovaskainen, V., Tolvanen, A. and Tyrväinen, L. (2017). Heterogeneous preferences for recreation-oriented management in commercial forests: the role of citizens' socioeconomic characteristics and recreational profiles. Journal of Environmental Planning and Management, 60(3), 399-418. doi:10.1080/09640568.2016.1159546

Kitek Kuzman, M., Medved, S. and Vratus̈a, S. (2010). Evaluation of slovenian contemporary timber construction. Drewno, 183, 85-100.

Knauf, M. (2015). Understanding the consumer: Multi-modal market research on consumer attitudes in Germany towards lightweight furniture and lightweight materials in furniture design. European Journal of Wood and Wood Products, 73(2), 259-270. doi:10.1007/s00107-014-0866-9

Krejčí, H., Stárová, M., Hrbek, I., Navrátilová, M. and Beranová, M. (2019). The perception of forests by the Czech Republic general public. Journal of Forest Science, 65(6), 226-233. doi:10.17221/138/2018-JFS

Kronholm, T. and Staal Wästerlund, D. (2017). Elucidation of young adults' relationships to forests in northern Sweden using forest story cards. Scandinavian Journal of Forest Research, 32(7), 607-619. doi:10.1080/02827581.2016.1269942

Kuzman, M. K., Motik, D., Bičanić, K., Vlosky, R. P. and Oblak, L. (2012). A comparative analysis of consumer attitudes on the use of wood products in Slovenia and Croatia. Drvna Industrija, 63(2), 71-79. doi:10.5552/drind.2012.1129

Lindberg, S., Roos, A., Kihlstedt, A. and Lindström, M. (2013). A product semantic study of the influence of the sense of touch on the evaluation of wood-based materials. Materials and Design, 52, 300-307. doi:10.1016/j.matdes.2013.05.069

Lupp, G., Förster, B., Kantelberg, V., Markmann, T., Naumann, J., Honert, C., . . Pauleit, S. (2016). Assessing the recreation value of urban woodland using the ecosystem service approach in two forests in the munich metropolitan region. Sustainability (Switzerland), 8(11). doi:10.3390/su8111156
Lähtinen, K., Harju, C. and Toppinen, A. (2019). Consumers' perceptions on the properties of wood affecting their willingness to live in and prejudices against houses made of timber. Wood Material Science and Engineering, 14(5), 325-331. doi:10.1080/17480272.2019.1615548

Matthies, B. D., Vainio, A. and D'Amato, D. (2018). Not so biocentric - Environmental benefits and harm associated with the acceptance of forest management objectives by future environmental professionals. Ecosystem Services, 29, 128136. doi:10.1016/j.ecoser.2017.12.003

Meyer, M. A., Rathmann, J. and Schulz, C. (2019). Spatiallyexplicit mapping of forest benefits and analysis of motivations for everyday-life's visitors on forest pathways in urban and rural contexts. Landscape and Urban Planning, 185, 83-95. doi:10.1016/j.landurbplan.2019.01.007

Mizaras, S. and Mizaraitè, D. (2015). Integrated economic and social approaches for the evaluation of forest management sustainability: The case of Lithuania. Baltic Forestry, 21(1), 96-105.

Moresová, M., Sedliačiková, M., Štefko, J. and Benčiková, D. (2019). Perception of wooden houses in the Slovak republic. Acta Facultatis Xylologiae Zvolen, 61(2), 121-135. doi:10.17423/afx.2019.61.2.12

Nijnik, M., Nijnik, A. and Brown, I. (2016). Exploring the linkages between multifunctional forestry goals and the legacy of spruce plantations in Scotland. Canadian Journal of Forest Research, 46(10), 1247-1254. doi:10.1139/cjfr-2015-0399

Nonić, M., Nedeljkovic, J., Radojevic, U., Vettori, C. and Šijacic-Nikolic, M. (2014). State and perspectives of genetically modified trees in some western Balkan countries. In Tree Biotechnology (pp. 366-391).

Nordlund, A., Schenk, T. and Westin, K. (2017). Forest Beliefs in an Urbanizing World: Views on and Usage of Forest Areas Among Persons with and Without a Migration Biography in Germany and Sweden. Society and Natural Resources, 30(2), 160-176. doi:10.1080/08941920.2016.1238988

Nummelin, T., Widmark, C., Riala, M., Sténs, A., Nordström, E. M. and Nordin, A. (2017). Forest future s by Swedish studentsdeveloping a mind mapping method for data collection. Scandinavian Journal of Forest Research, 32(8), 807-817. doi: 10.1080/02827581.2017.1287303

Olšiaková, M., Loučanová, E. and Paluš, H. (2016). Monitoring changes in consumer requirements for wood products in terms of consumer behavior. Acta Facultatis Xylologiae, 58(1), 137-147. doi:10.17423/afx.2016.58.1.15

Orzan, G., Cruceru, A. F., Balaceanu, C. T., and Chivu, R. G. (2018). Consumers' behavior concerning sustainable packaging: An exploratory study on Romanian consumers. Sustainability (Switzerland), 10(6). doi:10.3390/su10061787 
Osburg, V. S. (2016a). An empirical investigation of the determinants influencing consumers' planned choices of eco-innovative materials. International Journal of Innovation and Sustainable Development, 10(4), 339-360. doi:10.1504/ IJISD.2016.079580

Osburg, V. S., Appelhanz, S., Toporowski, W. and Schumann, M. (2016b). An empirical investigation of wood product information valued by young consumers. Journal of Cleaner Production, 110, 170-179. doi:10.1016/j.jclepro.2015.01.068

Osburg, V. S., Strack, M., and Toporowski, W. (2016c). Consumer acceptance of Wood-Polymer Composites: A conjoint analytical approach with a focus on innovative and environmentally concerned consumers. Journal of Cleaner Production, 110, 180-190. doi:10.1016/j.jclepro.2015.04.086

Pacurar, V. D. and Albu, R. G. (2018). Brasov community perception about forests functions. Bulletin of the Transilvania University of Brasov, Series II: Forestry, Wood Industry, Agricultural Food Engineering, 11(12-60), 21-28.

Paletto, A., Maino, F., De Meo, I. and Ferretti, F. (2013a). Perception of forest values in the alpine community of Trentino region (Italy). Environmental Management, 51(2), 414-422. doi:10.1007/s00267-012-9974-7

Paletto, A., De Meo, I., Cantiani, M. G., and Maino, F. (2013b). Social perceptions and forest management strategies in an Italian alpine community. Mountain Research and Development, 33(2), 152-160. doi:10.1659/MRDJOURNAL-D-12-00115.1

Paletto, A., Guerrini, S. and De Meo, I. (2017). Exploring visitors' perceptions of silvicultural treatments to increase the destination attractiveness of peri-urban forests: A case study in Tuscany Region (Italy). Urban Forestry and Urban Greening, 27, 314-323. doi:10.1016/j.ufug.2017.06.020

Paluš, H., Mat'ová, H. and Kaputa, V. (2012). Consumer preferences for joinery products and furniture in Slovakia and Poland. Acta Facultatis Xylologiae, 54(2), 123-132.

Panico, T., Pagnani, T. and Caracciolo, F. (2018). Intention to purchase sustainable wood products: An empirical analysis of the determinants. International Journal on Food System Dynamics, 9(4), 342-353. doi:10.18461/ijfsd.v9i4.945

Pastorella, F., Avdagić, A., Čabaravdić, A., Mraković, A., Osmanović, M. and Paletto, A. (2016). Tourists' perception of deadwood in mountain forests. Annals of Forest Research, 59(2), 311-326. doi:10.15287/afr.2016.482

Pätäri, S., Arminen, H., Albareda, L., Puumalainen, K. and Toppinen, A. (2017). Student values and perceptions of corporate social responsibility in the forest industry on the road to a bioeconomy. Forest Policy and Economics, 85, 201-215. doi:10.1016/j.forpol.2017.10.009
Rambonilaza, T. and Brahic, E. (2016). Non-market values of forest biodiversity and the impact of informing the general public: Insights from generalized multinomial logit estimations. Environmental Science and Policy, 64, 93-100. doi:10.1016/j. envsci.2016.06.008

Ranacher, L., Höfferer, K., Lettner, M., Hesser, F., Stern, T., Rauter, R. and Schwarzbauer, P. (2018). What would potential future opinion leaders like to know? An explorative study on the perceptions of four wood-based innovations. Bodenkultur, 69(1), 47-59. doi:10.2478/boku-2018-0005

Ranacher, L., Lähtinen, K., Järvinen, E. and Toppinen, A. (2017a). Perceptions of the general public on forest sector responsibility: A survey related to ecosystem services and forest sector business impacts in four European countries. Forest Policy and Economics, 78, 180-189. doi:10.1016/j. forpol.2017.01.016

Ranacher, L. and Stern, T. (2015) Are your messages being heard? Evaluation of the forest-based sector's communication on sustainable forest management in Austria. In: Vol. 25. Journal of the Austrian Society of Agricultural Economics (pp. 159-168).

Ranacher, L., Stern, T. and Schwarzbauer, P. (2017b). Do wood products protect the climate? Public perception of the forestbased sector's contribution to climate change mitigation. Austrian Journal of Forest Science, 2017(3), 281-298.

Riccioli, F., Marone, E., Boncinelli, F., Tattoni, C., Rocchini, D. and Fratini, R. (2019). The recreational value of forests under different management systems. New Forests, 50(2), 345-360. doi:10.1007/s11056-018-9663-3

Sheremet, O., Healey, J. R., Quine, C. P. and Hanley, N. (2017). Public Preferences and Willingness to Pay for Forest Disease Control in the UK. Journal of Agricultural Economics, 68(3), 781-800. doi:10.1111/1477-9552.12210

Šišák, L. (2011). Forest visitors' opinions on the importance of forest operations, forest functions and sources of their financing. Journal of Forest Science, 57(6), 266-270.

Solberg, B. and Veisten, K. (2011). An exploratory study of eco-oriented consumer segments at a retail store. International Journal of Environment and Sustainable Development, 10(2), 137-152. doi:10.1504/IJESD.2011.041970

Stachová, J. (2018). Forests in the Czech public discourse. Journal of Landscape Ecology(Czech Republic), 11(3), 33-44. doi:10.2478/jlecol-2018-0011 
Stern, T., Ranacher, L., Mair, C., Berghäll, S., Lähtinen, K., Forsblom, M., and Toppinen, A. (2018). Perceptions on the importance of forest sector innovations: Biofuels, biomaterials, or niche products? Forests, 9(5). doi:10.3390/f9050255

Švajlenka, J. and Kozlovská, M. (2018b). Quality parameters perception of modern methods of construction based on wood in the context of sustainability. Periodica Polytechnica Civil Engineering, 62(3). doi:10.3311/PPci.11224

Toivonen, R. M. (2012). Product quality and value from consumer perspective-An application to wooden products. Journal of Forest Economics, 18(2), 157-173. doi:10.1016/j. jfe.2011.12.004

Toppinen, A., Toivonen, R., Valkeapää, A. and Rämö, A. K. (2013). Consumer perceptions of environmental and social sustainability of wood products in the Finnish market. Scandinavian Journal of Forest Research, 28(8), 775-783. doi: 10.1080/02827581.2013.824021

Torkar, G. and Krašovec, U. (2019). Students' attitudes toward forest ecosystem services, knowledge about ecology, and direct experience with forests. Ecosystem Services, 37. doi:10.1016/j.ecoser.2019.100916

Tsourgiannis, L., Kazana, V. and lakovoglou, V. (2015). Exploring the potential behavior of consumers towards transgenic forest products: The Greek experience. IForest, 8(OCTOBER2015), 707-713. doi:10.3832/ifor1339-007

Tsourgiannis, L., Kazana, V., Karasavvoglou, A., Tsourgiannis, C. A., Florou, G. and Polychronidou, P. (2013). Exploring consumers attitudes towards paper products that could be derived from transgenic plantations in Greece. International Journal of Data Analysis Techniques and Strategies, 7(2), 156-171. doi:10.1504/IJDATS.2015.068748

Tyrväinen, L., Silvennoinen, H. and Hallikainen, V. (2017). Effect of the season and forest management on the visual quality of the nature-based tourism environment: a case from Finnish Lapland. Scandinavian Journal of Forest Research, 32(4), 349-359. doi:10.1080/02827581.2016.1241892

Upton, V., Dhubháin, A. N. and Bullock, C. (2012). Preferences and values for afforestation: The effects of location and respondent understanding on forest attributes in a labelled choice experiment. Forest Policy and Economics, 23, 17-27. doi:10.1016/j.forpol.2012.06.006

Upton, V., Dhubháin, Á. N. and Bullock, C. (2015). Are Forest Attitudes Shaped by the Extent and Characteristics of Forests in the Local Landscape? Society and Natural Resources, 28(6), 641-656. doi:10.1080/08941920.2014.933925
Valasiuk, S., Czajkowski, M., Giergiczny, M., Żylicz, T., Veisten, K., Landa Mata, I., . . . Angelstam, P. (2018). Is forest landscape restoration socially desirable? A discrete choice experiment applied to the Scandinavian transboundary Fulufjället National Park Area. Restoration Ecology, 26(2), 370-380. doi:10.1111/rec.12563

Valkeapää, A. and Karppinen, H. (2013). Citizens' view of legitimacy in the context of Finnish forest policy. Forest Policy and Economics, 28, 52-59. doi:10.1016/j.forpol.2013.01.004

Van Dael, M., Lizin, S., Swinnen, G. and Van Passel, S. (2017). Young people's acceptance of bioenergy and the influence of attitude strength on information provision. Renewable Energy, 107, 417-430. doi:10.1016/j.renene.2017.02.010

Varela, E., Jacobsen, J. B. and Mavsar, R. (2017). Social demand for multiple benefits provided by Aleppo pine forest management in Catalonia, Spain. Regional Environmental Change, 17(2), 539-550. doi:10.1007/s10113-016-1038-8 


\section{Annex}

\begin{tabular}{|l|l|l|}
\multicolumn{1}{l|}{ Region } & \multicolumn{1}{l}{ Countries from articles } & 18 \\
\hline Northern Europe & Finland and Sweden & 10 \\
\hline \hline Western Europe & Belgium, France, Ireland and United Kingdom & 14 \\
\hline \hline Central Europe & Austria and Germany & 10 \\
\hline \hline Southern Europe & Greece, Italy, Portugal and Spain & 18 \\
\hline \hline Eastern Europe & $\begin{array}{l}\text { Croatia, Czech Republic, Lithuania, Poland, Romania, Slovakia } \\
\text { and Slovenia }\end{array}$ \\
\hline
\end{tabular}

Table 5. Categorisation of region

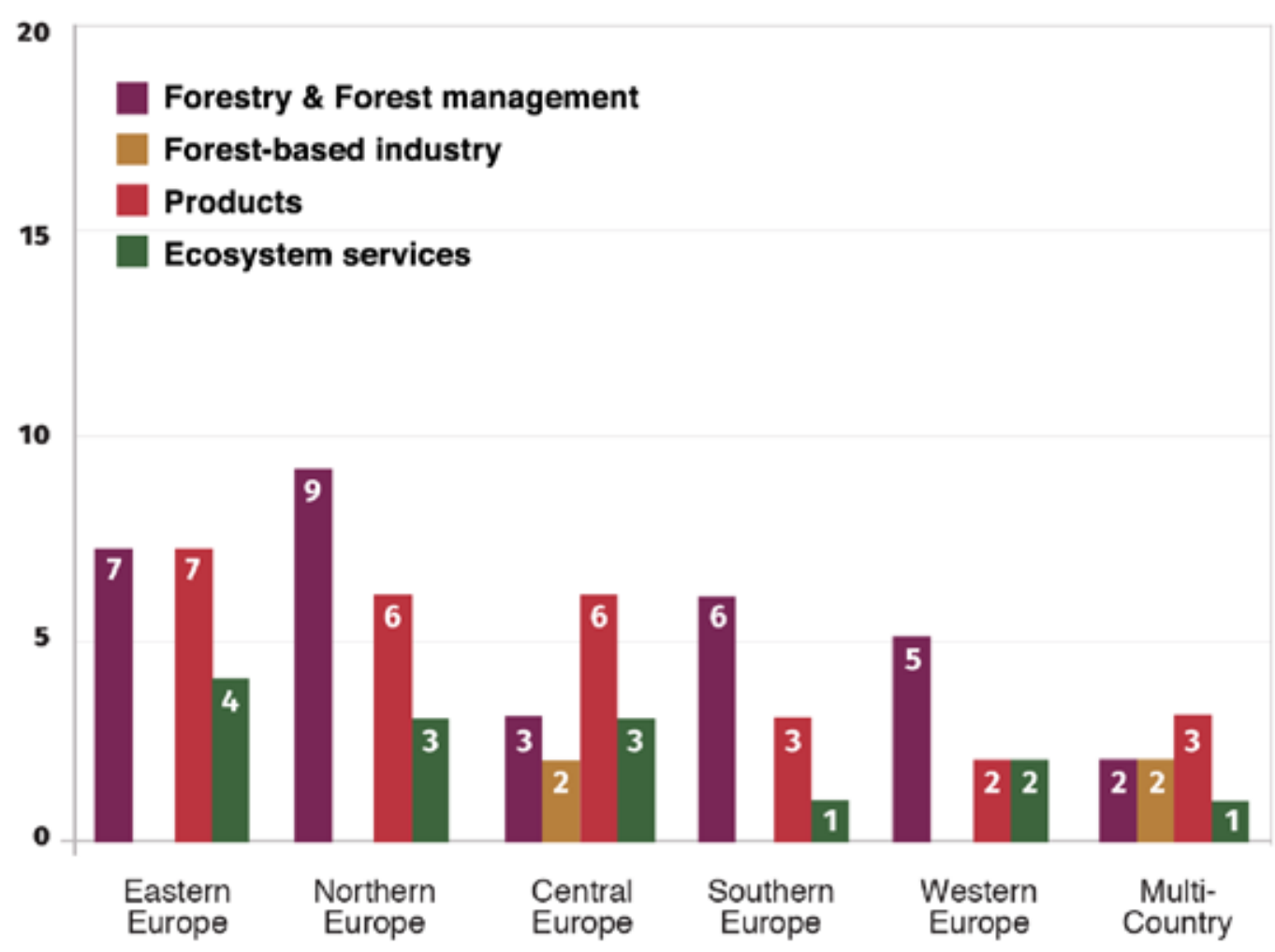

Figure 13. Distribution of topics by region, sorted by descending total value 
Journal

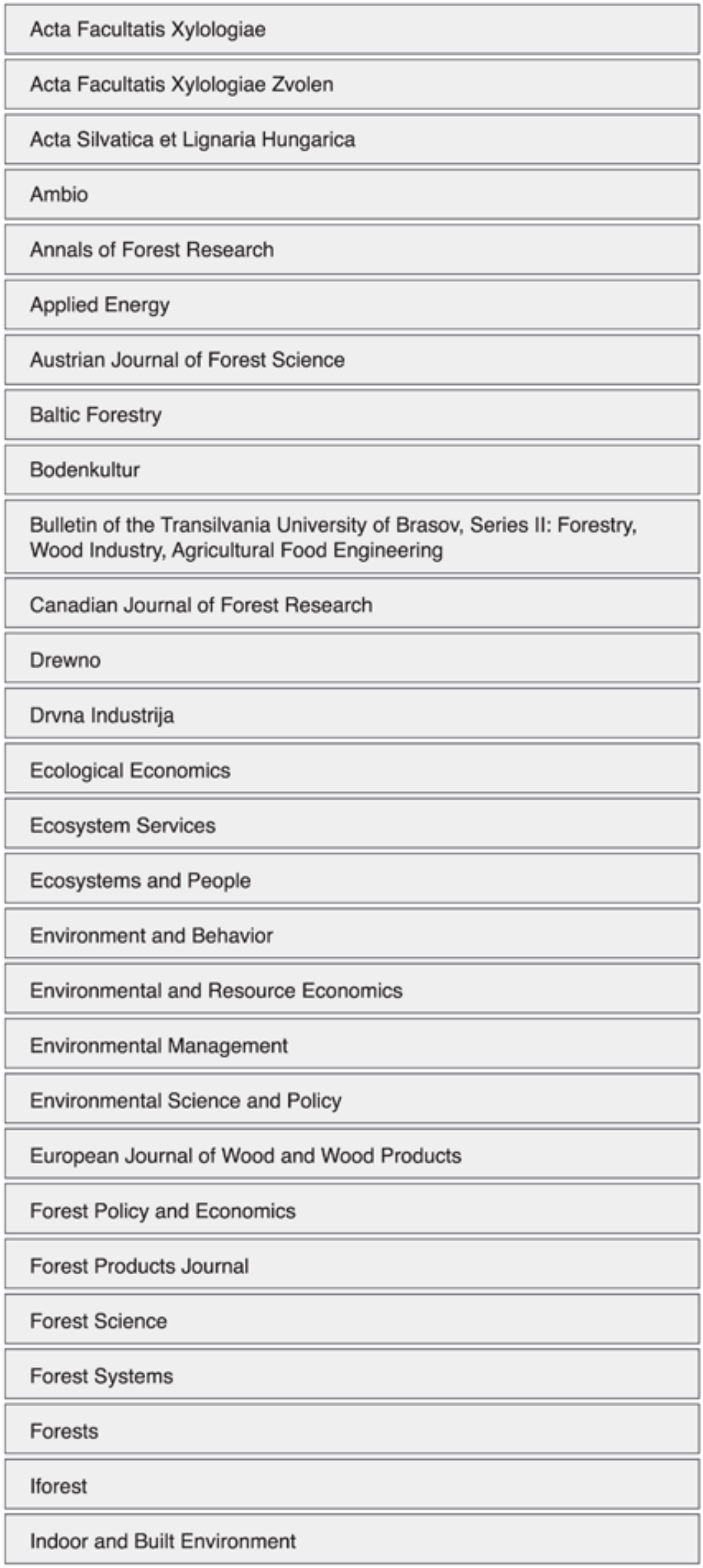

\section{Category}

\begin{tabular}{|l|}
\hline Forestry \\
\hline \hline Forestry \\
\hline \hline Forestry \\
\hline \hline Environment \\
\hline
\end{tabular}

\begin{tabular}{|l|}
\hline Forestry \\
\hline \hline Energy \\
\hline Forestry \\
\hline \hline Forestry \\
\hline \hline Environment \\
\hline
\end{tabular}

\begin{tabular}{|l|}
\hline Forestry \\
\hline \hline Forestry \\
\hline
\end{tabular}

\begin{tabular}{|l|}
\hline Forestry \\
\hline \hline Forestry \\
\hline
\end{tabular}

\begin{tabular}{|l|}
\hline Environment \\
\hline \hline Environment \\
\hline \hline Environment \\
\hline \hline Environment \\
\hline
\end{tabular}

\begin{tabular}{|l|}
\hline Environment \\
\hline Environment \\
\hline Environment \\
\hline
\end{tabular}

\begin{tabular}{|l|}
\hline Forestry \\
\hline Forestry \\
\hline
\end{tabular}

\begin{tabular}{|l|}
\hline Forestry \\
\hline Forestry \\
\hline Forestry \\
\hline
\end{tabular}

\begin{tabular}{|l|}
\hline Forestry \\
\hline \hline Forestry \\
\hline \hline Environment \\
\hline
\end{tabular}

\section{Number of articles}

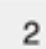

1

\section{1}

1

1

1

1

1

1

1

1

1

1

1

2

1

1

1

1

2

1

6

1

1

1

2

1

1

1
1
1
1
1
1
1
1

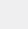

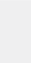

.

1

1

2

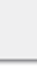

1

1

2

\begin{tabular}{|l|}
\hline 1 \\
\hline 6 \\
\hline 1 \\
\hline 1 \\
\hline 1 \\
\hline 2 \\
\hline 1 \\
\hline 1 \\
\hline
\end{tabular}

\begin{tabular}{|l|}
\hline 1 \\
\hline 6 \\
\hline 1 \\
\hline 1 \\
\hline 1 \\
\hline 2 \\
\hline 1 \\
\hline 1 \\
\hline
\end{tabular}




\section{Journal}

International Journal of Environment and Sustainable Development

International Journal of Innovation and Sustainable Development

International Journal on Food System Dynamics

Irish Geography

Journal of Agricultural Economics

Journal of Cleaner Production

Journal of Environmental Planning and Management

Journal of Forest Economics

Journal of Forest Science

Journal of Landscape Ecology (Czech Republic)

Journal of the Austrian Society of Agricultural Economics

Land Use Policy

Landscape and Urban Planning

Materials and Design

Mountain Research and Development

New Forests

Periodica Polytechnica Civil Engineering

Procedia Technology

Regional Environmental Change

Renewable Energy

Restoration Ecology

Scandinavian Journal of Forest Research

Scientia Agriculturae Bohemica

Society and Natural Resources

Sustainability (Switzerland)

Tree Biotechnology

Urban Forestry and Urban Greening

Wood Material Science and Engineering

\section{Category}

\begin{tabular}{|l|}
\hline Environment \\
\hline Environment \\
\hline Agriculture/Food \\
\hline Geography \\
\hline
\end{tabular}

\begin{tabular}{|l|}
\hline Agriculture \\
\hline Production \\
\hline
\end{tabular}

Environment

\begin{tabular}{l} 
Forestry \\
\hline Forestry \\
\hline
\end{tabular}

Ecology

Agriculture

Landscape

Landscape

Production

Mountain

Forestry

Engineering

Engineering

Environment

Energy

Forestry

\begin{tabular}{|l|}
\hline Agriculture \\
\hline Environment \\
\hline
\end{tabular}

\begin{tabular}{|l|}
\hline Environment \\
\hline Forestry
\end{tabular}

Forestry

Forestry

\section{Number of articles}

1

1

1

1

1

2

1

1

2

1

1

1

2

1

1

1

1

1

1

1

1

5

1

2

2

1

4

1 
Author and year

Almeida et al. 2018
Country

Germany
Target group, sample size

Other, $\mathrm{N}=520$
Data collection

Convenience sampling postal and online surveys
Study aim

Study aim

Study aim

Study aim

Study aim

Study aim

Study aim

Study aim

What are respondents' preferences when comparing mixed and monospecific forests of fir and beech? What are respondents' perceptions on ecosystem services provided by mixed forests compared to monospecific forests of fir and beech?

How are respondents' perceptions influenced by social profiles, such as age and profession, as well as their habits and preferences?

\begin{tabular}{|c|c|c|c|}
\hline Arnberger et al. 2018 & Germany & $\begin{array}{l}\text { Forest visitors, } \\
\mathrm{N}=514\end{array}$ & $\begin{array}{l}\text { Convenience sampling, } \\
\text { face-to-face }\end{array}$ \\
\hline
\end{tabular}

What are the visual preferences of national park visitors for technical and recreational infrastructures, barkbeetle impacted and non-impacted forest stands, and visitor numbers and composition? Do visitor preferences vary by viewing distances of technical infrastructures and forest stands in the landscape? What trade-offs do visitors make between technical, forest, infrastructural and social factors, and which factors influence visitors' preferences most? Are there differences in visual landscape preferences between tourists and local residents?

\begin{tabular}{|l||l|l|l|}
\hline Burnard et al. 2015 & $\begin{array}{l}\text { Finland, Norway, } \\
\text { Slovenia }\end{array}$ & $\begin{array}{l}\text { Local or regional } \\
\text { population, } \mathrm{N}=111\end{array}$ & $\begin{array}{l}\text { Convenience sampling, } \\
\text { face-to-face }\end{array}$ \\
\hline
\end{tabular}

To understand user perceptions of building material naturalness. Of special interest was identifying the materials identified as most natural and least natural.

\begin{tabular}{|c|c|c|c|}
\hline $\begin{array}{l}\text { Carvalho-Ribeiro et } \\
\text { al. } 2011\end{array}$ & Portugal & $\begin{array}{l}\text { Local or regional } \\
\text { population, } \mathrm{N}=375\end{array}$ & $\begin{array}{l}\text { Convenience sampling, } \\
\text { face-to-face }\end{array}$ \\
\hline
\end{tabular}

Do public preferences for level of forest cover and stand structure vary according to whether attractiveness or management objectives are considered?

Are there differences in aesthetic and management preferences across different user groups? Are there indications that public preferences might threaten the ecological functioning of forests by compromising the provision of ecosystem services? Do the results vary according to whether verbal or visual approaches are used?

\begin{tabular}{|l|l|l|l|}
\hline Costa et al. 2011 & France & Consumers, N=940 & Quota sampling \\
\hline
\end{tabular}

The data concern hypothetical purchase choices for specific materials (vinyl and wood) in the French window market. We assume that consumers do not necessarily place the same values on these window materials.

\begin{tabular}{|c|c|c|c|}
\hline $\begin{array}{l}\text { Czajkowski et al. } \\
2017\end{array}$ & Poland & $\begin{array}{l}\text { General public, } \\
N=1001\end{array}$ & $\begin{array}{l}\text { Random and stratified random } \\
\text { sampling }\end{array}$ \\
\hline
\end{tabular}

The main objective of our paper is to identify spatial determinants and spatial clustering of willingness to pay (WTP) for forest attributes in Poland.

\begin{tabular}{|c|c|c|c|}
\hline Dobsinska et al. 2016 & Slovakia & $\begin{array}{l}\text { General public, } \\
N=1503\end{array}$ & $\begin{array}{l}\text { Random and stratified random } \\
\text { sampling }\end{array}$ \\
\hline
\end{tabular}

Two surveys regarding the awareness of the general public and forest owners about forests, sustainable forest management, and ecosystem services.

Drábková et al. 2014

Czech Republic
Forest visitors, $\mathrm{N}=242$
Convenience sampling, face-toface

What would the forest which respondents want to visit look like? 
Author and year

Eriksson et al. 2012
Country

Sweden
Target group, sample size

General public,
Data collection

Convenience sampling postal and online surveys
Study aim

Study aim

Study aim

Study aim

Study aim

Study aim

Study aim

Study aim

Study aim

Examine whether urban fringe forest beliefs are influenced by socio-demographics, basic values and an ecological worldview, as well as forest values and forest beliefs. Urban residents' beliefs concerning three themes relevant for urban fringe forests.

\begin{tabular}{|l|l|l|l|}
\hline Eriksson et al. 2018 & \begin{tabular}{|l|l|l|} 
Local or regional \\
population, $\mathrm{N}=1026$
\end{tabular} & $\begin{array}{l}\text { Random and stratified random } \\
\text { sampling }\end{array}$ \\
\hline
\end{tabular}

To compare different approaches to acceptability of forest risk management in the public in Sweden.

\begin{tabular}{|l|l|l|l|}
\hline $\begin{array}{l}\text { Fabra-Crespo et al. } \\
2012\end{array}$ & Spain & $\begin{array}{l}\text { Local or regional } \\
\text { population, } \mathrm{N}=823\end{array}$ & Quota sampling \\
\hline
\end{tabular}

Main views of the citizens on key forest topics with the forest policies developed during recent years.

Contribute to a better understanding of the interrelations between public opinion and policy makers.

\begin{tabular}{|c|c|c|c|}
\hline Giergiczny et al. 2015 & Poland & $\begin{array}{l}\text { Forest visitors, } \\
\mathrm{N}=1000\end{array}$ & $\begin{array}{l}\text { Convenience sampling postal and } \\
\text { online surveys }\end{array}$ \\
\hline
\end{tabular}

Quantify forest structural attributes with respect to both the social and relative contribution of each attribute to recreational value expressed in monetary terms.

\begin{tabular}{|c|c|c|c|}
\hline Goodwin et al. 2019 & Sweden & Education, $\mathrm{N}=397$ & $\begin{array}{l}\text { Convenience sampling, face-to- } \\
\text { face }\end{array}$ \\
\hline
\end{tabular}

To elicit these different elements of value in the context of forest ecosystem services on a methodological level. Examine the interface between eco-systems and society on the level of a younger demographic by studying how to elicit these different forms of value (instrumental, intrinsic and relational) in the valuation of the contribution of ecosystems to human wellbeing.

\begin{tabular}{|c|c|c|c|}
\hline Gutsch et al. 2019 & Germany & $\begin{array}{l}\text { Forest visitors, } \\
\mathrm{N}=554\end{array}$ & $\begin{array}{l}\text { Convenience sampling, face-to- } \\
\text { face }\end{array}$ \\
\hline
\end{tabular}

Perceptions of tree pests and their management among visitors to urban forests in Berlin, Germany.

\begin{tabular}{|c|c|c|c|}
\hline Halder et al. 2011 & Finland & Education, $\mathrm{N}=495$ & $\begin{array}{l}\text { Convenience sampling postal and } \\
\text { online surveys }\end{array}$ \\
\hline
\end{tabular}

Students' perceptions and attitudes to bioenergy.

\begin{tabular}{|l|l|l|l|}
\hline Hauru et al. 2014 & Finland & $\begin{array}{l}\text { Forest visitors, } \\
\mathrm{N}=283\end{array}$ & $\begin{array}{l}\text { Convenience sampling, face-to- } \\
\text { face }\end{array}$ \\
\hline
\end{tabular}

Whether people find urban forests with decaying logs as aesthetically appealing as forests without decaying logs, and whether they accept logs in urban forests.

\begin{tabular}{|l|l|l|l|}
\hline \hline Hemström et al. 2014 & Sweden & $\begin{array}{l}\text { General public, } \\
\mathrm{N}=971\end{array}$ & $\begin{array}{l}\text { Random and stratified random } \\
\text { sampling }\end{array}$ \\
\hline
\end{tabular}

To understand if the general public of Sweden accepts the use of exotic tree species, forest fertilisation, and clones in Swedish forestry, and how perceptions influence the acceptance of such intensive forestry practice. 
Author and year

Holopainen et al. 2014
Country

Target group, sample size

Consumers, $\mathrm{N}=208$
Data collection

Finland
Convenience sampling, face-to-face
Study aim

To develop and operationalise a new and more comprehensive measurement scale regarding consumer value dimensions for sustainable wood products. In the next step, this scale is tested in the case of wooden terrace materials and dimensionality of consumer value is identified using an exploratory factor analysis of consumer data, consisting of 208 respondents in Finland.

\begin{tabular}{|c|c|c|c|}
\hline Howley et al. 2011 & Ireland & $\begin{array}{l}\text { General public, } \\
N=430\end{array}$ & Quota sampling \\
\hline
\end{tabular}

Study aim

Ascertain the general public's views regarding the visual amenity of forest landscapes. As such this paper also examines individuals' perceptions regarding the benefits of forests relative to other landscape elements and determines individuals' attitudes to the current level of land cover in forestry use.

Huber et al. 2017

Austria

Forest visitors

$\mathrm{N}=51$

Convenience sampling, face-toface
Study aim

To explore how peri-urban forest visitors' attitudes are affected by the provision of public information boards in the relatively emotional setting of a timber harvesting site.

\section{United Kingdom}

General public, $\mathrm{N}=1152$
Quota sampling

Study aim

Survey attitudes of British publics likely to be interested in the fate of ash trees and who might engage discursively and/or politically with tree health issues.

Jepson et al. 2017b

United Kingdom

Other, $\mathrm{N}=2036$

Random and stratified random sampling

Study aim

Study aim

Study aim of state-owned commercial forests (SOCFs) in Finland.

Kitek et al. 2010 Slovenia Consumers, $\mathrm{N}=628$
Random and stratified random sampling

Study aim

In the Slovenian public opinion survey on wooden building we were interested in people's opinion on the existing wooden buildings, their knowledge about passive houses and their environmental awareness.

Knauf 2015

Germany

Study aim
To conduct a comprehensive analysis on consumer attitudes to lightweight furniture and their acceptance of lightweight materials in furniture design. 
Author and year

Krejči et al. 2019
Country

Czech Republic
Target group, sample size

General public,

$\mathrm{N}=824$
Data collection

Convenience sampling postal and online surveys
Study aim

Study aim

Study aim

Study aim

Study aim

Study aim

Study aim

Study aim

Study aim

To identify current attitudes to forest perceptions.

\begin{tabular}{|l||l|l|l|}
\hline Kronholm et al. 2017 & Sweden & Other, $\mathrm{N}=49$ & $\begin{array}{l}\text { Convenience sampling, face-to- } \\
\text { face }\end{array}$ \\
\hline
\end{tabular}

How do young adults perceive their childhood relationships with forests? What perceptions and thoughts about forests and forestry do they have today? What hopes and intentions do they have regarding forests in the future?

Kuzman et al. 2012

Slovenia, Croatia

Consumers, $\mathrm{N}=743$

Quota sampling

To examine consumer perceptions of wood in each country and identify possibilities for increased consumer use of wood.

Lindberg et al. 2013

Sweden

Consumers, $\mathrm{N}=30$

Not specified

This study investigated how the tactile attributes of wood and wood-based composites are perceived and interpreted semantically by would-be customers.

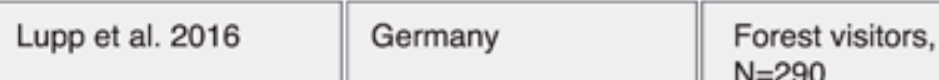

$\mathrm{N}=290$

Convenience sampling, face-toface

Actual on-site recreational use of two forests in the north of the Munich Metropolitan region using camera traps for visitor counting. Interviews were used to gain additional data for both the recreation quality and the importance of various ES for forest visitors, but also to better understand the catchment areas of the two forests and to calculate a monetary value.

\begin{tabular}{|l||l||l||l|}
\hline Lähtinen et al. 2019 & Finland & Consumers, N=256 & $\begin{array}{l}\text { Random and stratified random } \\
\text { sampling }\end{array}$ \\
\hline
\end{tabular}

Profiling different types of consumers according to their stated views on the benefits from wood especially in MSWB type of construction from technological, ecological, social and economic perspectives.

\begin{tabular}{|l||l||l||l|}
\hline Matthies et al. 2018 & Finland & Education, $\mathrm{N}=165$ & $\begin{array}{l}\text { Convenience sampling, face-to- } \\
\text { face }\end{array}$
\end{tabular}

Apply value-basis theory methods to elicit pro-environmental concern and acceptance of specific management objectives under a bioeconomy in Finnish forests.

\begin{tabular}{|c|c|c|c|}
\hline Meyer et al. 2019 & Germany & $\begin{array}{l}\text { Forest visitors, } \\
\mathrm{N}=478\end{array}$ & $\begin{array}{l}\text { Convenience sampling, face-to- } \\
\text { face }\end{array}$ \\
\hline
\end{tabular}

To quantitatively map and analyse spatial patterns of recreational use. To qualitatively examine demands of forest visitors concerning perceived and valued FB and evaluate spatial patterns. To analyse drivers of perceived FB and their influence on pathway choice.

\begin{tabular}{|c|c|c|c|}
\hline Mizaras et al. 2015 & Lithuania & $\begin{array}{l}\text { General public, } \\
\mathrm{N}=1003\end{array}$ & $\begin{array}{l}\text { Random and stratified random } \\
\text { sampling }\end{array}$ \\
\hline
\end{tabular}

To develop methods for evaluation of forest management sustainability and public opinion of importance of forest resources and forest management in Lithuania. 


\begin{tabular}{|c|c|c|c|c|}
\hline & Author and year & Country & Target group, sample size & Data collection \\
\hline & $\begin{array}{l}\text { Moresová et al. } \\
2019\end{array}$ & Slovakia & $\begin{array}{l}\text { Local or regional } \\
\text { population, } \mathrm{N}=728\end{array}$ & $\begin{array}{l}\text { Convenience sampling postal } \\
\text { online surveys }\end{array}$ \\
\hline dy aim & \multicolumn{4}{|c|}{$\begin{array}{l}\text { To define the position of wooden houses in contemporary society, as well as to identify the key factors, and } \\
\text { economic and social aspects in the context of traditions, competitiveness and green economy, which have } \\
\text { an impact on the way these houses establish and entrench in the market, and also influence the future } \\
\text { perspectives of their development. }\end{array}$} \\
\hline
\end{tabular}

\begin{tabular}{|l||l||l|}
\hline Nijnik et al. 2016 & United Kingdom & $\begin{array}{l}\text { Convenience sampling, face-to- } \\
\text { face }\end{array}$
\end{tabular}

Study aim To examine the heterogeneity of stakeholder attitudes towards the services that forest ecosystems can provide and the trade-offs between these services.

\begin{tabular}{|l||l||l|}
\hline Nonić et al. 2014 & $\begin{array}{l}\text { Croatia, Montenegro, } \\
\text { Serbia, Bosnia- } \\
\text { Herzegovina }\end{array}$ & $\begin{array}{l}\text { Education, N=325 } \\
\text { face }\end{array}$ \\
\hline
\end{tabular}

\begin{tabular}{l|l} 
Study aim & To analyse public attitudes toward adoption of transgenic forest plants.
\end{tabular}

\begin{tabular}{|l|l|l|l|}
\hline Nordlund et al. 2017 & Germany, Sweden & General public, & Random and stratified random \\
\hline
\end{tabular}

\begin{tabular}{|l|l|l} 
& $\mathrm{N}=2446$ & $\begin{array}{l}\text { Random } \\
\text { sampling }\end{array}$ \\
\hline
\end{tabular}

Study aim Relationship between individuals' residential biography and their forest-related environmental awareness, perceptions about forest requirements and forests' qualities, and activities performed in forests.

\begin{tabular}{|c|c|c|c|}
\hline $\begin{array}{l}\text { Nummelin et al. } \\
2017\end{array}$ & Sweden & Education, $\mathrm{N}=1002$ & $\begin{array}{l}\text { Convenience sampling postal and } \\
\text { online surveys }\end{array}$ \\
\hline
\end{tabular}

Study aim

What are students' visions and preferred features of future forests? Are there background factors, such as gender, academic discipline and hobbies, which can explain differences in visions of future forests?

\begin{tabular}{|l|l|l|l|}
\hline $\begin{array}{l}\text { Olšiaková et al. } \\
2016\end{array}$ & Czech Republic & Consumers, N=696 & $\begin{array}{l}\text { Convenience sampling, face-to- } \\
\text { face }\end{array}$ \\
\hline
\end{tabular}

Study aim

Monitor the changes in selected consumer requirements for wood products in terms of consumer behaviour in 10 years. In particular, results of two surveys are used for comparison of consumer behaviour requirements for wood products; results obtained by a questionnaire survey and a constructed Kano model in order to identify significant changes in consumers' behaviour.

\begin{tabular}{|c|c|c|c|}
\hline Orzan et al. 2018 & Romania & Consumers, $\mathrm{N}=268$ & $\begin{array}{l}\text { Convenience sampling postal and } \\
\text { online surveys }\end{array}$ \\
\hline
\end{tabular}

Study aim To determine the perception of the Romanian consumer regarding the role of eco-packaging, assessing consumer preferences for the types of ecological packaging, knowing the reasons for purchasing green packaging and the role of the information about eco-packaging in promoting sustainability.

\begin{tabular}{|c|c|c|c|}
\hline Osburg et al. 2016a & Germany & Consumers, $N=357$ & $\begin{array}{l}\text { Convenience sampling postal and } \\
\text { online surveys }\end{array}$ \\
\hline
\end{tabular}

Study aim To develop an understanding of WPC acceptance in relation to the established materials of solid wood and full plastics by testing all the TPB components as comparative scores. 
Author and year

Osburg et al. $2016 \mathrm{~b}$
Country

Germany
Target group, sample size

Consumers, $\mathrm{N}=185$
Data collection

Convenience sampling postal and online surveys
Study aim

Study aim

Study aim

Study aim

Study aim

Study aim

Study aim

Study aim

Study aim

Which young consumer groups value the provision of wood product information? What information is relevant for the identified consumer segments and is therefore evaluated by young consumers as increasing their product trust and purchase intention?

\begin{tabular}{|l|l|l|l|}
\hline Osburg et al. 2016c & Germany & Consumers, $\mathrm{N}=198$ & $\begin{array}{l}\text { Convenience sampling postal and } \\
\text { online surveys }\end{array}$ \\
\hline
\end{tabular}

To analyse consumer acceptance of WPCs in relation to two traditional materials.

\begin{tabular}{|l||l||l||l|}
\hline Pacurar et al. 2018 & $\begin{array}{l}\text { Local or regional } \\
\text { population, } \mathrm{N}=40\end{array}$ & Not specified \\
\hline
\end{tabular}

Identify the extent to which local people have knowledge about the concept of forest function; establish the Brasov's citizens' opinions regarding the importance of the two main forest functions (protection and production); study the perception of local population regarding the management of Brasov forests and the main factors affecting the quality of these woods; determine the level of information regarding the initiatives of different companies (Corporate Social Responsibility schemes) for forest protection projects and the citizens' willingness to participate in forest protection activities.

\begin{tabular}{|l||l||l|l|}
\hline Paletto et al. 2013a & Italy & $\begin{array}{l}\text { Local or regional } \\
\text { population, } \mathrm{N}=721\end{array}$ & $\begin{array}{l}\text { Random and stratified random } \\
\text { sampling }\end{array}$ \\
\hline
\end{tabular}

This work aimed to test a survey method to evaluate the preferences attributed by the population to different forest functions and thus include peoples' perceptions in the planning process.

\begin{tabular}{|l||l|l|l|}
\hline Paletto et al. 2013b & Italy & $\begin{array}{l}\text { Local or regional } \\
\text { population, } \mathrm{N}=346\end{array}$ & $\begin{array}{l}\text { Random and stratified random } \\
\text { sampling }\end{array}$ \\
\hline
\end{tabular}

To investigate people's perceptions of forest management practices by considering individual preferences.

Paletto et al. 2017

Italy

Forest visitors, $\mathrm{N}=201$
Convenience sampling, face-toface

To investigate people's perceptions of forest management practices by considering individual preferences.

\begin{tabular}{|l||l||l}
\hline Paluš et al. 2012 & Slovakia, Croatia & Consumers, $\mathrm{N}=848$
\end{tabular}

Convenience sampling postal and online surveys

To identify and compare furniture preferences of consumers in Slovakia and Croatia. Transnational comparison is a fruitful method. Exposure to a contrary view allows for a better understanding of national specifics. Clustering furniture consumers according to their affinity for certain materials could possibly outline useful segments in each investigated country.

\begin{tabular}{|l|l|l|l|}
\hline Panico et al. 2018 & Italy & Consumers, $\mathrm{N}=371$ & $\begin{array}{l}\text { Convenience sampling postal and } \\
\text { online surveys }\end{array}$ \\
\hline
\end{tabular}

The precise objective is to ascertain the main motivational purchasing drivers for SFM-certified products in Italy.

\begin{tabular}{|c|c|c|c|}
\hline $\begin{array}{l}\text { Pastorella et al. } \\
2016\end{array}$ & $\begin{array}{l}\text { Italy, Bosnia- } \\
\text { Herzegovina }\end{array}$ & $\begin{array}{l}\text { Forest visitors, } \\
\mathrm{N}=273\end{array}$ & $\begin{array}{l}\text { Convenience sampling, face-to- } \\
\text { face }\end{array}$ \\
\hline
\end{tabular}

To analyse tourists' perception and preferences about the amount of standing dead trees and lying deadwood in forests. 
Author and year

Pätāri et al. 2017
Country

Finland, Hong Kong, Spain
Target group, sample size

Students, $\mathrm{N}=350$
Data collection

Convenience sampling postal and online surveys
Study aim

Examining the determinants of students' CSR perceptions, especially in the multi-country context, and analysing their views of the future of forest industry on the road to a bioeconomy.
Study aim

Study aim

Study aim

Study aim

Study aim

Study aim

Study aim

Study aim
How are wood-based innovations perceived by potential future opinion leaders? What kind of information regarding the potential of wood-based innovations substituting fossil-based products is requested?

\begin{tabular}{|l|l|l|l}
\hline Ranacher et al. 2017a & $\begin{array}{l}\text { Austria, Germany, } \\
\text { Finland, Slovenia }\end{array}$ & $\begin{array}{l}\text { General public, } \\
\mathrm{N}=219\end{array}$ & $\begin{array}{l}\text { Convenience sampling postal and } \\
\text { online surveys }\end{array}$ \\
\hline
\end{tabular}

To evaluate the views of the general public on the importance of the contribution of forests to different ES; to determine the public's need for information on the impact of forest sector businesses on ecosystems; and assess how responsibly the public believes that forest sector companies act in relation to their impacts on ecosystems.

Ranacher et al. 2017b Austria, Germany

General public, $\mathrm{N}=194$

Convenience sampling postal and online surveys

Perception of FBS regarding contribution to $\mathrm{Cc}$ mitigation.

Ranacher et al. 2015

Austria

General public, $\mathrm{N}=204$
Convenience sampling postal and online surveys

To investigate which key messages are communicated by the Austrian forest-based sector concerning sustainable forest management, and how these key messages are perceived by respondents with different sociodemographic backgrounds.

\begin{tabular}{|c|c|c|c|}
\hline Riccioli et al. 2019 & Italy & $\begin{array}{l}\text { Forest visitors, } \\
\mathrm{N}=248\end{array}$ & $\begin{array}{l}\text { Convenience sampling, face-to- } \\
\text { face }\end{array}$ \\
\hline
\end{tabular}

To demonstrate that different forest management systems result in differing willingness to pay for maintaining the recreational use of forests, such that we are able to identify what has the greater impact in terms of increasing users' recreational value.

\begin{tabular}{|c|c|c|c|}
\hline Sheremet et al. 2017 & United Kingdom & $\begin{array}{l}\text { General public, } \\
\mathrm{N}=605\end{array}$ & $\begin{array}{l}\text { Random and stratified random } \\
\text { sampling }\end{array}$ \\
\hline
\end{tabular}

To investigate the preferences and willingness to pay of the UK general public for a range of forest disease control measures.

\begin{tabular}{|c|c|c|c|}
\hline Šišák 2011 & Czech Republic & $\begin{array}{l}\text { Forest visitors, } \\
\mathrm{N}=1122\end{array}$ & $\begin{array}{l}\text { Convenience sampling, face-to- } \\
\text { face }\end{array}$ \\
\hline
\end{tabular}

What forest visitors know about the issues in question is a very important informative source for forest policy and forestry public relations plans and activities. Collect opinions on forest functions, on the importance of forest operations and on sources of financing forest functions. 
Author and year

Solberg et al. 2011

United Kingdom, Norway
Target group, sample size

Consumers, $\mathrm{N}=590$
Data collection

Convenience sampling, face-toface

Study aim

Study aim How are different types of innovations perceived among our respondents?

\begin{tabular}{|c|c|c|c|}
\hline Švajlenka 2018b & Slovakia & Consumers, $\mathrm{N}=25$ & $\begin{array}{l}\text { Convenience sampling postal and } \\
\text { online surveys }\end{array}$ \\
\hline
\end{tabular}

Study aim

Determining preferences regarding the parameters of wooden structures with future users, and evaluating the quality of the buildings according to the users of existing wooden buildings.

\begin{tabular}{|l||l||l|}
\hline Toivonen 2012 & Finland & $\begin{array}{l}\text { Consumenience sampling, face-to- } \\
\text { face }\end{array}$ \\
\hline
\end{tabular}

Study aim

Is the structure of the perceived quality dimensions consistent over the two wood product categories (wooden flooring, wooden panelling materials and wooden furniture)? Is the importance of product attributes, including environmental quality, consistent over the two product categories from a consumer perspective? How is the perceived value of a product linked with perceived quality?

\begin{tabular}{|c|c|c|c|}
\hline Toppinen et al. 2013 & Finland & Consumers, $\mathrm{N}=227$ & $\begin{array}{l}\text { Convenience sampling, face-to- } \\
\text { face }\end{array}$ \\
\hline
\end{tabular}

\begin{tabular}{l|l} 
Study aim & The aim of this paper is to address three questions: (1) What does the perceived social and environmental
\end{tabular} sustainability of wood products consist of for the Finnish consumer? (2) Does perceived environmental and social sustainability help to explain the consumer's self-declared willingness to pay for environmentally and socially responsible product features, and (3) Is it possible to segment the Finnish consumers based on their environmental and social perceptions?

\begin{tabular}{|c|c|c|c|}
\hline Torkar et al. 2019 & Slovenia & Education, $\mathrm{N}=377$ & $\begin{array}{l}\text { Convenience sampling, face-to- } \\
\text { face }\end{array}$ \\
\hline
\end{tabular}

Study aim

How do students' knowledge of ecology correlate with their attitudes to provisioning, regulating, cultural, and supporting forest ecosystem services? Does the frequency of direct experiences in forests correlate with students' attitudes toward forest ecosystem services? Does the frequency of direct experiences in forests correlate with students' knowledge of ecology? Do students' sex and grade affect their knowledge of ecology and attitudes toward forest ecosystem services?

\begin{tabular}{|c|c|c|c|}
\hline $\begin{array}{l}\text { Tsourgiannis et al. } \\
2013\end{array}$ & Greece & Consumers, $N=418$ & Quota sampling \\
\hline
\end{tabular}

Study aim To explore the attitudes of consumers towards wood products that could be derived from transgenic forest plantations and profile them according to personal characteristics and their attitude towards establishment of such plantations. 
Author and year

Tsourgiannis et al. 2015

Study aim

Surveying the attitude and the potential purchasing behaviour of Greek consumers to products derived from transgenic forest tree plantations. Including role of sociodemographic variables.

Tyrväinen et al. 2017

Finland

Other, $\mathrm{N}=750$
Convenience sampling, face-toface

Study aim

How do commercial forests correspond to the wishes and expectations of international nature-based tourists? How does the season affect tourists' forest landscape preferences? Is it possible to group forest vistas into forest vista types on the basis of their suitability for tourism?

\begin{tabular}{|c|c|c|}
\hline Upton et al. 2012 & Ireland & $\begin{array}{l}\text { General public, } \\
\mathrm{N}=996\end{array}$ \\
\hline
\end{tabular}

Study aim

To investigate public preferences and values for management approaches to an extensive afforestation programme.

Upton et al. 2015 Ireland General public, $\mathrm{N}=996$

Quota sampling

Study aim

To examine whether the extent, ownership and composition of forests in respondents' localities influence their expressed attitudes and rankings of forest outputs (forest management, afforestation) from a household survey.

\begin{tabular}{|l|l||l|l|}
\hline Valasiuk et al. 2018 & Sweden, Norway & $\begin{array}{l}\text { General public, } \\
\mathrm{N}=2531\end{array}$ & Quota sampling \\
\hline
\end{tabular}

Study aim

To fill the gap in terms of valuation of benefits of boreal forest landscape restoration.

\begin{tabular}{|l|l|l|l|}
\hline $\begin{array}{l}\text { Valkeapää et al. } \\
2013\end{array}$ & Finland & $\begin{array}{l}\text { General public, } \\
\mathrm{N}=1260\end{array}$ & $\begin{array}{l}\text { Random and stratified random } \\
\text { sampling }\end{array}$ \\
\hline
\end{tabular}

Study aim What issues are generally agreed upon in Finnish forest policy? What aspects of Finnish forest policy in general are criticised by citizens? Differences between forest owners and those who do not own forests were examined further: on which issues do forest owners' perceptions of forest policy differ from those of other citizens? Finally, the model constructed above was used to understand the phenomenon of legitimacy from two viewpoints: forest owners and those who do not own forests. How do various predictors affect legitimacy for forest owners and for those who do not own forests?

\begin{tabular}{|l|l|l|l|}
\hline Van Dael et al. 2017 & Belgium & Education, $\mathrm{N}=715$ & $\begin{array}{l}\text { Convenience sampling, face-to- } \\
\text { face }\end{array}$ \\
\hline
\end{tabular}

Study aim To investigate Flemish students' intention to use and learn about bioenergy and to understand the relationship between knowledge, perception, attitude strength, and attitude concerning bioenergy.

\begin{tabular}{|l|l|l|l|}
\hline Varela et al. 2017 & Spain & $\begin{array}{l}\text { Local or regional } \\
\text { population, } \mathrm{N}=410\end{array}$ & Quota sampling \\
\hline
\end{tabular}

Study aim Social preferences for forest management in the Mediterranean. 
龄

EFI 


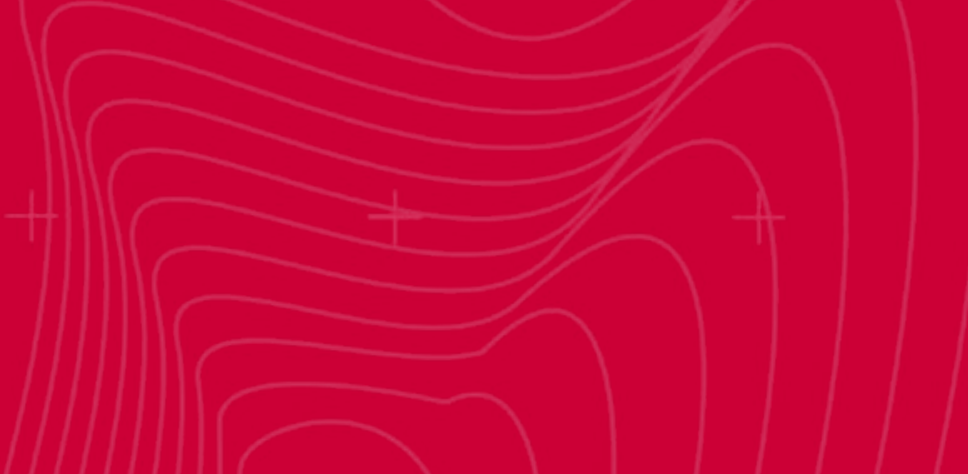

Knowledge to Action (K2A) is an EFI publication series bringing a wide range of research, projects and initiatives on forest-related issues closer to society. Knowledge to Action complements the existing EFI series, What Science Can Tell Us and From Science to Policy.

The European Forest Institute is an international organisation established by European states. EFI conducts research and provides policy advice on forest-related issues. It facilitates and stimulates forest-related networking and promotes the dissemination of unbiased and policy-relevant information on forests and forestry. It also advocates for forest research and for the use of scientifically sound information as a basis for forest policies. 